\title{
If a Rail Keks and No One is Around, Does It Make a Sound?: Investigating the Use of Autonomous Recording Units to Monitor King and Clapper Rails
}

Lydia Lenora Stiffler

Follow this and additional works at: https://researchrepository.wvu.edu/etd

\section{Recommended Citation}

Stiffler, Lydia Lenora, "If a Rail Keks and No One is Around, Does It Make a Sound?: Investigating the Use of Autonomous Recording Units to Monitor King and Clapper Rails" (2017). Graduate Theses,

Dissertations, and Problem Reports. 6728.

https://researchrepository.wvu.edu/etd/6728

This Thesis is protected by copyright and/or related rights. It has been brought to you by the The Research Repository @ WVU with permission from the rights-holder(s). You are free to use this Thesis in any way that is permitted by the copyright and related rights legislation that applies to your use. For other uses you must obtain permission from the rights-holder(s) directly, unless additional rights are indicated by a Creative Commons license in the record and/ or on the work itself. This Thesis has been accepted for inclusion in WVU Graduate Theses, Dissertations, and Problem Reports collection by an authorized administrator of The Research Repository @ WVU. For more information, please contact researchrepository@mail.wvu.edu. 


\title{
If a Rail Keks and No One is Around, Does It Make a Sound?: Investigating the Use of Autonomous Recording Units to Monitor King and Clapper Rails
}

\author{
Lydia Lenora Stiffler
}

Thesis submitted to the

Davis College of Agriculture, Natural Resources, and Design

at West Virginia University

in partial fulfillment of the requirements for the degree of

Master of Science

in

Wildlife and Fisheries Resources

James T. Anderson, Ph.D., Chair

Todd E. Katzner, Ph.D., Co-Chair

Amy B. Welsh, Ph.D.

Division of Forestry and Natural Resources

Morgantown, West Virginia

2017

Keywords: autonomous recording units, detection, Rallus crepitans, Rallus elegans, Virginia, vocalization

Copyright 2017 Lydia Lenora Stiffler 


\section{ABSTRACT \\ If a Rail Keks and No One is Around, Does It Make a Sound?: Investigating the Use of Autonomous Recording Units to Monitor King and Clapper Rails}

\section{Lydia Lenora Stiffler}

Secretive marsh birds are challenging to monitor due to the difficulty in locating and trapping them within the dense emergent vegetation they occupy. Recently autonomous recording units (ARUs) have emerged as a novel alternative method to survey birds, although the technology has only been applied to a few species in specific field settings. There is limited information on how ARUs compare to human surveyors or how best to use ARU data that can be collected continuously. This thesis examines the applicability of ARUs for monitoring King (Rallus elegans) and Clapper (R. crepitans) rails (collectively "rails") in two tidal marsh riverine systems of the Chesapeake Bay within intracoastal Virginia. It includes three chapters: (1) an evaluation of autonomous acoustic surveying techniques for rails; (2) an investigation of diel variation in detection and vocalization rates of rails; and, (3) a utilization of acoustic recordings to assess occupancy and distribution of rails. In the first chapter, I evaluated the effectiveness of an ARU in replacing human personnel by comparing the results of callback point count surveys to concurrent ARU sampling. The success of ARUs at detecting rails that human observers recorded decreased with distance $(P \leq 0.001)$, such that ARUs detected $90.3 \%$ of rails $<25 \mathrm{~m}$ away from human observers, but only $34.0 \%$ of rails at $>75 \mathrm{~m}$. I also investigated the use of subsampling schemes for 720 hours of continuous ARU data and recommended using a minimum of 30 minute subsampling intervals to effectively survey for presence and call rates of rails. In my second chapter, I investigated diel variation in rail vocal behavior using 3,600 hours of audio. I showed that naïve rail occupancy did not vary hourly at either the marsh- or study area-level. Detection rates of rails varied as a function of time of day, marsh location, tidal stage, and date. However, vocalization rates varied as a function of time of day, marsh location, and date. Rail detections and vocalizations varied across marshes $(P<0.01)$ and decreased as the sampling season progressed. Rail detection was greatest during low tides rising $(P<0.01)$. Although there were statistically significant differences in hourly detection and vocalization rates $(P<0.01)$, because there were no patterns in these difference, they may not be biologically relevant and likely are of little use to management. In my third chapter, I evaluated the use of ARUs in conjunction with occupancy models. I found that both marsh riverine systems exhibited similarities in both mean occupancy probability of rails and detection probabilities, although their probabilities were explained by varying covariates by model selection. Areas of higher salinity produced higher estimates of occupancy probability by a factor of 1.62 (95\% CI: 0.6, 2.65) per ppt of salinity. However, estimates of detection probability decreased by 0.02 (95\% CI: -0.03, 0) per day as the season progressed. This multidimensional assessment of ARUs for monitoring King-Clapper Rails provides insight into the applicability of this alternative management tool for conducting long-term continuous monitoring over large spatial and temporal scales. Overall, species-, habitat-, and ARU-specific limitations to ARU sampling should be considered when making inferences about abundances and distributions from acoustic data. 


\title{
DEDICATION
}

\author{
For my parents
}

Michael and Denise Stiffler

Who always encourage me to go on every adventure 


\section{ACKNOWLEDGMENTS}

I thank the Virginia Department Game and Inland Fisheries for providing funding through the Federal Aid in Wildlife Restoration grant from the U.S. Fish and Wildlife Service. I also thank all private landowners and caretakers for providing access to their marshes.

I express my gratitude for my committee chair, Jim Anderson, for his mentorship and guidance through my graduate career. I thank Todd Katzner for taking an active advising role. His guidance has had the most profound impact on my development as a research scientist and provided valuable advice along the way. I also thank my committee member Amy Welsh for her critical evaluation of my research methods and resulting inferences.

I recognize my field technicians Tyler Woollard and Luke Costilow, without whom I would still be stuck out in the marshes of Virginia. I also offer sincere thanks to my peers among the Katzner and Anderson lab groups. These members provided both support and criticism to allow me to excel in my work.

More personally, I thank William C. Alexander (“Dr. Bill”) for his pivotal role in shaping my early education. He took me under his wing and shared his love of wildlife. Without him, I would not have discovered my passion.

Finally, it would be impossible to describe the amount of love and support that I have received from my family and friends during my time in graduate school. Without ya'll, I would have given up on this journey a long time ago. 


\section{TABLE OF CONTENTS}

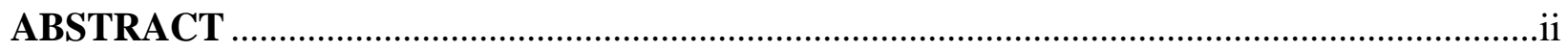

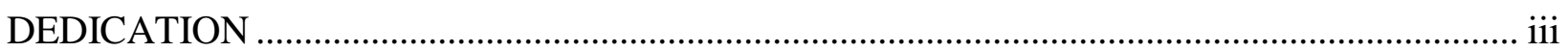

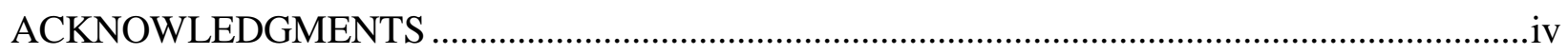

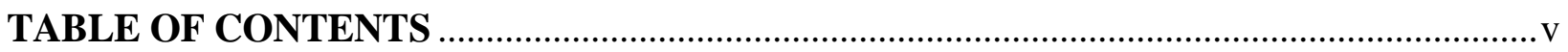

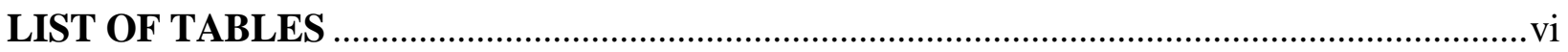

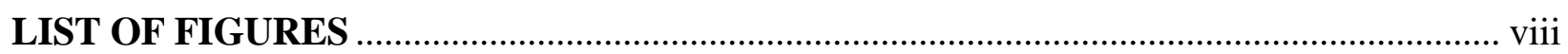

CHAPTER 1: Evaluating Autonomous Acoustic Surveying Techniques in Tidal Marshes .....1

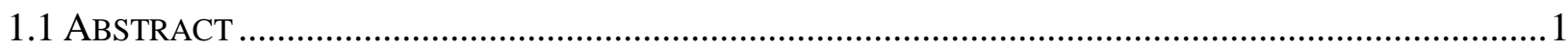

1.2 INTRODUCTION

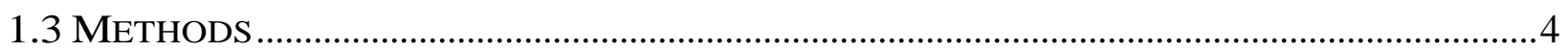

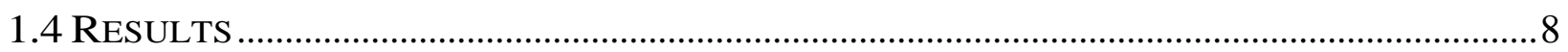

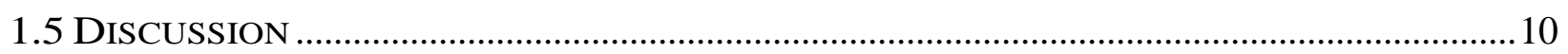

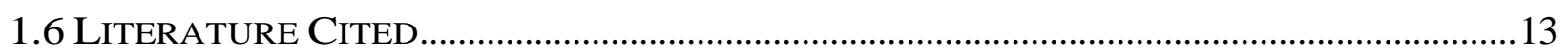

CHAPTER 2: Diel Variation in Detection and Vocalization Rates of Rails in Virginia Intracoastal Waterways........................................................................................................22

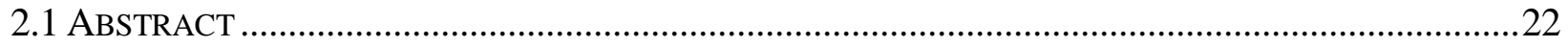

2.2 INTRODUCTION

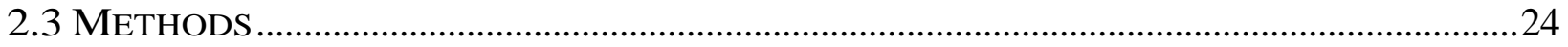

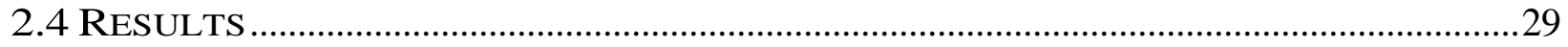

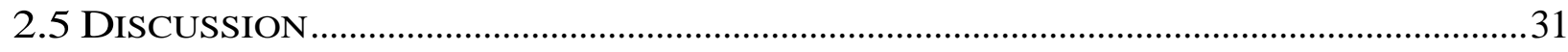

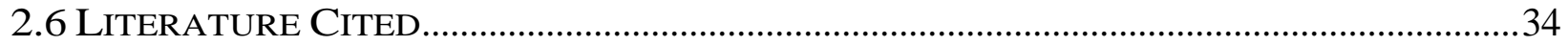

CHAPTER 3: Using Acoustic Recordings to Assess Occupancy and Distribution of Rails....50

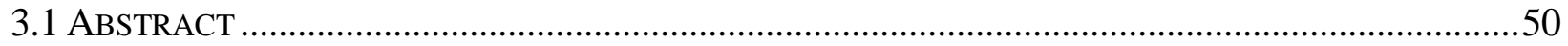

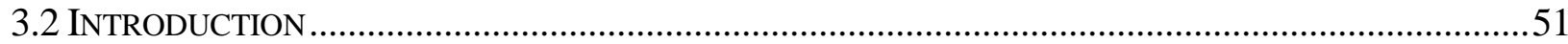

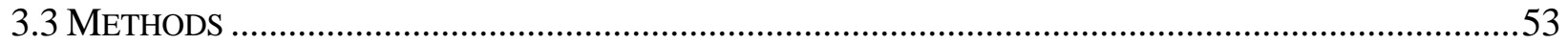

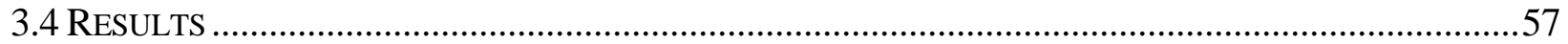

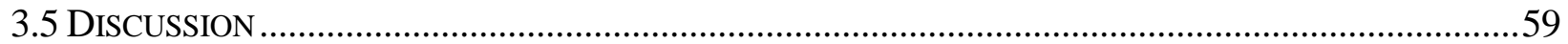

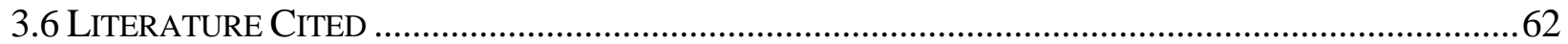

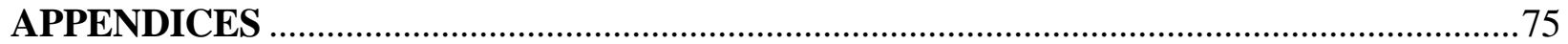

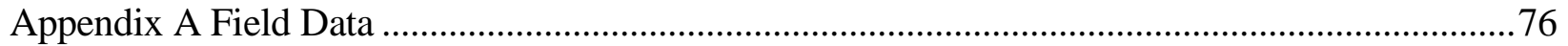

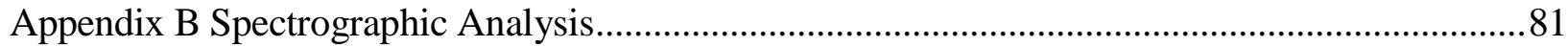

Appendix C Additional Tables and Figures ……………................................................................8 


\section{LIST OF TABLES}

Table 1.1 The rate at which autonomous recording unit (ARU) based detection of King-Clapper Rails in a subsampling period compared to the hourly rate of ARU-based detection of rails. Rails were monitored for 48-hr periods during May-July 2015 in Eltham Marsh along the Pamunkey River, near West Point, Virginia, USA. In each case, the rates reported are a comparison between a rate as measured during an entire hour as recorded on an ARU in which a rail vocalized and as measured during a period of that hour (a subsampling period)

Table 2.1 Model selection results for the hourly detection and vocalization rates of King-Clapper Rails in intracoastal Virginia, USA May-July 2015. Models are ranked by difference in corrected Akaike's Information Criterion $\left(\triangle \mathrm{AIC}_{\mathrm{c}}\right)$ with the model weight $\left(w_{i}\right)$ and number of parameters $(K)$. Parameters included time of day (Time), marsh location (Marsh), day of the year (Date), and tidal stage (Tide). Only the top three models are shown; each model set contained 16 models......41

Table 3.1 Model selection results for the occupancy and detection of King-Clapper Rails in marshes in Virginia along (A) the Pamunkey River, May-July 2015; and (B) the Mattaponi River, May-July 2016. The model name shows effects on occupancy probability $(\Psi)$ and detection probability $(p)$; models are ranked based on AICc relative differences between the top ranked model and each other model ( $\triangle \mathrm{AICc})$, AICc model weights $\left(w_{i}\right)$, and number of parameters $(K)$. Parameters included salinity and dominant emergent marsh community (veg) for occupancy probability and day of the year (date), time of day (time), and survey number (survey) for detection probability. Only models with $\triangle \mathrm{AICc}<2$ are shown; each model set contained 32 models.............................71

Table C.1 The proportion of sites where at least one rail was detected for all 15 sampling locations within each marsh. The overall study area is calculated by averaging hourly proportions across all marshes. The $X^{2}$ test statistic and associated $P$ - value $(\alpha=0.05)$ assessed hourly variation in naïve occupancy for each marsh and across the study area...................................... 87

Table C.2 Selection tables for models estimating detection frequencies using 48-hour autonomous acoustic recordings for King-Clapper Rails in four marshes along the Pamunkey River, near West Point, Virginia, USA, May-July 2015. Models are ranked based on AICc relative differences between the top ranked model and each other model ( $\triangle \mathrm{AICc})$, AICc model weights $\left(w_{i}\right)$, and number of parameters $(K)$. Parameters included time of day (Time), marsh location (Marsh), day of the year

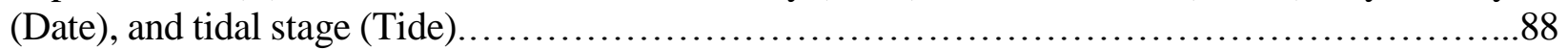

Table C.3 Selection tables for models estimating vocalization frequencies using 48-hour autonomous acoustic recordings for King-Clapper Rails in two varying apparent density marshes along the Pamunkey River, near West Point, Virginia, USA, May-July 2015. Models are ranked based on AICc relative differences between the top ranked model and each other model ( $\triangle \mathrm{AICc})$, AICc model weights $\left(w_{i}\right)$, and number of parameters $(K)$. Parameters included time of day (Time), marsh location (Marsh), day of the year (Date), and tidal stage (Tide) .......................89 
Table C.4 Model selection results for the occupancy and detection of King-Clapper Rails in marshes in Virginia along the Pamunkey River May-July 2015. The model name shows effects on occupancy probability $(\Psi)$ and detection probability $(p)$; models are ranked based on AICc relative differences between the top ranked model and each other model ( $\triangle \mathrm{AICc})$, AICc model weights $\left(w_{i}\right)$, and number of parameters $(K)$. Parameters included salinity and dominant emergent marsh community (veg) for occupancy probability and day of the year (date), time of day (time), and survey number (survey) for detection probability.

Table C.5 Model selection results for the occupancy and detection of King-Clapper Rails in marshes in Virginia along the Mattaponi River May-July 2015. The model name shows effects on occupancy probability $(\Psi)$ and detection probability $(p)$; models are ranked based on AICc relative differences between the top ranked model and each other model ( $\triangle \mathrm{AICc})$, AICc model weights $\left(w_{i}\right)$, and number of parameters $(K)$. Parameters included salinity and dominant emergent marsh community (veg) for occupancy probability and day of the year (date), time of day (time), and survey number (survey) for detection probability. 


\section{LIST OF FIGURES}

Figure 1.1 Five named marshes surveyed for King-Clapper Rails May-July 2015 along the Pamunkey River, near West Point, Virginia, USA. Marshes follow a salinity gradient from Eltham (highest salinity, closest to the Chesapeake Bay) to Cousiac (lowest salinity)..................... 19

Figure 1.2 The rate at which autonomous recording units successfully detected vocalizations of King-Clapper Rails in marshes along the Pamunkey River, near West Point, Virginia, USA during May-July 2015. In all cases, human observer point count detections were used as a baseline. Distance bands of $<25 \mathrm{~m}, 25-49 \mathrm{~m}, 50-75 \mathrm{~m}$, and $>75 \mathrm{~m}$ were defined in point count data. Error bars illustrate variation across sampling sites. Significant differences between hours are indicated by letter groupings "a" and "b" ......................................................... 20

Figure 1.3 Relation between rates of detection and sampling period of King-Clapper Rail vocalizations using autonomous recording unit hourly recordings in marshes along the Pamunkey River, near West Point, Virginia, USA during May-July 2015. The detection rate of rails exhibits a strong logarithmic relation with sampling time. The extrapolated vocalization rate of rails demonstrates a non-significant linear relation with sampling time. The outer curves delineate $95 \%$ CI. Each point denotes the average detection rate or standardized vocalization rate for each

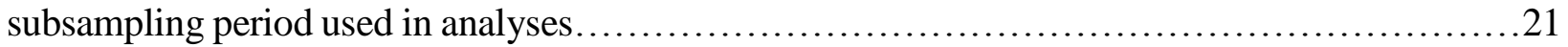

Figure 2.1 Five named marshes surveyed for King-Clapper Rails May-July 2015 along the Pamunkey River, near West Point, Virginia, USA. Marshes follow a salinity gradient from Eltham (highest salinity, closest to the Chesapeake Bay) to Cousiac (lowest salinity). Survey locations where autonomous recording units (ARUs) were deployed are shown with dots......................42

Figure 2.2 Hourly naïve occupancy rates for each marsh inhabited by rails and surveyed during May-July 2015 along the Pamunkey River, near West Point, Virginia, USA. Data were summed across 15 sampling locations within a study area encompassing all marsh locations shown in Figure

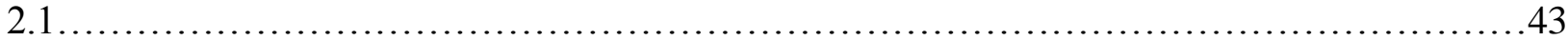

Figure 2.3 Parametric bootstrapped estimates of rail detection rates, by hour, from a generalized linear negative binomial model for data collected from four marshes along the Pamunkey River, near West Point, Virginia USA during May-July 2015. Model parameter estimates are shown with a 99\% confidence interval estimated by bootstrapping. The letters above each hour displays significant differences indicated by pairwise comparisons between hourly rail estimates $(n=10,000) \ldots \ldots \ldots \ldots 44$

Figure 2.4 Parametric bootstrapped estimates of rail detection rates, by marsh, from a generalized linear negative binomial model for data collected from four marshes along the Pamunkey River, near West Point, Virginia USA during May-July 2015. Model parameter estimates are shown with a 99\% confidence interval estimated by bootstrapping. The letters above each marsh displays significant differences indicated by pairwise comparisons between rail estimates $(n=10,000)$ within each

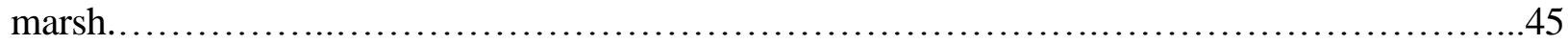


Figure 2.5 Parametric bootstrapped estimates of rail detection rates, by tidal stage, from a generalized linear negative binomial model for data collected from four marshes along the Pamunkey River, near West Point, Virginia USA during May-July 2015. Model parameter estimates are shown with a $99 \%$ confidence interval estimated by bootstrapping. The letters above each tidal stage displays significant differences indicated by pairwise comparisons between rail estimates $(n=10,000)$

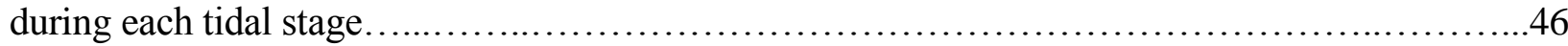

Figure 2.6 Parametric bootstrapped estimates of rail detection rates, by day of the year, from a generalized linear negative binomial model for data collected from four marshes along the Pamunkey River, near West Point, Virginia USA during May-July 2015. Model parameter estimates are shown with a $99 \%$ confidence interval estimated by bootstrapping. ....

Figure 2.7 Parametric bootstrapped estimates of rail vocalization rates, by hour, from a generalized linear negative binomial model for data collected from four marshes along the Pamunkey River, near West Point, Virginia USA during May-July 2015. Model parameter estimates are shown with a 99\% confidence interval estimated by bootstrapping. The letters above each hour displays significant differences indicated by pairwise comparisons between hourly rail estimates

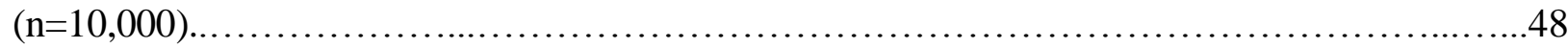

Figure 2.8 Parametric bootstrapped estimates of rail vocalization rates, by day of the year, from a generalized linear negative binomial model for data collected from four marshes along the Pamunkey River, near West Point, Virginia USA during May-July 2015. Model parameter estimates are shown with a $99 \%$ confidence interval estimated by bootstrapping.

Figure 3.1 Map of the study site showing marshes along Pamunkey and Mattaponi Rivers, near West Point, Virginia, USA. Maps also show salinity gradients, extrapolated from salinity measurements taken at autonomous recording unit (ARU) sampling locations throughout each marsh along the Pamunkey River during May - July 2015 and along the Mattaponi River during May - July 2016. Salinity data were extrapolated across the marsh system using inverse distance weighted interpolation. Inset shows the location of these rivers in the Chesapeake

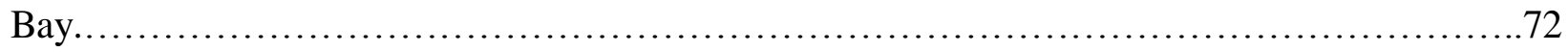

Figure 3.2 Relative importance of model covariates to the probability of occupancy and detection of rails in the King-Clapper complex in marshes along the Pamunkey and Mattaponi Rivers, Virginia. Importance values are the sum of the Akaike weight of each model containing a particular variable. Covariates represent salinity (salinity), dominant community type (veg), day of the year (date), time of day (time), and survey number (survey) .................................. 73

Figure 3.3 Predicted model estimates of (A) occupancy and (B) detection probabilities for KingClapper Rails in marshes along the Pamunkey River, Virginia May - July 2015. Estimate means and $95 \% \mathrm{CI}$ of model-averaged predictions from models with $\triangle \mathrm{AICc}<2$ shown. The probability of occupancy is plotted against salinity and probability of detection is plotted against day of the

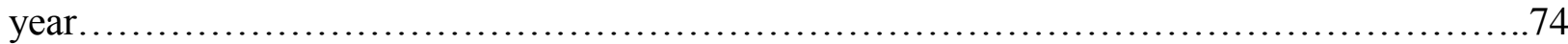

Figure A.1 The data sheet used for traditional call-broadcast point count surveys................77 
Figure A.2 The data sheet used for modified call-broadcast point count surveys................78

Figure A.3 The data sheet used for vegetative community surveys.........................79

Figure A.4 The data sheet used for dominant vegetative species surveys and water quality

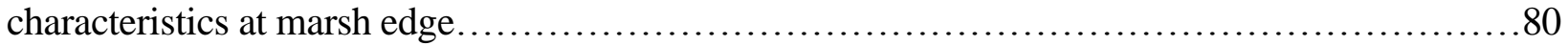

Figure B. 1 Spectrogram of a Clapper rail "kek" call analyzed in Raven Pro 1.5..................82

Figure B. 2 Spectrogram of a Clapper rail "grunt" call analyzed in Raven Pro $1.5 \ldots \ldots \ldots \ldots . . . . .83$

Figure B. 3 Spectrogram of a Clapper rail "kek-burr" call analyzed in Raven Pro 1.5.............84

Figure B. 4 Three spectrograms of two overlapping King-Clapper rail vocalizations analyzed in Raven Pro 1.5.

Figure C.1 The average number of King-Clapper Rails detected per hour within marshes along the Pamunkey River.

Figure C.2 The maximum number of King-Clapper Rails detected per hour within marshes along the Pamunkey River. 


\section{CHAPTER 1}

\section{Evaluating Autonomous Acoustic Surveying Techniques in}

\section{Tidal Marshes}

\subsection{AbSTRACT}

There is a growing trend towards the use of autonomous recording units (ARUs) for acoustic surveying of secretive marsh bird populations. However, there is little information on how ARUs compare to human surveyors or how best to use ARU data that can be collected continuously. I implemented two acoustic surveying techniques using ARUs within a tidal marsh complex along the Pamunkey River, Virginia to survey King (Rallus elegans) and Clapper (R. crepitans) rails during May-July 2015. To determine the effectiveness of an ARU in replacing human personnel, I compared the results of callback point count surveys to concurrent acoustic recordings and calculated estimates of detection probability for rails (both species combined). The success of ARUs at detecting rails that human observers recorded decreased with distance $(P \leq 0.001)$, such that rails $<25$ m were detected at $90.3 \%$ of human-recorded observations, but rail detection was only $34.0 \%$ at $>75 \mathrm{~m}$. To determine a subsampling scheme for continuous ARU data that allows for effective surveying of presence and call rates of rails, I conducted 15 48-hr passive acoustic surveys using ARUs. I established 5 subsampling periods of 5-min, 10-min, 15-min, 30-min, and 45-min, and evaluated the rates at which ARU-based presence and vocalization detections of rails in a subsampling period compared to the full 60 min sampling of ARU-based detection of rails. All subsampling periods resulted in significantly different $(P \leq 0.001)$ detections and unstandardized 
vocalization rates as compared to the hourly sampling period. However, standardizing vocalization counts from the 30-min subsampling period produced no significant difference from vocalization counts of the hour sampling period, thus establishing a suitable subsampling period. When surveying rail species in estuarine environments, species-, habitat-, and ARU-specific limitations to ARU sampling should be considered when making inferences about abundances and distributions from ARU data.

\subsection{INTRODUCTION}

Secretive marsh birds are difficult to monitor using traditional surveying techniques because they tend to occupy dense, emergent vegetation, which makes them difficult to locate and trap (Bystrak 1981, Gibbs and Melvin 1993, Perkins et al. 2010). Acoustic surveying provides an alternative method for sampling, where human observers aurally record species presence, call rate, and abundance estimates of birds (Conway 2011). However, logistical and financial constraints make deploying field teams challenging and there is a growing trend towards the use of autonomous recording units (ARUs) as a substitute for field personnel.

Autonomous recording units allow for a reduction in some restrictions incurred during acoustic monitoring. Three benefits of ARUs have been noted in literature. First, they provide permanent recordings of surveys that can be listened to repeatedly by multiple observers to validate species and counts (Rempel et al. 2005). Second, data collection does not rely upon human presence or skill level during sampling, thereby reducing detectability and observer biases (Haselmayer and Quinn 2000, Acevedo and Villanueva-Rivera 2006). Third, multiple locations can be surveyed simultaneously for extended periods of time, reducing temporal constraints and providing replicate sampling needed for population estimates (MacKenzie et al. 2002, Tegeler et al. 2012). 
However, ARUs also incur costs. In particular, they have limits to battery life and data storage that constrain prolonged deployment required to capture temporal and seasonal trends. While automated species detectors for spectrographic analysis software can aid in analyzing large sets of acoustic data, they tend to require large training data sets and can ultimately lead to a large bias of false positives and negatives (Waddle et al. 2009, Bardeli et al. 2010, Towsey et al. 2012). In contrast, manual analysis provides more accurate results, but is time and effort consuming (Swiston and Mennill 2009). Because manual analysis is so labor intensive, some degree of subsampling of recordings is, therefore, desirable, thus creating a tradeoff between sampling continuity and duration (Thomisch et al. 2015). Using a subset of data may also aid in expediting manual analysis of large, comprehensive data sets. Yet, limited information is available on optimal subsampling schemes that provide reasonable representations of the vocal behavior of a particular species in a specific location.

In this study, I assessed the use of ARUs as an acoustic surveying technique for King (Rallus elegans) and Clapper (R. crepitans) rails in a tidal marsh complex within Virginia's intracoastal waterways. The specific objectives were to: 1) determine the effectiveness of an ARU in replacing human observers during point count sampling and 2) determine a subsampling scheme for continuous ARU data that allows for effective surveying of presence and vocalization rates of rails. To address objective 1, I compared (a) success of detecting rail vocalizations by human observers and in manually classified ARU data and (b) the success of detection for rail vocalizations at increasing distances from the ARU. To address objective 2, I assessed the rate at which hourly ARUbased detection data could be subsampled. I compared (a) the number of rails detected and (b) the number of rail vocalizations detected when data were and were not standardized to a full hourly sampling period. 


\section{Study Area}

I conducted the study in five tidal marshes along the Pamunkey River near West Point, Virginia during May-July 2015. The Pamunkey River is a secondary tributary within the Chesapeake Bay Watershed. The five surveyed marshes were named Eltham (288 ha), nearest the river mouth, followed upriver by Lee (579 ha), Hill (508 ha), Sweet Hall (395 ha), and Cousiac (387 ha).

These marshes occurred along a salinity gradient from mesohaline $(5-10$ parts per thousand [ppt]) at Eltham to fresh $(0-0.5 \mathrm{ppt})$ at Cousiac (Figure 1.1). The marshes themselves were regularly flooded by daily tides and possessed a mosaic of vegetative community types (Wilson et al. 2007). Vegetation in lower areas was dominated by smooth cordgrass (Spartina alterniflora). The higher, irregularly flooded areas were dominated by saltmeadow cordgrass (S. patens) and big cordgrass (S. cynosuroides). Freshwater and brackish areas were characterized by arrow arum (Peltandra virginica), pickerelweed (Pontederia cordata), narrow-leaved cattail (Typha angustifolia), marsh mallow (Kosteletzkya virginica), and southern wild rice (Zizania aquatica).

\subsection{METHODS}

\section{Focal Species}

The ranges of King and Clapper rails overlap along the Atlantic and Gulf coasts of the United States. These secretive marsh birds exist along a salinity gradient, with King Rails inhabiting both freshwater and brackish marshes and Clapper Rails residing in tidal salt marshes (Meanley 1985). However, in areas of intermediate brackish salinity, they coexist and can readily hybridize (Meanley 
and Wetherbee 1962, Chan et al. 2006). These species exhibit similarities both morphologically and acoustically, which makes differentiating between species difficult unless they are in hand (Meanley 1969, Meanley 1985, Conway 2011). Thus for the study, I did not differentiate between the two and I recorded all individuals and vocalizations as King-Clapper Rails (Conway 2011).

\section{Point Count Surveying}

I conducted double-observer dependent callback point count surveys (Forcey et al. 2006) at 74 locations throughout the five marshes during the two hours surrounding sunrise. I used ArcMap ${ }^{\text {TM }}$ (ESRI 2011) to randomly select survey locations within each of the marshes. I constrained survey locations such that each location was at least $400 \mathrm{~m}$ from every other survey location (Conway 2011), at least $50 \mathrm{~m}$ from marsh edge, and easily accessible by boat from the Pamunkey River.

I implemented two point-count methods at each location, each using a double-observer approach to detect birds aurally and visually. The first point count I implemented followed the traditional North American Marsh Bird Monitoring callback approach (Conway 2011; Figure A.1), with a 5 min silent period, followed by a broadcast sequence played over an ECOXPRO ${ }^{\mathrm{TM}}$ loudspeaker (ECOXGEAR). The broadcast sequence consisted of the standardized call notes from both the king and clapper rails for $30 \mathrm{sec}$ followed by $30 \mathrm{sec}$ of silence prior to the next calls (Conway 2011). For each rail encounter, I recorded the time interval of detection, whether the rail was seen, and the call type if it vocalized. I also estimated the distance, to the nearest meter, and direction from the human observer to the bird.

The second callback point count method used was developed to provide a longer period of callback surveying with amplified rail call notes in order to elicit a higher frequency of rail vocalizations to increase sample size. The second point count method immediately followed the first 
and began with a 5 min silent period, followed by a broadcast sequence of $30 \mathrm{sec}$ of calls interspersed with $30 \mathrm{sec}$ of silence prior to the next calls (Figure A.2). The broadcast sequence began with rail grunts, followed by rail keks, rail kek-burrs, rail keks, and rail grunts.

I used a Song Meter SM3 ${ }^{\mathrm{TM}}$ (Wildlife Acoustics) autonomous recording unit to record concurrently during point counts. I attached the ARU to a t-post and staked it into the ground next to the human observers at approximately $1.5 \mathrm{~m}$ above the marsh substrate. I programmed the ARU to record 16-bit with a sampling rate at $24 \mathrm{kHz}$. To minimize disturbance associated with my arrival and ARU setup, I worked as quickly and quietly as possible (setup task 2-4 min) and implemented a 5 min quiet period prior to the start of the point count.

\section{Continuous 48-hr ARU Data Collection}

I deployed another ARU for 48-hr at 15 survey sites within Eltham, the marsh with the most frequent rail vocalizations. To ensure passive acoustic sampling of rails, I deployed the ARU independent of current point count sampling. Each sampling period started at midnight and lasted exactly $48 \mathrm{hrs}$. The ARU recorded at a similar bit and sampling rate as used during the point count surveys. Following the sampling period, I moved the ARU to the next random location and repeated the two-day protocol. During rainy weather or when wind speeds exceeded $20 \mathrm{~km} / \mathrm{h}$ (Gibbs and Melvin 1993), I delayed sampling for a day.

\section{Data Analysis}

I used the interactive sound analysis software Raven Pro ${ }^{\mathrm{TM}}$ (Bioacoustics Research Program 2014) to manually identify vocalizations of rails from the ARU recordings. I defined a 
vocalization as the complete series of calling notes from start to end. For each vocalization, I identified the start, end, and duration of calling.

To compare the detection success of rail vocalizations between humans and manually classified ARU data (my first research question), I calculated the proportion of total rail observations that were detected visually and the proportion detected aurally during point count sampling. I also calculated the proportion of rail vocalizations that were detected by a) only the human observers, b) only the ARU, and c) both human observers and the ARU. Data were analyzed in R (R Development Core Team 2012).

To establish an effective distance radius for capturing rail vocalizations using ARUs (my second research question), I used the distance estimates from the human observer point count data to generate distance bands of $<25 \mathrm{~m}, 25-50 \mathrm{~m}, 50-75 \mathrm{~m}$, and $>75 \mathrm{~m}$ for each rail vocalization. Because human observers had more rail detections than ARUs (see results), I used the humanobserver point count detections as a baseline and calculated the rate at which ARUs successfully detected vocalizations of rails heard by humans. I conducted a one-way analysis of variance (ANOVA) to test for differences in success rates of detection based on the distance of rail from the ARU. I used Tukey's post-hoc two-way comparison tests $(\alpha=0.05)$ to test for significant differences in detection success amongst distance bands (Freund et al. 2010).

To evaluate the effects of the duration of subsampling periods on the detection of rails and vocalization rates on continuous ARU data (my third research question), I analyzed a total of 720 hours of acoustic recordings. I established subsampling periods that lasted 5-min, 10-min, 15-min, 30-min, and 45-min of each hour. Subsampling periods always started at the top of the hour and extended for the duration of the subsampling (i.e., I did not randomly choose periods within each hour). For each period, I recorded presence of rails and I counted the total number of rail 
vocalizations using the 720 hours of passive continuous sampling data. I standardized the number of vocalizations captured within each subsampling period to a full 60 min sampling period, by multiplying the number of vocalizations within a 5 -min period by 12 , the number of vocalizations within a 10 -min period by 6 , the number of vocalizations within a 15 -min by 4 , the number of vocalizations within a 30 -min by 2 , and the number of vocalizations within a 45 -min by four-thirds.

I evaluated the rates at which ARU-based detection of King and Clapper Rails in a subsampling period compared to the hourly rate of ARU-based detection of rails. Presence detection rates were calculated by dividing the total number of rails detected during each subsampling period by the total number of rail detections for the entire hour. I used a repeated measures Chi-square test (i.e., a McNemar's test) to determine differences amongst subsampling periods and the full 60 min sampling period (Feuer and Kessler 1989). Rail vocalization rates were calculated by dividing the total number of rail vocalizations captured for each subsampling period by the total number of rail vocalizations in the entire hour. Standardized rail vocalization rates are similar to vocalization rates, except they are extrapolated to a full hourly period by multiplying by a correction factor. I used paired t-tests to test for differences in unstandardized vocalization and standardized vocalization rates between each subsampling period and the entire hourly period.

\subsection{RESUlTS}

Twelve King-Clapper Rails were detected visually during point counts by human observers, while 8 rails were detected both visually and aurally. The ARU missed $35 \%$ of the detections of the 750 rail vocalizations detected during point counts by human observers. All other rail vocalizations (the remaining 65\%) were detected by both the human observers and ARU. The ARU did not detect any rails missed by the human observers. 
The success of the ARU in detecting rails varied significantly based on the distance between the ARU and the vocalizing rail $\left(F_{3,105}=22.21, P \leq 0.001\right)$ (Figure 1.2$)$. The ARU detected $90.3 \%$ of the rails within $25 \mathrm{~m}$ but only $34.0 \%$ of rails at a distance of $\geq 75 \mathrm{~m}$. Post-hoc tests addressing pairwise comparisons between detection success at each distance band indicated significant differences between rails detected $>50 \mathrm{~m}$ and those detected $\leq 50 \mathrm{~m}$.

The probability of detecting a rail within a given hour increased with the duration of the subsampling period (Table 1.1), such that 5-min subsampling periods detected $57.7 \%$ of rails in an hour and 45-min subsampling periods detected $96.7 \%$ of rails detected within the full $60-$ min sampling period. The relation between sampling time and detection rates showed a strong logarithmic pattern $\left(F_{1,4318}=271.6, P \leq 0.001\right)$, with the best fit curve following the function: detection rate $=0.134 \times \log ($ time $)+0.253($ Figure 1.3). Each subsampling period had detection rates significantly different from the full sampling period $(P \leq 0.001)$.

Unstandardized rail vocalization rates increased with increasing subsampling periods (Table 1.1), such that 5-min subsampling periods had a detection rate of $9.8 \%$ and $45-\mathrm{min}$ subsampling periods captured $76.6 \%$ of rails detected within the full 60 -min sampling period. Each subsampling period had unstandardized vocalization rates significantly different from those of the full sampling period $(P \leq 0.001)$. Standardized rail vocalization rates varied with subsampling period, with all subsampling periods overestimating the number of vocalizations within the full 60 -min period (Table 1.1). The 5 min subsampling period overestimated vocalizations $17.6 \%$, while the 30 -min subsampling period only overestimated $0.1 \%$ of vocalizations. All subsampling periods except 30-min produced standardized rail vocalization rates significantly different from the full 60-min sampling period. No significant linear relationship existed between sampling time and standardized vocalization rates $(t=-1.77, P=0.0764)$ (Figure 1.3). 


\subsection{DISCUSSION}

My findings suggest that ARUs can be a useful tool in detecting secretive marsh birds. That said, the ARUs I used detected fewer rails than did human observers. Previous studies on ARU effectiveness in other settings have been inconsistent. Some studies found that ARUs can produce similar (Haselmayer and Quinn 2000, Hobson et al. 2002, Klingbeil and Willig 2015) or higher (Acevedo and Villanueva-Rivera 2006, Wimmer et al. 2013) estimates of species richness and abundance of a single species as compared to traditional human observer point counts. However, other studies have also reported that human observers outperform ARUs (Hutto and Stutzman 2009, Venier et al. 2012, Sidie-Sletthedahl et al. 2015). The lower detection performance of ARUs in those studies may be a combination of multiple factors including field sampling error (i.e., birds detected visually but not by the ARU and birds too distant from ARUs for detection) and spectrographic analysis error (i.e., recorded vocalizations that were too difficult to correctly identify, and recorded vocalizations that were overlooked by the person evaluating recordings) (Hutto and Stutzman 2009).

Distance plays a significant role in determining whether a bird is detected during a point count (Alldredge et al. 2007, Hutto and Stutzman 2009). I found significant differences in the detection rate of rails at $>50 \mathrm{~m}$ and those at $\leq 50 \mathrm{~m}$, suggesting an effective surveying radius of $50 \mathrm{~m}$ for King-Clapper Rails using SM-3 recorders. Previous studies also reported a similar radius of detectability for ARUs (Furnas and Callas 2015, Venier et al. 2012). However, Yellow Rail (Coturnicops noveboracensis) vocalizations have been detected up to an average distance of $175 \mathrm{~m}$ (Drake et al. 2016). In fact, it is likely that the detectable range of ARUs can be similar, better, or worse than the detectability of human observers and likely is highly species-, habitat-, and ARUspecific. 
Because birds are often detected aurally instead of visually, accurately estimating distances of birds to observers and to ARUs is difficult to achieve during most avian surveys (Scott et al. 1981, Alldredge et al. 2007, Nadeau and Conway 2012). Biased or imprecise distance estimations often result from a combination of localization error, the ability of an observer to locate a bird, and distance estimation error, the ability of an observer to accurately estimate distance to the bird (Alldredge et al. 2007). Previous studies have indicated a suite of factors lead to errors in distance estimation, including habitat structure (Richards and Wiley 1980), the species of the bird (Richards 1981, Schieck 1997, Hobson et al. 2002, Alldredge et al. 2007, Nadeau and Conway 2012), the distance from the bird to the observer (Nadeau and Conway 2012), the volume of the vocalization (Nadeau and Conway 2007), the orientation of the bird (Alldredge et al. 2007), and environmental factors such as wind and noise (Simons et al. 2007). These factors can ultimately lead to overestimating distances of birds close to the observer and underestimating distances of birds farther away (Nadeau and Conway 2012).

My findings suggest that subsampling of acoustic data can lead to biases in estimates of both presence and vocalization rates of rails. As expected, longer subsampling periods more accurately represented the rail presence and vocalization rates than did shorter subsampling periods. Shortening subsampling periods resulted in increasingly underestimated detection rates of rails. Previous studies reported similar trends where subsampling one-third of Killer Whale (Orcinus orca) calls led to a 24\% decline in detections (Riera et al. 2013) and subsampling less than one-tenth of the North American Right Whale (Eubalaena glacialis) calls resulted in a reduction in acoustic presence up to 26\% (Thomisch et al. 2015). These findings demonstrate the importance of understanding the species- and site-specific tradeoffs between subsampling duration and estimation biases prior to the analysis of acoustic data. 


\section{Management Implications}

Population monitoring is a fundamental function of agencies undertaking the management and conservation of wildlife species and their habitats. Acoustic surveys allow for monitoring of species that are difficult to locate or trap. However, deploying skilled field teams across large regions for these surveys can be logistically and financially challenging. My findings suggest the use of ARUs may be a viable tool to assist managers with both short-term (single-season) and long-term (multi-season) monitoring if the data they produce are interpreted appropriately. Short-term monitoring of a species may be most effective and least biased with a combination of both ARUs and human observers. This approach may best be accomplished by conducting point counts during deployment and retrieval of the ARU. While long-term monitoring using ARUs provides a viable alternative for traditional seasonal and annual surveying, ARUs incur the cost of producing large acoustic data sets that can be labor intensive to analyze. To alleviate this burden, managers may choose to subsample recordings in a manner that allows for a representation of the overall data. However, making informed decisions on appropriate subsampling schemes requires several considerations. Subsampling will be most effective if based upon prior knowledge of the species' vocal behavior through a complete acoustic sample. Sampling periods using ARUs can be adjusted accordingly based on the management goals of species presence or call rates. With those considerations in mind, a subsampling period of a minimum of $30 \mathrm{~min}$ intervals is likely to effectively capture presence and standardized vocalization rates of King-Clapper Rails in Virginia's intracoastal tidal marshes. Overall, species-, habitat-, and ARU-specific limitations to ARU sampling should be considered when making inferences about abundances and distributions from acoustic data. 


\subsection{Literature Cited}

Acevedo, M. A., and L. J. Villanueva-Rivera. 2006. Using automated digital recording systems as effective tools for the monitoring of birds and amphibians. Wildlife Society Bulletin 34: 211214.

Alldredge, M. W., T. R. Simons, and K. H. Pollock. 2007. A field evaluation of distance measurement error in auditory avian point count surveys. Journal of Wildlife Management 71: 2759-2766.

Bardeli, R., D. Wolff, F. Kurth, N. Koch, K. H. Tauchert, and K. H. Frommolt. 2010. Detecting bird sounds in a complex acoustic environment and application to bioacoustics monitoring. Pattern Recognition Letters 31: 1524-1534.

Bioacoustics Research Program. 2014. Raven Pro: Interactive Sound Analysis Software, v. 1.5. Cornell Lab of Ornithology, Ithaca, New York.

Bystrak, D. 1981. The North American breeding bird survey. Pages 34-41 in Estimating Number of Terrestrial Birds (C. J. Ralph and J. M. Scott, Eds.). Studies in Avian Biology, No. 6.

Chan, Y. L., C. E. Hill, J. E. Maldonado, and R. C. Fleischer. 2006. Evolution and conservation of tidal-marsh vertebrates: Molecular approaches. Studies in Avian Biology 32: 54-75.

Conway, C. 2011. Standardized North American marsh bird monitoring protocol. Waterbirds 34 : 319-346.

Drake, K. L., M. Frey, D. Hogan, and R. Hedley. 2016. Using digital recordings and sonogram analysis to obtain counts of yellow rails. Wildlife Society Bulletin 40: 346-354. 
ESRI. 2011. ArcGIS Desktop. v.10.0. Environmental Systems Research Institute. Redlands, California.

Feuer, E. J., and L. G. Kessler. 1989. Test statistic and sample size for a two-sample McNemar Test. Biometrics 45: 629-636.

Forcey, G. M., J. T. Anderson, F. K. Ammer, and R. C. Whitmore. 2006. Comparison of two doubleobserver point-count approaches for estimating breeding bird abundances. Journal of Wildlife Management 70: 1674-1681.

Freund, R. J., W. J. Wilson, and D. L. Mohr. 2010. Statistical Methods, Third Edition. Elsevier: New York.

Furnas, B. J., and R. L. Callas. 2015. Using automated recorders and occupancy models to monitor common forest birds across a large geographic region. Journal of Wildlife Management 79: $325-337$.

Gibbs, J. P., and S. M. Melvin. 1993. Call-response surveys for monitoring breeding waterbirds. Journal of Wildlife Management 7: 27-34.

Haselmayer, J., and J. S. Quinn. 2000. A comparison of point counts and sound recording as bird survey methods in Amazonian southeast Peru. Condor 102: 887-893.

Hobson, K. A., R. S. Rempel, H. Greenwood, B. Turnbull, and S. L. Van Wilgenburg. 2002. Acoustic surveys of birds using electronic recordings: new potential from an omnidirectional microphone system. Wilson Society Bulletin 30: 709-720.

Hutto, R. L., and R. J. Stutzman. 2009. Humans versus autonomous recording units: a comparison of point-count results. Journal of Field Ornithology 80: 387-398. 
Klingbeil, B. T., and M. R. Willig. 2015. Bird biodiversity assessments in temperate forests: the value of point count versus acoustic monitoring protocols. PeerJ 3: e973.

MacKenzie, D. I., J. D. Nichols, G. B. Lachman, S. Droege, J. A. Royles, and C. A. Langtimm. 2002. Estimating site occupancy rates when detection probabilities are less than one. Ecology 83: $2248-2255$.

Meanley, B. 1969. Natural history of the king rail. North American Fauna 67: 1-108.

Meanley, B. 1985. The marsh hen: A natural history of the clapper rail of the Atlantic Coast salt marsh. Tidewater Publishers, Centreville, Maryland.

Meanley, B., and D. K. Wetherbee. 1962. Ecological notes on mixed populations of king rails and clapper rails in Delaware Bay marshes. Auk 79: 453-457.

Nadeau, C. P., and C. J. Conway. 2012. Field evaluation of distance-estimation error during wetlanddependent bird surveys. Wildlife Research 39: 311-320.

Perkins, M., S. King, J. Linscombe. 2010. Effectiveness of capture techniques for rails in emergent marsh and agricultural wetlands. Waterbirds 33: 376-380.

R Development Core Team. 2012. R: a language and environment for statistical computing v. 3.1.3. R Foundation for Statistical Computing, Vienna, Austria. http://www.R-project.org.

Rempel, R. S., K. A. Hobson, G. Holborn, S. L. van Wilgenburg, and J. Elliott. 2005. Bioacoustic monitoring of forest songbirds: interpreter variability and effect of configuration and digital processing methods in the laboratory. Journal of Field Ornithology 76: 1-11.

Richards, D. G. 1981. Environmental acoustics and censuses of singing birds. Studies in Avian Biology 6: 297-300. 
Richards, D. G., and R. H. Wiley. 1980. Reverberations and amplitude fluctuations in the propagations of sound in a forest: implications for animal communication. American Naturalist 115: 381-399.

Riera, A., J. K. Ford, and N. R. Chapman. 2013. Effects of different analysis techniques and recording duty cycles on passive acoustic monitoring of killer whales. Journal of Acoustical Society of America 134: 2393-2404.

Schieck, J. 1997. Biased detection of bird vocalizations affects comparisons of bird abundance among forested habitats. Condor 99: 179-190.

Scott, J. M., F. L. Ramsey, and C. B. Kepler. 1981. Distance estimation as a variable in estimating bird numbers from vocalizations. Studies in Avian Biology 6: 334-340.

Sidie-Slettedahl, A. M., K. C. Jensen, R. R. Johnson, T. W. Arnold, J. E. Austin, and J. D. Stafford. 2015. Evaluation of autonomous recording units for detecting 3 species of secretive marsh birds. Wildlife Society Bulletin 39: 626-634.

Simons, T. R., M. W. Alldredge, K. H. Pollock, and J. M. Wettroth. 2007. Experimental analysis of the auditory detection process on avian point counts. Auk 124: 986-999.

Swiston, K. A., and D. J. Mennill. 2009. Comparison of manual and automated cross-correlation methods for identifying target sounds in continuous audio recordings of pileated, pale-billed, and putative ivory-billed woodpeckers. Journal of Field Ornithology 80: 42-50.

Tegeler, A. K., M. L. Morrison, and J. M. Szewczak. 2012. Using extended-duration audio recordings to survey avian species. Wildlife Society Bulletin 36: 21-29. 
Thomisch, K., O. Boebel, D. P. Zitterbart, F. Samaran, S. Van Parijs, and I. Van Opzeeland. 2015. Effects of subsampling of passive acoustic recordings on acoustic metrics. Journal of the Acoustical Society of America 138: 267-278.

Towsey, M., B. Planitzm A. Nantes, J. Wimmer, and P. Roe. 2012. A toolbox for animal call recognition. Bioacoustics 21: 107-125.

Venier, L. A., S. B. Holmes, G. W. Holborn, K. A. McIlwrick, and G. Brown. 2012. Evaluation of an automated recording device for monitoring forest birds. Wildlife Society Bulletin 36: 3039.

Waddle, J., T. F. Thigpen, and B. M. Glorioso. 2009. Efficacy of automatic vocalization recognition software for anuran monitoring. Herpetological Conservation and Biology 4: 384-388.

Wilson, M. D., B. D. Watts, and D. F. Brinker. 2007. Status review of Chesapeake Bay marsh lands and breeding marsh birds. Waterbirds 30: 122-137.

Wimmer, J., M. Towsey, P. Roe, and I. Williamson. 2013. Sampling environmental acoustic recordings to determine bird species richness. Ecological Applications 23: 1419-1428. 
Table 1.1. The rate at which autonomous recording unit (ARU) based detection of King-Clapper Rails in a subsampling period compared to the hourly rate of ARU-based detection of rails. Rails were monitored for 48-hr periods during May-July 2015 in Eltham Marsh along the Pamunkey River, near West Point, Virginia, USA. In each case, the rates reported are a comparison between a rate as measured during an entire hour recorded on an ARU in which a rail vocalized and as measured during a period of that hour (a subsampling period).

\begin{tabular}{cccc}
\hline $\begin{array}{c}\text { Subsampling } \\
\text { Periods (min) }\end{array}$ & $\begin{array}{c}\text { Detection Rate } \\
(95 \% \mathrm{CI})\end{array}$ & $\begin{array}{c}\text { Unstandardized Vocalization } \\
\text { Rate }(95 \% \mathrm{CI})\end{array}$ & $\begin{array}{c}\text { Standardized Vocalization } \\
\text { Rate }(95 \% \mathrm{CI})\end{array}$ \\
\hline 5 & $0.5767^{* * *}$ & $0.0980^{* * *}$ & $1.176^{*}$ \\
& $(0.5750-0.5784)$ & $(0.0975-0.0986)$ & $(1.170-1.183)$ \\
10 & $0.7249^{* * *}$ & $0.1908^{* * *}$ & $1.145^{* *}$ \\
& $(0.7233-0.7898)$ & $(0.1901-0.1916)$ & $(1.141-1.149)$ \\
15 & $0.7884^{* * *}$ & $0.2699^{* * *}$ & $1.079^{* *}$ \\
& $(0.7869-0.7898)$ & $(0.2690-0.2707)$ & $(1.1076-1.083)$ \\
30 & $0.9101^{* * *}$ & $0.5007^{* * *}$ & 1.001 \\
& $(0.9091-0.9110)$ & $(0.4997-0.5016)$ & $(0.9994-1.003)$ \\
45 & $0.9665^{* * *}$ & $0.7661^{* * *}$ & 1.021 \\
& $(0.9659-0.9671)$ & $(0.7653-0.7669)$ & $(1.020-1.022)$ \\
${ }^{*} P<0.05$ & & & \\
${ }^{* * *} P<0.01$ & & & \\
${ }^{* * * *} P \leq 0.001$ & & &
\end{tabular}




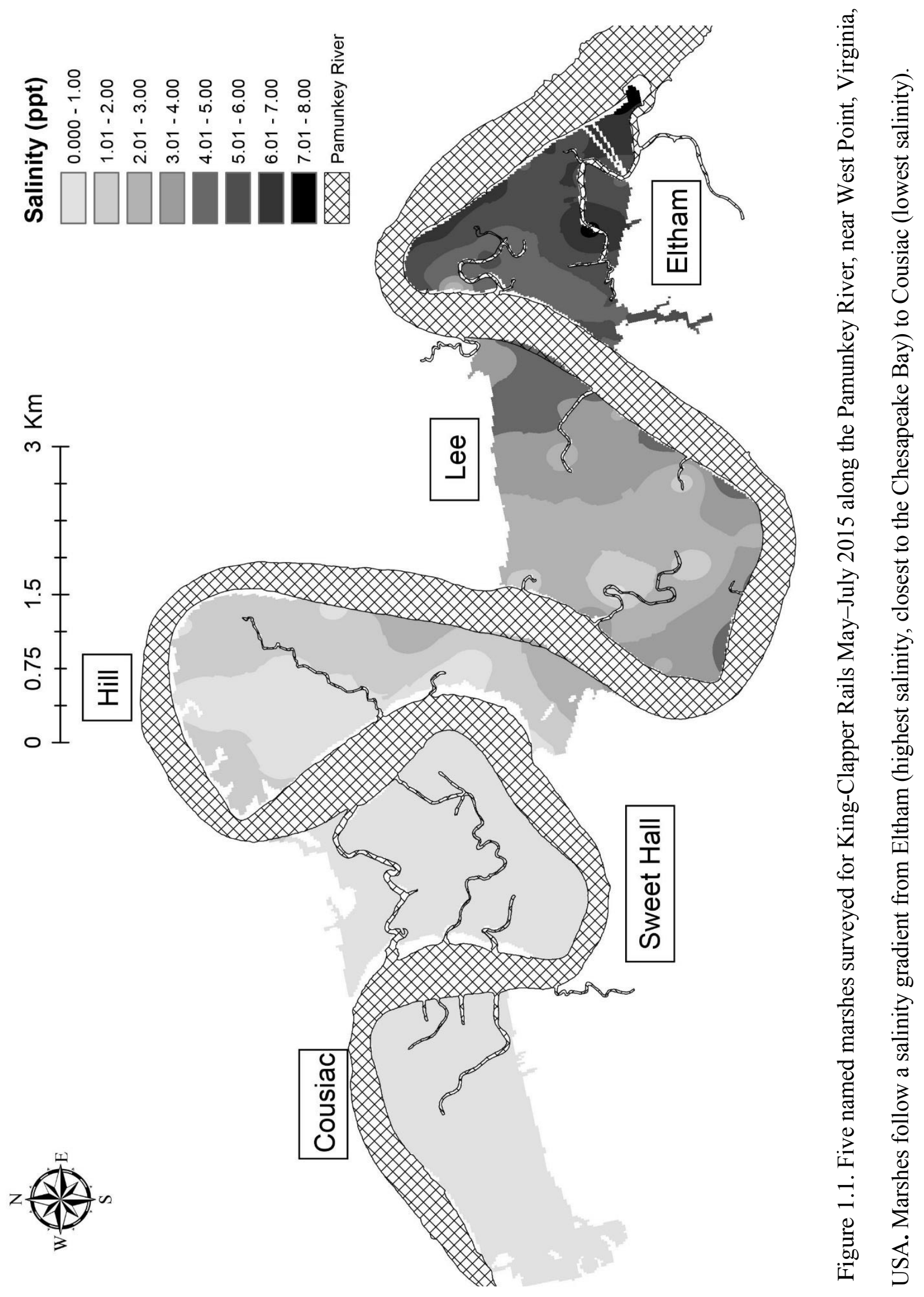




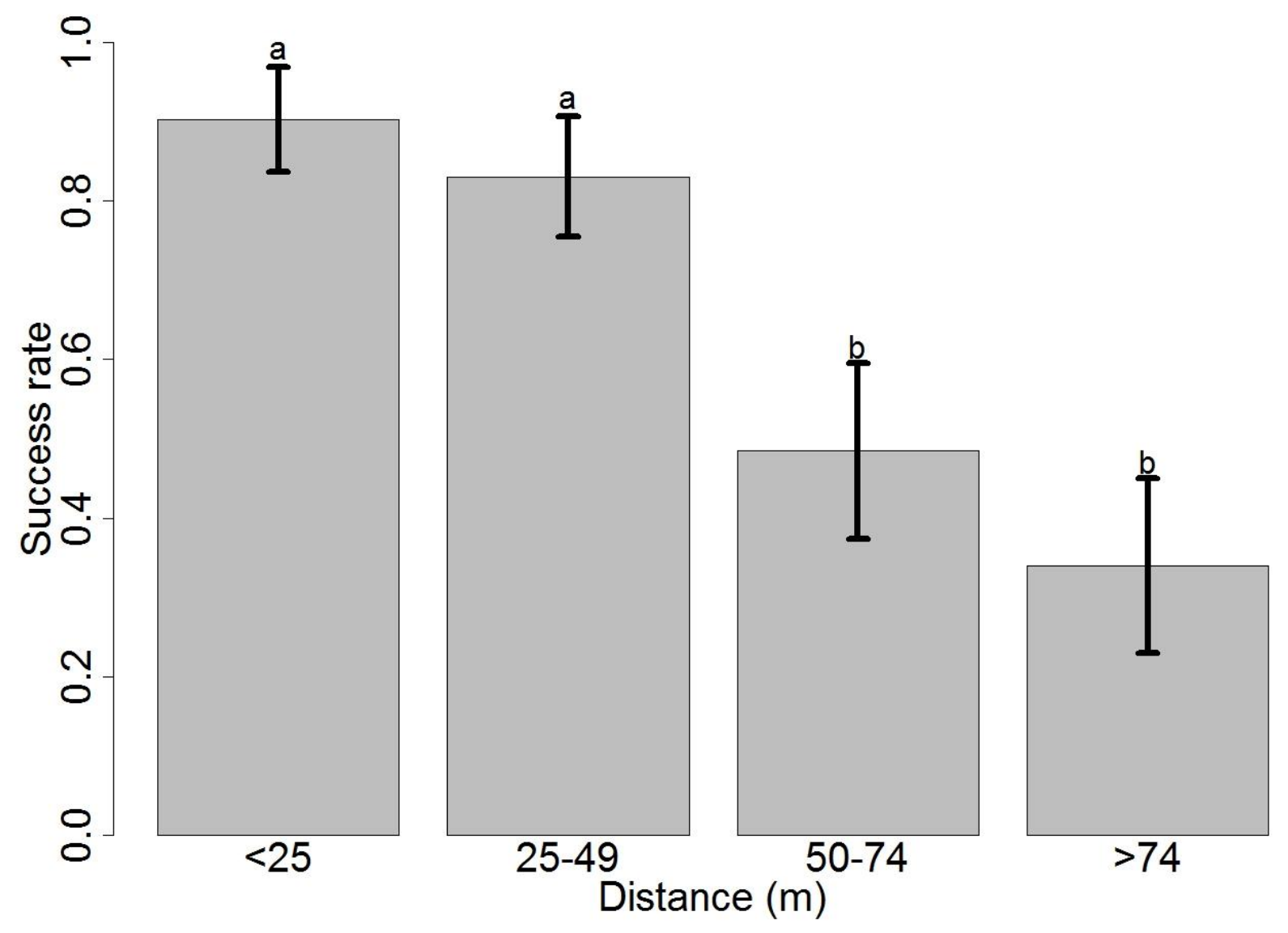

Figure 1.2. The rate at which autonomous recording units successfully detected vocalizations of King-Clapper Rails in marshes along the Pamunkey River, near West Point, Virginia, USA during May-July 2015. In all cases, human observer point count detections were used as a baseline. Distance bands of $<25 \mathrm{~m}, 25-49 \mathrm{~m}, 50-75 \mathrm{~m}$, and $>75 \mathrm{~m}$ were defined in point count data. Error bars illustrate variation across sampling sites. Statistically significant differences between hours are indicated by letter groupings " $a$ " and " $b$ ". 


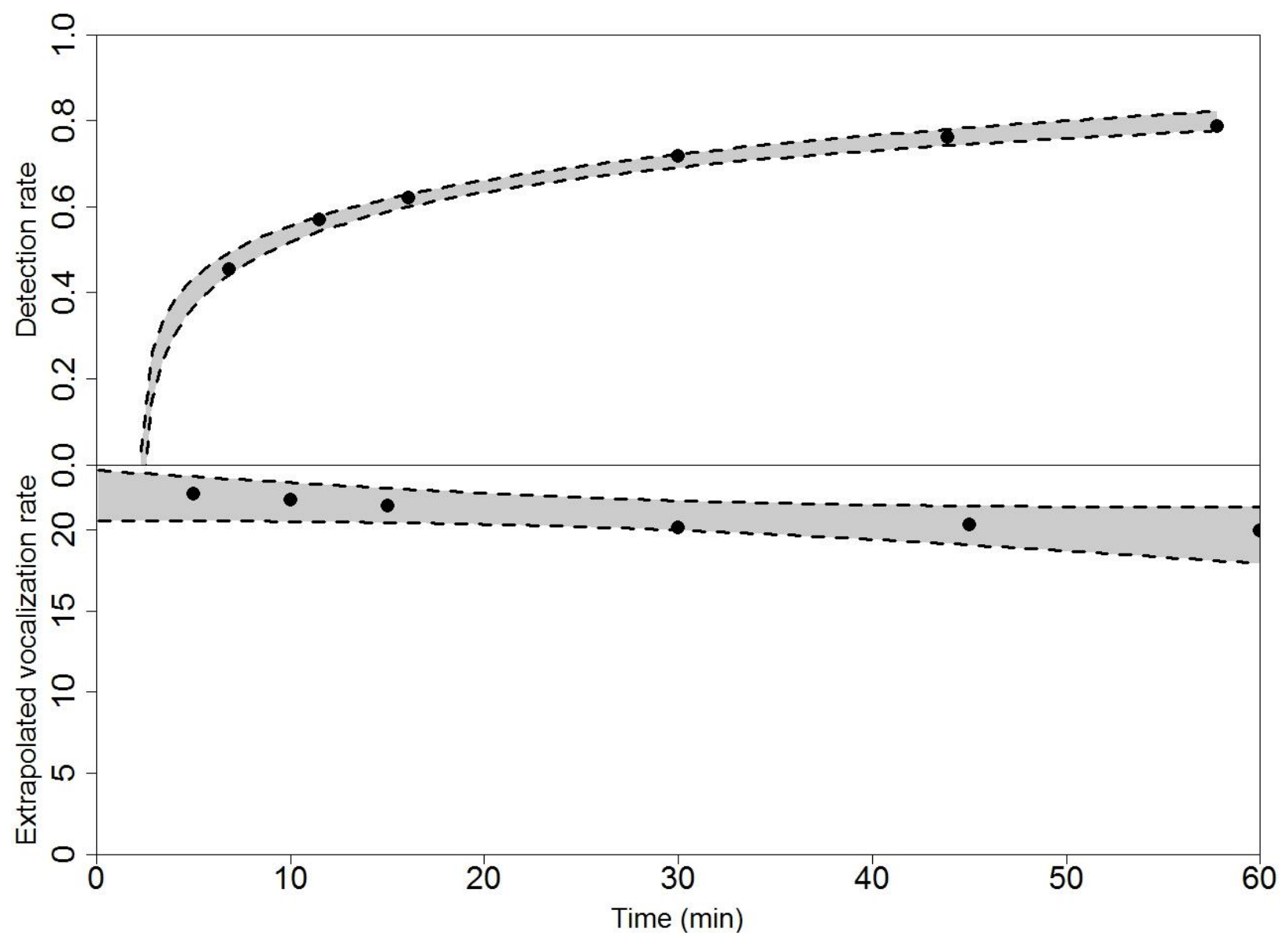

Figure 1.3. Relation between rates of detection and duration of sampling period of King-Clapper Rail vocalizations using autonomous recording unit hourly recordings in marshes along the Pamunkey River, near West Point, Virginia, USA during May-July 2015. The detection rate of rails exhibits a strong logarithmic relation with sampling time. The standardized extrapolated vocalization rate of rails demonstrates a non-significant linear relation with sampling time. The outer curves delineate $95 \%$ CI. Each point denotes the average detection rate or standardized vocalization rate for each subsampling period used in analyses. 


\section{CHAPTER 2}

\section{Diel Variation in Detection and Vocalization Rates of Rails in}

\section{Virginia Intracoastal Waterways}

\subsection{AbSTRACT}

Surveys for secretive marsh birds could improve with refinements to address regional and speciesspecific variation in detection probabilities with regards to optimal times of day to survey. I studied diel variation of naïve occupancy, detection rates, and vocalization rates of King (Rallus elegans) and Clapper (R. crepitans) rails in intracoastal waterways in Virginia, USA from May-July 2015. Autonomous recording units recorded vocalizations of King-Clapper Rails at 75 locations for 48-hr periods in a series of five marshes within a tidal marsh complex. Naïve rail occupancy did not vary hourly at either the marsh- or study area-level. Detection rates of rails varied as a function of time of day, marsh location, tidal stage, and date. Vocalization rates varied as a function of time of day, marsh location, and date. Rail detections and vocalizations varied across marshes $(P<0.01)$ and decreased as the sampling season progressed. Rail detection was greatest during low rising tides. Hourly variation occurred between $7.8 \%$ of pairwise comparisons for rail detections and $10.5 \%$ of pairwise comparisons for rail vocalizations $(P<0.01)$. Although statistically significant, because there were no patterns in these hourly differences, they may not be biologically relevant and are of little use to management. In fact, these findings demonstrate that surveys for rails in Virginia intracoastal waterways may be effectively conducted throughout the day. 


\subsection{INTRODUCTION}

Secretive marsh birds are challenging to monitor due to the difficulty in locating and trapping them within the dense emergent vegetation they occupy (Zembal and Massey 1983; Perkins et al. 2010). Thus, surveys for these species are usually conducted aurally by human observers who record numbers of vocalizations and estimate numbers of birds (e.g., The North American Marsh Bird Monitoring Protocol; Conway 2011). However, even these surveys can be improved with refinements to address regional, diel, and species-specific variation in detection probabilities (Conway and Gibbs 2011; Wiest and Shriver 2016). In particular, although there may be optimal times of day to survey for given species, these details are poorly understood (Conway and Gibbs 2011).

There are demonstrated temporally-driven inconsistencies in detection rates and abundance estimates for birds. This is especially true for members of the Family Rallidae. For example, morning sampling produced higher estimates of relative abundance and detection rate of Clapper Rails (Rallus crepitans) in Maryland (Lehmicke et al. 2013), California Black Rails (Laterallus jamaicensis coturniculus) in Arizona (Conway et al. 2004), and species within the Family Rallidae in Florida (Clapper Rail; Purple Gallinule (Porphyrio martinicus); Common Gallinule (Gallinula galeata); and American Coot (Fulica americana); Nadeau et al. 2008). However, in California, Light-footed Rails (R. obsoletus levipes) and California Black Rails were detected more frequently during evening sampling (Zembal and Massey 1987; Conway et al. 2004). In contrast, other studies have found no diel variation in outcomes of surveys conducted for California Black Rails (Spear et al. 1999) and a group of Rallidae species (King Rail, R. elegans; Virginia Rail, R. limicola; Sora, Porzana carolina; Common Gallinule; Harms and Dinsmore 2014). 
To better understand patterns in diel variation of rail behaviors, I studied variation in detection and vocalization rates of rails in Virginia intracoastal waterways. Within Virginia, populations of King and Clapper rails are declining and both species have been listed as Species of Greatest Conservation Need (Wilson et al. 2007; Virginia Department of Game and Inland Fisheries 2015; Correll et al. 2016). I recorded vocalizations of King-Clapper Rails using autonomous recording units (ARUs) and evaluated the recordings with survey covariates to determine hourly variation in: 1) the proportion of sites at which rails were detected, henceforth naïve occupancy; 2) estimates of the number of rails individuals detected; and 3) the frequency of rail vocalizations.

\subsection{METHODS}

\section{Study Area}

I studied rail vocalizations during the rail breeding season (Eddleman and Conway 1994; Reid et al. 1994) from May through July of 2015 in five tidal marshes along the Pamunkey River near West Point, Virginia, USA. The Pamunkey River is situated within the Chesapeake Bay Watershed and is a tributary of the York River. The five surveyed marshes were Eltham (288 ha), nearest the confluence with the York, followed upriver by Lee (579 ha), Hill (508 ha), Sweet Hall (395 ha), and Cousiac (387 ha) (Figure 2.1).

These marshes occur along a salinity gradient from mesohaline (5 - $18 \mathrm{ppt})$ at Eltham to fresh $(0-0.5 \mathrm{ppt})$ at Cousiac (Virginia Institute of Marine Science 2005). Previous avian surveys have shown rail density to follow the salinity gradient, with the highest density of rails within Eltham Marsh (S. R. Harding and G. R. Costanzo, VDGIF, unpubl. data) and decreasing densities within Lee and Hill (Paxton and Watts 2002). The marshes themselves are low and 
inundated twice daily by tidal flow. Vegetation in lower areas is dominated by smooth cordgrass (Spartina alterniflora). The higher, irregularly flooded areas are dominated by saltmeadow cordgrass (S. patens) and big cordgrass (S. cynosuroides). Freshwater and intermediate brackish salt marsh areas are characterized by arrow arum (Peltandra virginica), pickerelweed (Pontederia cordata), and wild rice (Zizania aquatica).

During the study, the average daily temperature was $25.4{ }^{\circ} \mathrm{C}$, with average maximum and minimum temperatures of $30.3{ }^{\circ} \mathrm{C}$ and $20.5^{\circ} \mathrm{C}$. Average daily wind speed was $1.96 \mathrm{~m} / \mathrm{s}$, with maximum wind speeds approaching $5.31 \mathrm{~m} / \mathrm{s}$. Sunrise and sunset occurred at 05:55 and 20:12 on the first day of sampling and at 06:00 and 20:27 on the last day. I obtained daily tidal information from National Oceanic and Atmospheric Association (NOAA) predictions for Sewells Point in West Point, VA (NOAA 2015) and categorized into six tidal stages: high tide, high tide falling, low tide falling, low tide, low tide rising, and high tide rising.

\section{Study Species}

King and Clapper rails are secretive marsh birds whose ranges overlap along the Atlantic and Gulf coasts of the United States. Although they are challenging to differentiate by physical appearance at a distance, King Rails are slightly larger, heavier, and have chestnut breast coloration, whereas Clapper Rails are slenderer and a grayish-brown coloration (Meanley 1969; Reid et al. 1994). These species coexist along a salinity gradient, with King Rails found in freshwater marshes and Clapper Rails in tidal salt marshes. However, both species can inhabit transitional zones of intermediate brackish-salt marshes (Meanley and Wetherbee 1962; Meanley 1969). In such areas, these species are often classified as King-Clapper Rails (Conway 2011). King and Clapper Rails 
have high genetic similarity (Maley and Brumfield 2013) and, in areas of coexistence, hybridization and introgression can occur between the two species (Meanley 1985; Chan et al. 2006).

King and Clapper Rails exhibit similarities not only morphologically and genetically, but also acoustically. Both have three main call series described as "keks", "grunts", and "kek-burrs". Males of both species give a series of sharp "kek" notes, accelerating then slowing at the end (Massey and Zembal 1987; Figure B.1). The "grunt" series is given by both species as contact calls. "Grunts" are characterized by fast, sharp notes that gradually decrease in frequency (Massey and Zembal 1987; Figure B.2). The "kek-burr" series is used solely by females, and is believed to be a way to attract a new mate or to call back a straying mate (Zembal and Massey 1985). This call begins with one or more "kek" notes followed by a "brrr" (Figure B.3).

\section{Survey Site Selection}

I used ArcMap 10.0 (ESRI 2011) to design a simple random sample for survey site selection. I constrained sample site selection so that each location was at least $400 \mathrm{~m}$ from every other survey location (Conway 2011), at least $50 \mathrm{~m}$ from marsh edge, and easily accessible by boat from the Pamunkey River. In total I selected 75 locations, with 15 locations in each of the five marshes.

\section{Sampling Protocols}

I deployed five Song Meter SM3 ${ }^{\mathrm{TM}}$ (Wildlife Acoustics) ARUs at survey sites within marshes. ARUs were mounted onto t-posts that were subsequently placed into the ground such that the ARUs were approximately $1.5 \mathrm{~m}$ above the marsh substrate. I sampled using one ARU per marsh for a single period of two consecutive days and I then moved the ARU to a new 
location within that same marsh and repeated the two-day protocol. Each sampling period started at midnight and lasted exactly 48 hrs. I programmed the ARUs to record 16-bit with a sampling rate at $24 \mathrm{kHz}$. Recordings were stored hourly onto $128 \mathrm{~GB}$ memory cards.

The order of sampling locations within a marsh at which ARUs were deployed was random. If the water level was too low to access a location, I selected the next sampling location and rescheduled the inaccessible location for the following high tide placement. If upon visiting a location, I determined the location did not meet the original selection constraints, I selected a new randomized replacement site. During rainy weather or when wind speeds exceeded $20 \mathrm{~km} / \mathrm{h}$ (Gibbs and Melvin 1993), I delayed sampling for a day. This approach allowed for concurrent sampling across the five marshes.

\section{Spectrographic Analyses}

I placed an ARU for two days at each of the 15 sampling locations within five marshes, resulting in a total of 3,600 hrs of acoustic recordings for analysis. I used the interactive sound analysis software Raven Pro (Bioacoustics Research Program 2014) to manually identify vocalizations of rails in the recordings. Since there is no widely accepted acoustic method to definitively differentiate between vocalizations of the two species (Graves 2001; Conway 2011), I pooled all vocalizations as King-Clapper Rails for analysis. I defined a vocalization as a complete series of calling notes. For each vocalization, I identified the start and end points and the duration of calling. As an example, one vocalization can be a single stand alone "kek" note and another, a series of "kek" notes. 
Once I identified all vocalizations, I estimated, for each marsh, the total number of individual rails detected per hour for each sampling period. Because I could not distinguish between calls of individual rails, I only counted $>1$ rail when there was overlap in the timing of vocalizations by multiple birds (Figure B.4). Finally, within two marshes with high and low apparent densities of rails, I estimated the total number of hourly rail vocalizations recorded.

\section{Statistical Analyses}

To assess hourly variation in naïve occupancy at the marsh- and study area-level, I calculated, by hour, the proportion of sites where at least one rail was detected for all 15 sampling locations in each marsh. I then calculated an overall hourly proportion of sites where at least one rail was detected by averaging across all marshes. I used a $\chi^{2}$ test $(\alpha=0.05)$ to assess hourly variation in naïve occupancy for (a) each marsh individually and (b) the combined study area.

To understand diel fluctuations in number of rails detected, I calculated the number of rails detected in each hour separately for each marsh. For this analysis, for each hour of the day, I summed data across all 15 sampling points, which was equivalent to 30 sampling days. I removed outliers within the data (Zuur et al. 2010), and since I detected overdispersion within the count data (R package: AER, Kleiber and Zeileis 2008), I developed models using Negative Binomial distributions (Zuur et al. 2009). I generated generalized univariate and additive linear models $(\mathrm{n}=16)$ with time, marsh, date, and tidal stage as fixed effects to determine which covariates had the greatest effect on the response variable, rail detection rate per hour ( $\mathrm{R}$ package: glmmAMDB, Skaug et al. 2016). I used corrected Akaike information criterion $\left(\mathrm{AIC}_{\mathrm{c}}\right)$ to compare all combinations of sub-models using log-likelihoods and I ranked models 
based on $\triangle \mathrm{AIC}_{\mathrm{c}}$ and weights (Burnham and Anderson 2004; R package: AICcmodavg, Mazerolle 2016). I regarded the model with the lowest $\mathrm{AIC}_{\mathrm{c}}$ to be the top model and considered models with $\Delta \mathrm{AIC}_{\mathrm{c}}<2$ to have substantial support (Burnham and Anderson 2004). I used parametric bootstrapping $(n=10,000)$ to calculate estimates for each model parameter of interest to allow for pairwise comparisons (99\% CIs) while controlling for additional parameters within the model (e.g., the effect of time on detection while controlling for marsh, date, and tide) (Anderson and Burnham 2002; Hothorn et al. 2008; Burnham et al. 2011; R package: mnormt, Azzalini and Genz 2016).

To understand variation in the rate of rail vocalizations throughout the day, I calculated the number of rail vocalizations per hour, summed across all 15 sites and 30 sampling days. For this analysis I only considered two marshes: Eltham, which had the greatest apparent density of rails, and Hill, which had a low apparent density of rails from previous work in the marsh complex. I again removed outliers within the data. I used similar model development (n = 16), model selection, and parametric bootstrapping processes as above, building and comparing multiple sub-models with the same Negative Binomial distribution. I analyzed data using the statistical program R (R Development Core Team 2012) and RStudio (RStudio Team 2015).

\subsection{RESULTS}

Naïve occupancy estimates decreased with decreasing site salinity. The highest average percentage of ARU sampling sites at which rails were detected occurred at Eltham $(86.7 \pm 1.9$ SE \%), followed by Lee (47.0 \pm 2.3 SE \%), Hill (26.1 \pm 2.6 SE \%), and Sweet Hall (11.1 \pm 1.6 
SE \%) (Figure 2.2). No rails were detected at Cousiac Marsh. Overall, I detected rails at an average of $42.7 \pm 1.6 \mathrm{SE} \%$ of sites. There was no significant variation in naïve occupancy among hours within each individual marsh and across the entire study area (Table C.1).

The global model was the single best for estimating frequency of rail detections (Table 2.1; Table C.2). Detection of rails varied only among a few hours of the day, with significant differences $(P<0.01)$ among $7.8 \%$ (20 of 256$)$ of the hourly pairwise comparisons of bootstrapped estimates for rail detection (Figure 2.3). I found no patterns of increasing or decreasing rail detection rates at any time throughout the day. Higher rates of detection occurred during the hour of 00:00 and between 04:00 - 06:59 and 13:00 - 15:59. Lower rates of detection occurred between 07:00 - 09:59. The frequency of rail detections varied significantly amongst all marshes $(P<0.01)$, with Eltham appearing to have both the highest and most variable detection rate (Figure 2.4; Figure C.1; Figure C.2). The number of rails detected varied with tidal stage $(P<0.01)$, with detection rates lower at low falling tides than at either high tides or low rising tides (Figure 2.5). Frequency of rail detections also decreased as the season progressed $(P<0.01 ;$ Figure 2.6).

The best model for estimating frequency of rail vocalizations had fixed additive effects for Time, Marsh, and Date (Table 2.1; Table C.3). In contrast to the model results for detection frequency, models with Tide were not well supported. Frequency of rail vocalizations varied with time of day, with significant differences $(P<0.01)$ among $10.5 \%$ (27 of 256$)$ of the hourly pairwise comparisons of bootstrapped estimates for rail vocalizations (Figure 2.7). Again, I did not detect diel patterns (peaks and valleys) in vocalization rates during the day. Higher rates of vocalizations occurred during the hours of 00:00 - 00:59, 05:00 - 05:59, 10:00 - 11:59, and 14:00 - 15:59, and lower rates during the hours of 07:00 - 09:00 and 22:00 - 23:00. Rail 
vocalizations varied amongst marshes $(P<0.01)$ and were more frequent and more variable at Eltham than at Hill. Vocalization rates decreased as the season progressed $(P<0.01$; Figure 2.8).

\subsection{DISCUSSION}

While the findings suggest statistically significant differences in rail vocalization behavior throughout the day, those differences are not indicative of daily patterns in these rates and are likely only biologically or ecologically significant in a small set of circumstances. For example, naïve rail occupancy did not vary hourly among sites. Similarly, although there were statistically significant differences in hourly detection and vocalization rates, those differences do not appear to be evidence of a biological pattern and provide no clear distinctions between vocalization behavior between the morning and afternoon. While lower detection and vocalization rates occurred during the early morning (07:00 - 09:59), higher rates occurred at seemingly random times of the day (00:00 - 00:59, 05:00 - 06:59, and 14:00 - 14:59).

As has been observed in other studies, the vocalization and detection frequencies I recorded were greatest early in the season (Conway and Gibbs 2005; Conway and Nadeau 2010; Wiest and Shriver 2016). Tidal stage also had an influence on the data, but only for rail detections and not rail vocalizations. Previous studies found reduced rail detection during high tide (Zembal and Massey 1987; Wiest and Shriver 2016) and greater detection during mid-level tides (Lehmicke et al. 2013; Wiest and Shriver 2016).

These findings have important implications both for rail biology and for design of surveys to detect rails and other secretive marsh birds. There has been little comprehensive 
study of diel variation of vocalization rates of birds and the study is the first investigation into 24-hr diel vocalization patterns for secretive marsh birds. The rails I studied vocalized consistently across the day at all of the study sites where rails were detected and most hours were similar to each other in vocalization and detection rates. The only differences I detected were small and were between hours during early morning and during late evening following sunset. The higher frequency of vocal activity during sunrise might be influenced by increased social interactions amongst breeders to reinforce territorial mating boundaries following the nocturnal rest period (Massey and Zembal 1987). Decreased nighttime vocal activity may also be a mechanism to decrease nest predation by nocturnal predators (e.g., raccoons (Procyon lotor); Meanley 1985).

Rail density appears to influence the effectiveness and accuracy of acoustic sampling. Apparent high density areas had higher rates of detection and vocalization, and rails were detected at a greater proportion of sites in those areas. In contrast, all three metrics were lower at apparently low density areas. This density-dependent response of vocalization probability has been demonstrated for Virginia Rails (Glahn 1974; Robertson and Olsen 2014) and Light-footed Rails (Zembal and Massey 1987). This response can be problematic when interpreting sampling data because it increases sampling error and can result in overestimates of abundance (Bart and Schoultz 1984; Conway and Gibbs 2001; Robertson and Olsen 2014).

Our findings have several implications for design of surveys to detect rails and other secretive marsh birds, in particular, for the use of ARUs and for the timing of surveys. Secretive marsh birds are traditionally sampled via callback surveys to increase detection probability (Conway 2011; Conway and Gibbs 2011). However, since callbacks may change behavior of birds, using callbacks may alter the diel pattern of vocalization. ARUs can provide an alternative 
method to traditional sampling for long-term, continuous monitoring of secretive marsh birds without introducing bias that playback and human presence may create. The use of autonomous devices can also allow for simultaneous surveying of multiple locations thereby reducing temporal, spatial, and financial constraints associated with having a person visit each location simultaneously (Tegeler et al. 2012). In addition to having the potential to minimize observer bias, ARUs are also beneficial because they produce a permanent survey record that can be validated by multiple observers and can allow for more frequent detection of rare species (Rempel et al. 2005; Acevedo and Villanueva-Rivera 2006; Hutto and Stutzman 2009).

However, ARUs possess drawbacks that impose limitations on their utility. ARUs generate large volumes of acoustic recordings that can be difficult to store and analyze (Rempel et al. 2005). While automated species detectors can be built for spectrographic analysis software, they tend to require large training data sets and they often produce many false positives and false negatives (Waddle et al. 2009; Bardeli et al. 2010; Towsey et al. 2012). Manual analysis of recordings can provide higher accuracy, but is often time and effort consuming (Swiston and Mennill 2009). The ARUs also may detect fewer individuals than humans, especially when rails are calling farther away from the recording instrument (Venier $e t$ al. 2012; Furnas and Callas 2015).

This study illustrates that in intracoastal Virginia, rail detection and vocalization rates varied minimally with time of day, suggesting that, King-Clapper Rails can be surveyed there throughout the day. Future studies over broader spatial ranges may reveal if the lack of diel variation in this study is representative across the entire region or if it is driven by local variability in behaviors. Using this information, wildlife managers and biologists can develop a more informed regional monitoring program for secretive marsh birds. 


\subsection{Literature Cited}

Acevedo, M. A. and L. J. Villanueva-Rivera. 2006. Using automated digital recording systems as effective tools for the monitoring of birds and amphibians. Wildlife Society Bulletin 34: 211214.

Anderson, D. R. and K. P. Burnham. 2002. Avoiding pitfalls when using information-theoretic methods. Journal of Wildlife Management 66: 912-918.

Azzalini, A. and A. Genz. 2016. The R package 'mnormt': The multivariate normal and t distributions. $\mathrm{R}$ package version 1.5-5, https://cran.r-project.org/package=mnormt.

Bardeli, R., D. Wolff, F. Kurth, N. Koch, K. H. Tauchert, and K. H. Frommolt. 2010. Detecting bird sounds in a complex acoustic environment and application to bioacoustics monitoring. Pattern Recognition Letters 31: 1524-1534.

Bart, J. and J. D. Schoultz. 1984. Reliability of singing bird surveys: changes in observer efficiency with avian density. Auk 101:307-318.

Bioacoustics Research Program. 2014. Raven Pro: Interactive Sound Analysis Software, v. 1.5. Cornell Lab of Ornithology, Ithaca, New York. http://www.birds.cornell.edu/raven, accessed 12 June 2014.

Burnham, K. P. and D. R. Anderson. 2004. Multimodel inference: Understanding AIC and BIC in model selection. Sociological Methods Research 33: 261-304. 
Burnham, K. P., D. R. Anderson, and K. P. Huyvaert. 2011. AIC model selection and multimodel inference in behavioral ecology: some background, observations, and comparisons. Behavioral Ecology and Sociobiology 65: 23-35.

Chan, Y. L., C. E. Hill, J. E. Maldonado, and R. C. Fleischer. 2006. Evolution and conservation of tidalmarsh vertebrates: Molecular approaches. Studies in Avian Biology 32: 54-75.

Conway, C. J. 2011. Standardized North American marsh bird monitoring protocol. Waterbirds 34: $319-346$.

Conway, C. J. and J. P. Gibbs. 2001. Factors influencing detection probabilities and the benefits of call broadcast surveys for monitoring marsh birds. Unpublished Report, U.S. Geological Survey Patuxent Wildlife Research Center, Laurel, Maryland, USA.

Conway, C. J. and J. P. Gibbs. 2005. Effectiveness of call-broadcast surveys for monitoring marsh birds. Auk 122: 26-35.

Conway, C. J. and J. P. Gibbs. 2011. Summary of intrinsic and extrinsic factors affecting detection probability of marsh birds. Wetlands 31: 403-411.

Conway, C. J. and C. P. Nadeau. 2010. Effects of broadcasting conspecific and heterospecific calls on detection of marsh birds in North America. Wetlands 30: 358-368.

Conway, C. J., C. Sulzman, and B. E. Raulston. 2004. Factors affecting detection probability of California black rails. Journal of Wildlife Management 68: 360-370.

Correll, M. D., W. A. Wiest, T. P. Hodgman, W. G. Shriver, C. S. Elphick, B. J. McGill, K. M. O’Brien, and B. J. Olsen. 2016. Predictors of specialist avifaunal decline in coastal marshes. Conservation Biology 31: 172-182. 
Eddleman, W. R. and C. J. Conway. 1994. Clapper Rail. Pages 167-179 in Migratory shore and upland game bird management in North America (Tacha, T.C. and C. E. Braun, Eds.). Allen Press, Lawrence, Kansas, USA.

ESRI 2011. ArcGIS Desktop: Release 10. Redlands, CA: Environmental Systems Research Institute.

Furnas, B. J. and R. L. Callas. 2015. Using automated recorders and occupancy models to monitor common forest birds across a large geographic region. Journal of Wildlife Management 79: 325-337.

Gibbs, J. P. and S. M. Melvin. 1993. Call-response surveys for monitoring breeding waterbirds. Journal of Wildlife Management 57: 27-34.

Glahn, J. F. 1974. Study of breeding birds with recorded calls in north-central Colorado. Wilson Bulletin 86: 206-214.

Graves, C. 2001. Avian use of tidal marshes across a salinity gradient at Savannah National Wildlife Refuge, Georgia-South Carolina. M.S. Thesis, University of Tennessee, Knoxville.

Harms, T. M. and S. J. Dinsmore. 2014. Influence of season and time of day on marsh bird detections. Wilson Journal of Ornithology 26: 30-38.

Hothorn, T., F. Bretz, and P. Westfall. 2008. Simultaneous inference in general parametric models. Biometrical Journal 50: 346-363.

Hutto, R. L. and R. J. Stutzman. 2009. Humans versus autonomous recording units: A comparison of point-count results. Journal of Field Ornithology 80: 387-398.

Kleiber, C. and A. Zeileis. 2008. Applied Econometrics with R. Springer-Verlag, New York, NY. R package version 1.2-4, http://CRAN.R-project.org/package $=$ AER 
Lehmicke, A. J. J., J. L. Bowman, A. E. Banning, and B. L. Vasilas. 2013. Effect of tide level and time of day on detection rate and abundance of clapper rails (Rallus longirostris) in a Mid-Atlantic tidal marsh system. Wetlands 36: 364-368.

Maley, J. and R. Brumfield. 2013. Mitochondrial and Next-Generation sequence data used to infer phylogenetic relationships and species limits in the Clapper/King Rail complex. Condor 115: 316-329.

Massey, B. W. and R. Zembal. 1987. Vocalizations of Light-Footed Clapper Rail. Journal of Field Ornithology 58: 32-40.

Mazerolle, M. J. 2016. AICcmodavg: Model selection and multimodal inference based on (Q)AIC(c). R package version 2.0-4, http://CRAN.R-project.org/package= AICcmodavg.

Meanley, B. 1969. Natural history of the king rail. North American Fauna 67: 1-108.

Meanley, B. 1985. The marsh hen: A natural history of the clapper rail of the Atlantic Coast salt marsh. Tidewater Publishers, Centreville, MD.

Meanley, B. and D. K. Wetherbee. 1962. Ecological notes on mixed populations of king rails and clapper rails in Delaware Bay marshes. Auk 79: 453-457.

Nadeau C. P., C. J. Conway, B. S. Smith, and T. E. Lewis. 2008. Maximizing detection probability of wetland-dependent birds during point- count surveys in northwestern Florida. Wilson Journal of Ornithology 120: 513-518.

National Oceanic and Atmospheric Administration. 2015. NOAA tides and currents. http://tidesandcurrents.noaa.gov/.

Paxton, B. J. and B. D. Watts. 2002. Bird surveys of Lee and Hill marshes on the Pamunkey River: Possible affects of sea-level rise on marsh bird communities. Center for Conservation 
Biology Technical Report Series. CCBTR-03-04. College of William and Mary, Williamsburg, Virginia, USA.

Perkins, M., S. King, and J. Linscombe. 2010. Effectiveness of capture techniques for rails in emergent marsh and agricultural wetlands. Waterbirds 33: 376-380.

R Development Core Team. 2012. R: a language and environment for statistical computing v. 3.1.3. R Foundation for Statistical Computing, Vienna, Austria. http://www.R-project.org.

Reid, F. A., B. Meanley, and L. H. Fredrickson. 1994. King Rail. Pages 181-191 in Migratory shore and upland game bird management in North America (Tacha, T.C. and C. E. Braun, Eds.). Allen Press, Lawrence, Kansas.

Rempel, R. S., K. A. Hobson, G. Holborn, S. L. van Wilgenburg, and J. Elliott. 2005. Bioacoustic monitoring of forest songbirds: interpreter variability and effect of configuration and digital processing methods in the laboratory. Journal of Field Ornithology 76: 1-11.

Robertson, E. P. and B. J. Olsen. 2014. Density, sex, and nest stage affect rail broadcast survey results. Journal of Wildlife Management 78: 1293-1301.

RStudio Team. 2015. RStudio: Integrated Development for R v. 0.98.1028. RStudio, Inc., Boston, MA. http://www.rstudio.com.

Spear, L. B., S. B. Terrill, C. Lenihan, and P Delevoryas. 1999. Effects of temporal and environmental factors on the probability of detecting California Black Rails. Journal of Field Ornithology 70: 465-480.

Skaug, H., D. Fournier, A. Nielsen, A. Magnusson, and B. Bolker. 2016. Generalized linear mixed models using ‘AD Model Builder’. R package version 0.8.3.3, http://glmmadmb.r-forge.rproject.org. 
Swiston, K. A., and D. J. Mennill. 2009. Comparison of manual and automated cross-correlation methods for identifying target sounds in continuous audio recordings of pileated, pale-billed, and putative ivory-billed woodpeckers. Journal of Field Ornithology 80: 42-50.

Tegeler, A. K., M. L. Morrison, and J. M. Szewczak. 2012. Using extended-duration audio recordings to survey avian species. Wildlife Society Bulletin 36: 21-29.

Towsey, M., B. Planitzm A. Nantes, J. Wimmer, and P. Roe. 2012. A toolbox for animal call recognition. Bioacoustics 21: 107-125.

Venier, L. A., S. B. Holmes, G. W. Holborn, K. A. Mcllwrick, and G. Brown. 2012. Evaluation of an automated recording device for monitoring forest birds. Wildlife Society Bulletin 36: 3039.

Virginia Department of Game and Inland Fisheries (VDGIF). 2015. Virginia's 2015 Wildlife Action Plan. Virginia Department of Game and Inland Fisheries, Henrico, Virginia. http://bewildvirginia.org/wildlife-action-plan/pdf/2015-Virginia-Wildlife-Action-Plan.pdf, accessed 5 March 2017.

Virginia Institute of Marine Science. 2005. VECOS Lower Pamunkey Oligohaline (PMKOH) dataflow cruise data. Virginia Institute of Marine Science, Gloucester Point, Virginia. http://web2.vims.edu/vecos, accessed 5 March 2017.

Waddle, J., T. F. Thigpen, and B. M. Glorioso. 2009. Efficacy of automatic vocalization recognition software for anuran monitoring. Herpetological Conservation and Biology 4: 384-388.

Wiest, W. A. and W. G. Shriver. 2016. Survey frequency and timing affect occupancy and abundance estimates for salt marsh birds. Journal of Wildlife Management 80: 48-56. 
Wilson, M. D., B. D. Watts, and D. F. Brinker. 2007. Status review of Chesapeake Bay marsh lands and breeding marsh birds. Waterbirds 30: 122-137.

Zembal, R. and B. W. Massey. 1983. To catch a clapper rail-twice. North American Bird Bander 8: 144-148.

Zembal, R. and B. W. Massey. 1985. Function of a rail “mystery” call. Auk 102: 179-180.

Zembal, R. and B. W. Massey. 1987. Seasonality of vocalizations by light-footed clapper rails. Journal of Field Ornithology 58: 41-48.

Zuur, A. F., E. N. Ieno, N. J. Walker, A. A. Saveliev, and G. M. Smith. 2009. Mixed effects models and extensions in ecology with R. Springer, New York.

Zuur, A. F., E. N. Ieno, and C. S. Elphick. 2010. A protocol for data exploration to avoid common statistical problems. Methods in Ecology and Evolution 1: 3-14. 
Table 2.1 Model selection results for the hourly detection and vocalization rates of King-Clapper Rails in intracoastal Virginia, USA May-July 2015. Models are ranked by difference in corrected Akaike's Information Criterion $\left(\Delta \mathrm{AIC}_{\mathrm{c}}\right)$ with the model weight $\left(w_{i}\right)$ and number of parameters $(K)$. Parameters included time of day (Time), marsh location (Marsh), day of the year (Date), and tidal stage (Tide). Only the top three models are shown; each model set contained 16 models.

\begin{tabular}{lrrr}
\hline Model & $K$ & $\Delta \mathrm{AIC}_{\mathrm{c}}{ }^{\mathrm{a}}$ & $w_{i}$ \\
\hline Detection & & & \\
Count $\sim$ Time + Marsh + Date + Tide & 34 & 0 & 1 \\
Count $\sim$ Time + Marsh + Date & 29 & 20.7 & $<0.001$ \\
Count $\sim$ Marsh + Date + Tide & 11 & 39 & $<0.001$ \\
& & & \\
Vocalization & & & \\
Count $\sim$ Time + Marsh + Date & 27 & 0 & 0.967 \\
Count $\sim$ Time + Marsh + Date + Tide & 32 & 6.8 & 0.033 \\
Count $\sim$ Marsh + Date & 4 & 44.1 & $<0.001$ \\
\hline
\end{tabular}

${ }^{\mathrm{a}} \mathrm{The} \mathrm{AIC}_{\mathrm{c}}$ value of the best model was 4796.8 for Detection and 7221.8 for Vocalization. 


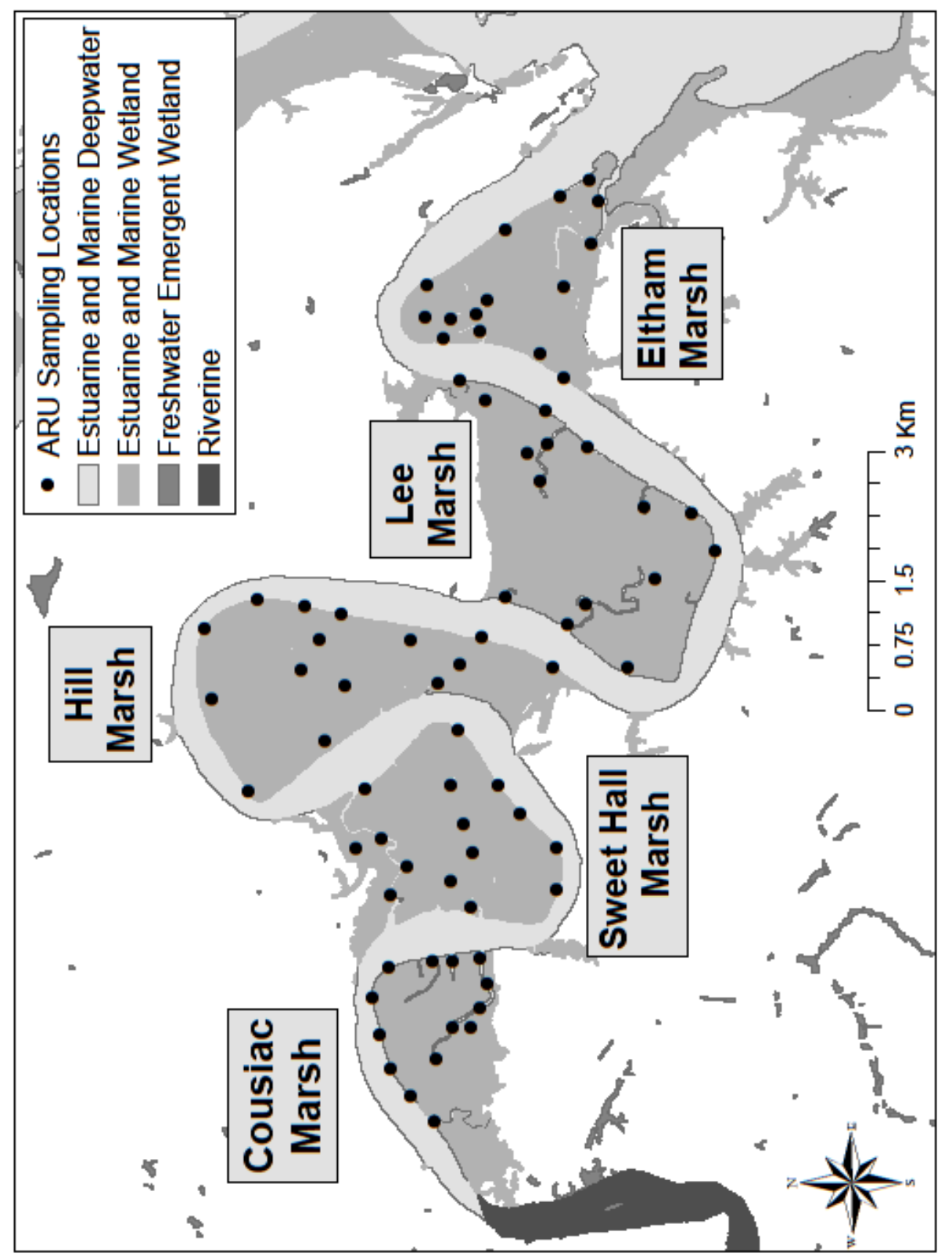

营 离

氛育

过

33

크을

Ð

这泀

췅응

灵

르

‡

on

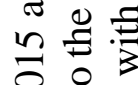

은

출웡

主㐫

之氜

흘 증

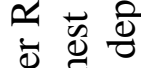

을. 일

긍

占

氞壳

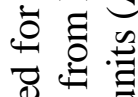

0

히를

क

\& 0 क

氙.

惑

유

클 응

0

i

. w

길

$0 \dot{0}$

总造苞 


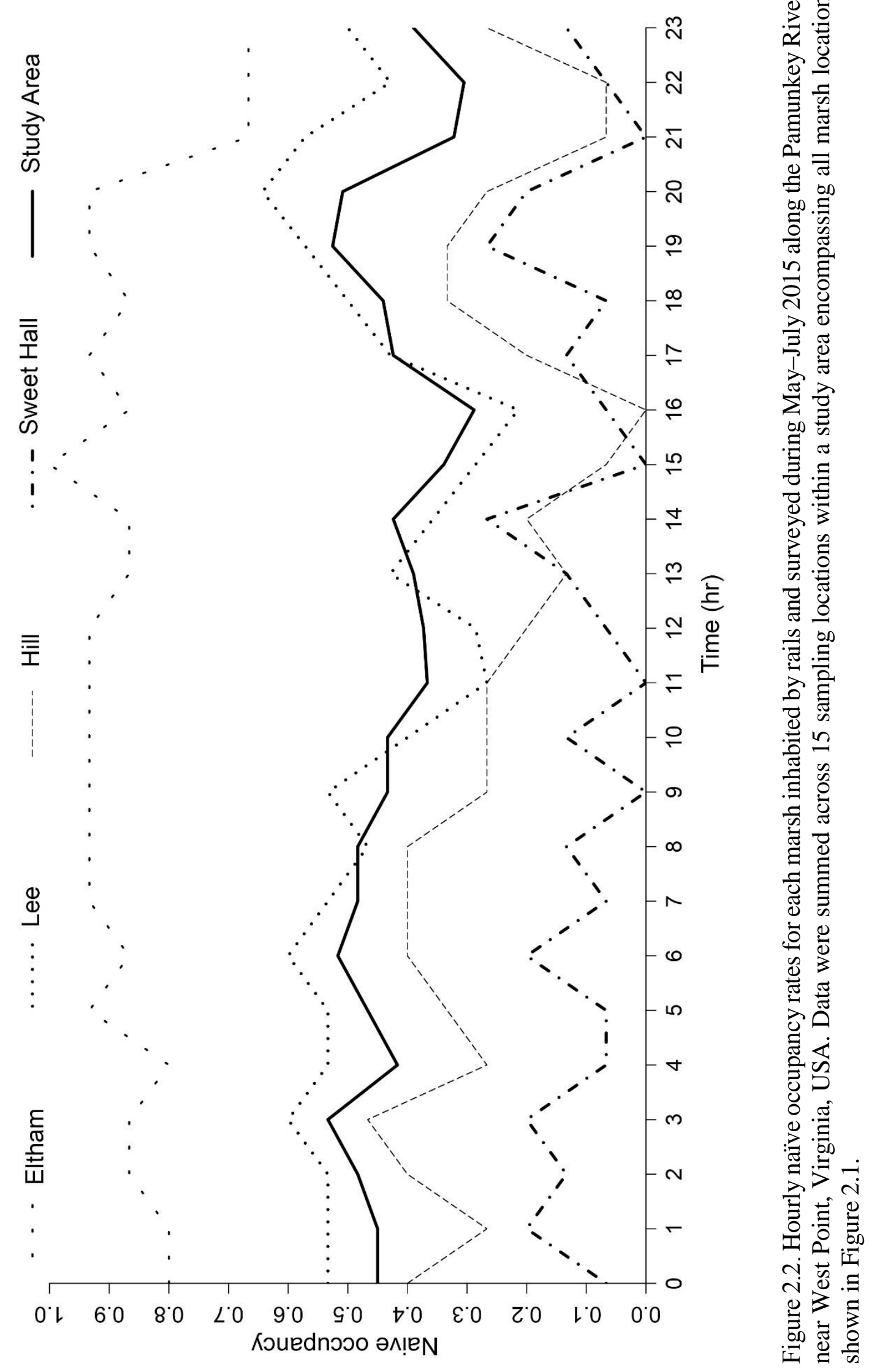




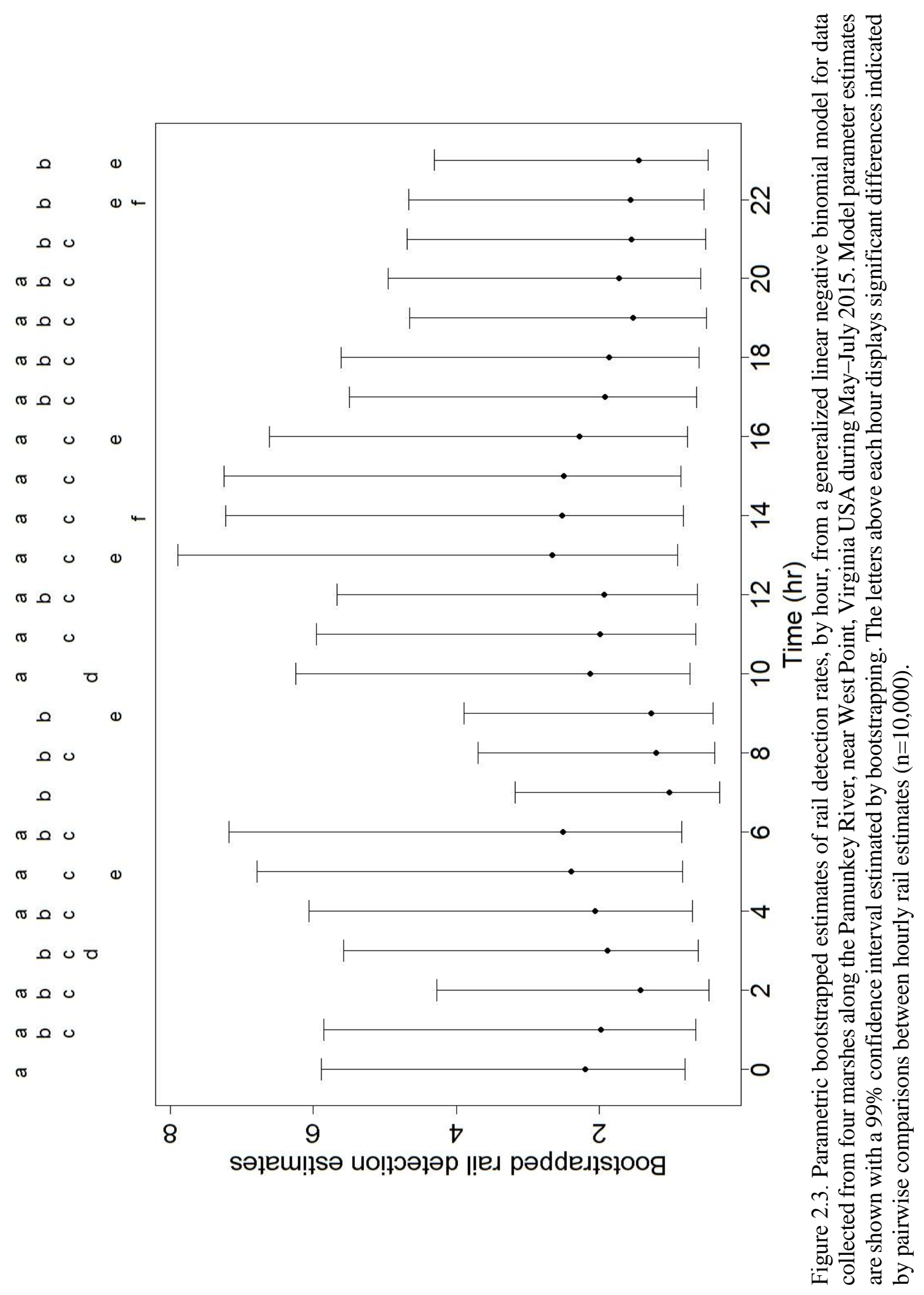




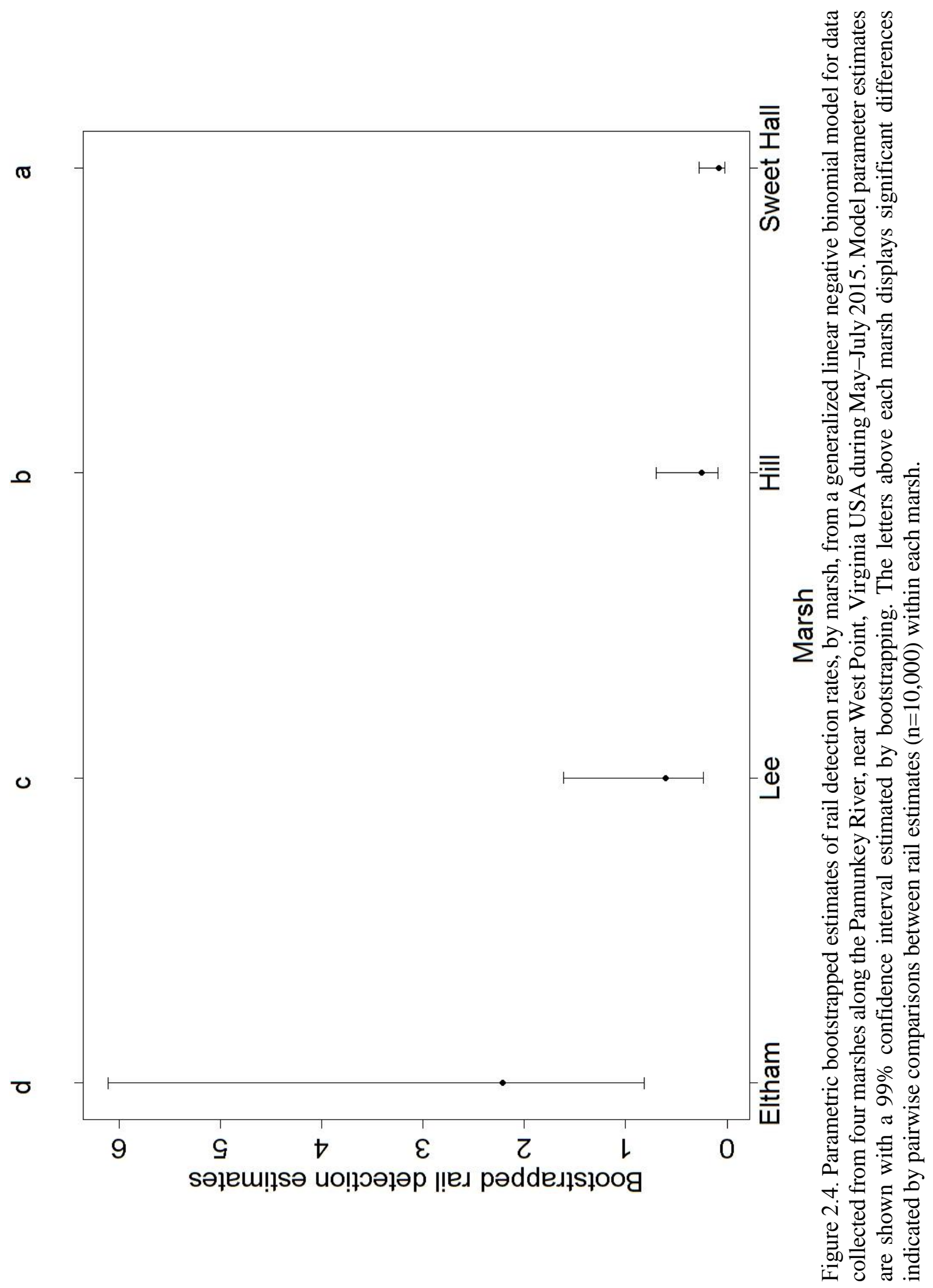




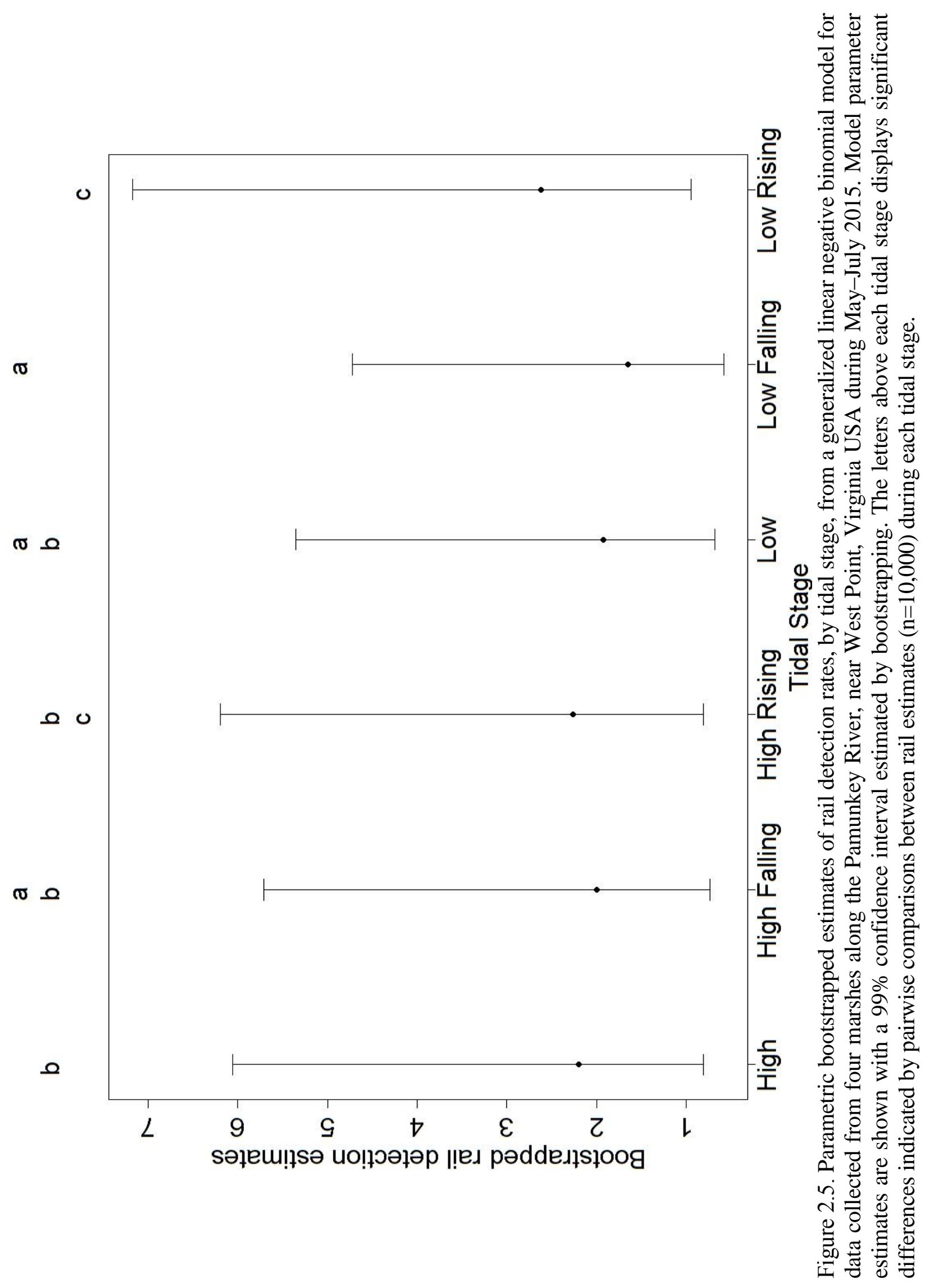




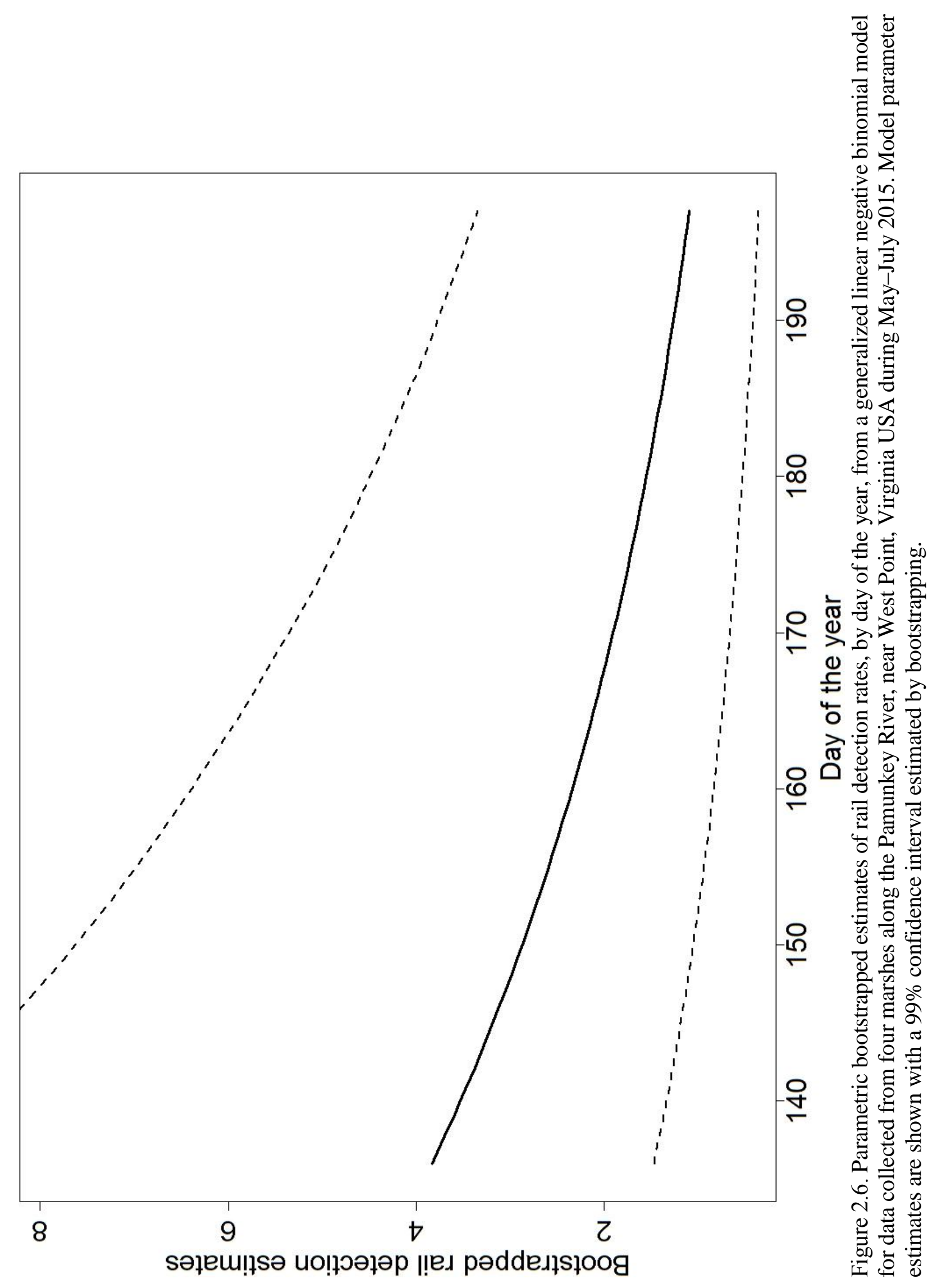




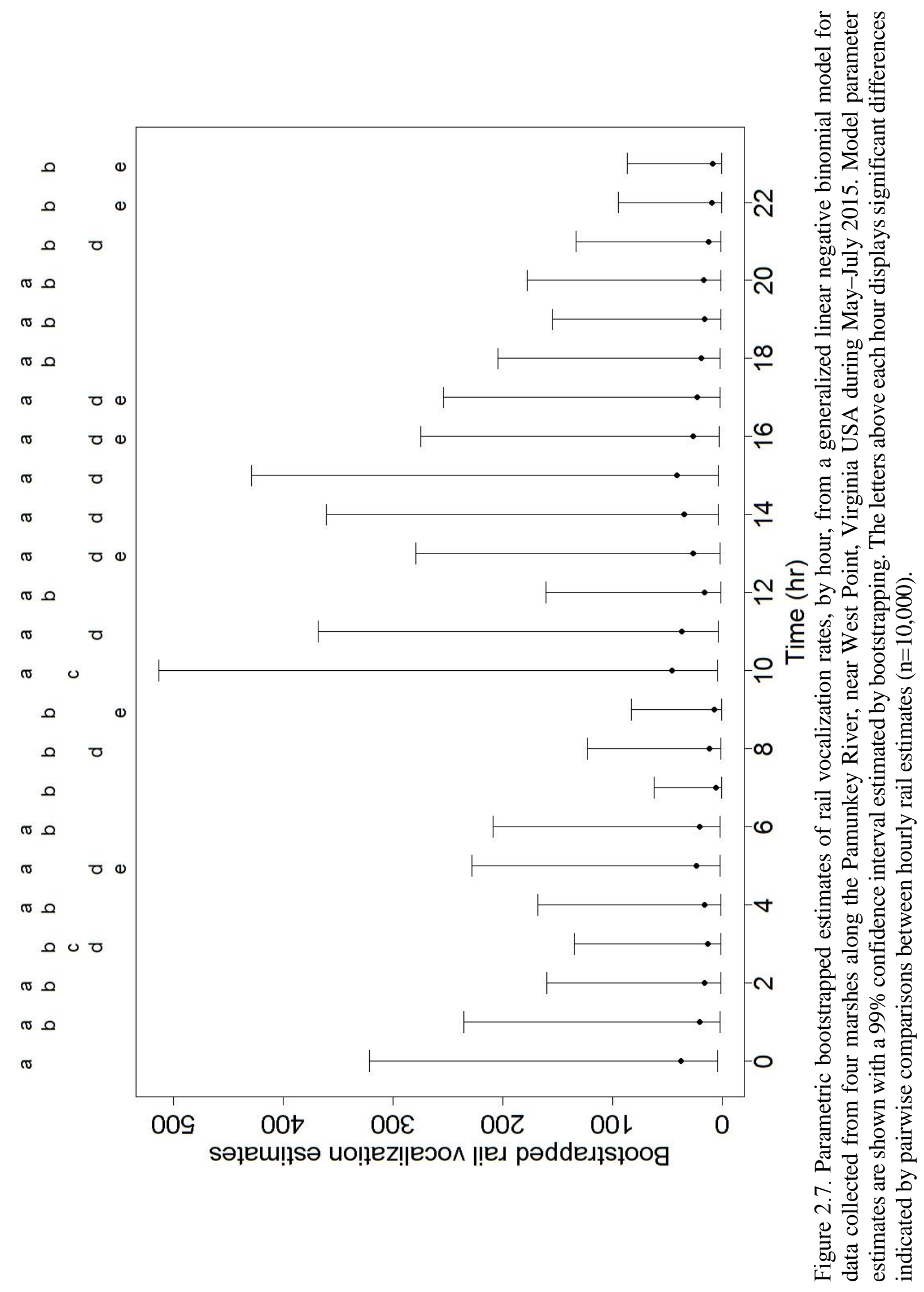




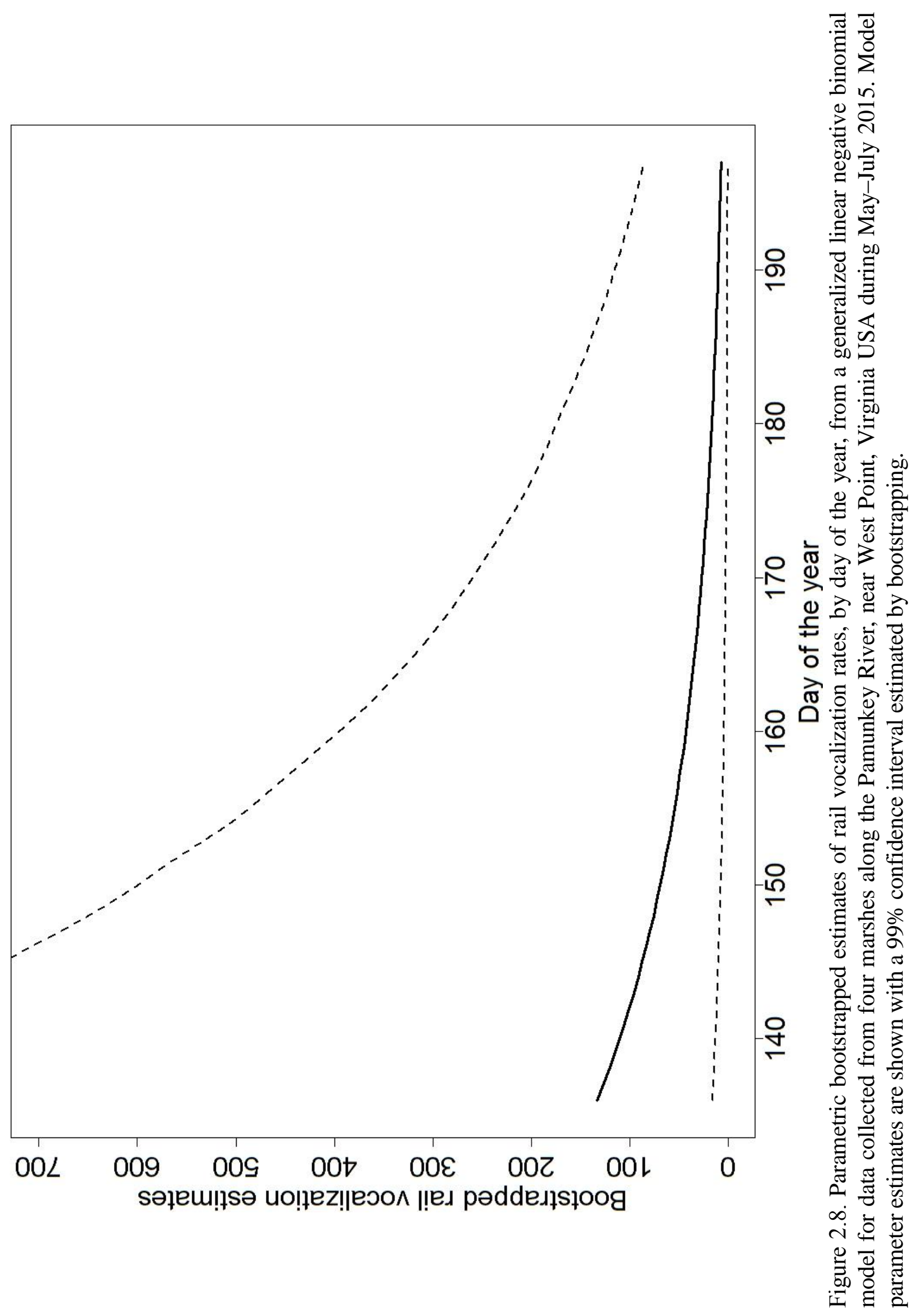




\section{CHAPTER 3}

\section{Using Acoustic Recordings to Assess Occupancy and}

\section{Distribution of Rails}

\subsection{AbSTRACT}

Identifying the distribution and habitat associations of indicator species allows for the assessment of ecosystem health and can provide a foundation for subsequent conservation efforts. I used autonomous recording units (ARUs) to passively monitor presence or absence of King (Rallus elegans) and Clapper ( $R$. crepitans) rails in marsh systems along the Pamunkey and Mattaponi Rivers in intracoastal Virginia. I used ARUs in conjunction with occupancy modelling to determine the effects of salinity and emergent marsh community type on occupancy estimates of the combined King-Clapper rail complex. I also quantified detection probability of those rails using ARUs. In marshes along the Pamunkey River, the mean estimated probability of occupancy for both species combined was $0.64(95 \%$ CI: $0.53,0.75)$ as opposed to $0.59(95 \%$ CI: $0.45,0.72)$ along the Mattaponi River. The mean estimated detection probability, again for the rail complex, across both marshes was 0.63 (95\% CI: 0.62, 0.65). Probability of occupancy on the Pamunkey was strongly influenced by salinity, increasing by a factor of 1.62 (95\% CI: 0.6, 2.65) per parts per thousand (ppt) of salinity. Detection probability along the Pamunkey varied significantly by date, changing by a factor of -0.02 (95\% CI: $-0.03,0)$ per day as the nesting season progressed. The best models describing occupancy probability for the Mattaponi River included a term for vegetative community type, although estimates for this term was not different from zero. My findings provide insight into how rails within 
this system respond to environmental variation and into the utility of ARUs for occupancy modeling of the distribution and habitat associations of rails within intracoastal Virginia. These results also are useful because they provide a baseline data set for comparison with future monitoring efforts.

\subsection{INTRODUCTION}

Tidal marshes face numerous threats and, as such, assessing their overall health is often important to conservation management. Marsh birds, particularly members of Rallidae, can act as indicator species for the health of estuarine habitats on local and landscape levels (Novack et al. 2005). They fill this role well because of their strong site fidelity, high trophic level, and diets dominated by aquatic macroinvertebrates sensitive to habitat alteration (Zembal et al. 1989, Terres 1991, DeLuca et al. 2004).

Within marshes of the Atlantic and Gulf coasts of the United States, two of the most prevalent rallids are King (Rallus elegans) and Clapper (R. crepitans) rails. In those regions, these species exist along a salinity gradient. King Rails inhabit brackish and fresh tidal marshes, whereas Clapper Rails reside in tidal salt marshes (Eddleman and Conway 1994, Reid et al. 1994). However, both species can occur within intermediate brackish-salt marshes (Meanley and Wetherbee 1962, Meanley 1985, Bledsoe 1988). In these areas, differentiating between species can be challenging due to similarities in phenotypes, morphometrics, and vocalizations (Massey and Zembal 1987, Graves 2002, Perkins et al. 2009, Maley and Brumfield 2013). In such instances, these birds often have been classified as King-Clapper Rails (Conway 2011).

In spite of their potential value as biological indicators, these two species are poorly monitored. Large-scale monitoring programs such as the Breeding Bird Survey underrepresent tidal marsh habitat and provide unreliable estimates of current population status of marsh birds (Sauer et 
al. 2014). As an alternative, the recent standardization of monitoring protocols for secretive marsh birds has provided a targeted sampling framework to estimate occupancy and abundance and to track population trends of these species (Johnson et al. 2009, Conway 2011).

Recently, the use of autonomous recording units (ARUs) has emerged as alternative method for surveying for marsh birds. ARUs may be especially useful for Rallids because of their secretive nature, their use of inaccessible habitats, and the high rate at which they can be detected by their vocalizations (Sidie-Slettedahl et al. 2015). The use of ARUs is also sometimes favored because it provides a permanent recording of surveys that can be independently verified and it allows for reduction in observer, detection, temporal, and spatial bias (Haselmayer and Quinn 2000, Rempel et al. 2005, Acevedo and Villanueva-Rivera 2006, Tegeler et al. 2012).

The applicability of ARUs to avian surveys is a somewhat novel idea and, as such, has not been studied for all species and systems. Nevertheless, there are several studies that have compared the performance of human-observer point counts with acoustic recordings from ARUs in assessing species richness and relative abundance (Haselmayer and Quinn 2000, Acevedo and VillanuevaRivera 2006, Hutto and Stutzman 2009, Venier et al. 2012). In many of these cases, because of the sensitivity, robustness, and accuracy of ARUs, their performance was often similar to, or better than, traditional human observer point counts (Haselmayer and Quinn 2000, Hobson et al. 2002, Acevedo and Villanueva-Rivera 2006, Digby et al. 2013, Wimmer et al. 2013, Klingbeil and Willig 2015). However, other studies have reported downsides to ARUs (Hutto and Stutzman 2009, Venier et al. 2012). These drawbacks include the cost, the effort required for computer analysis and the high level of species-, habitat-, and ARU-specific variability in the detectable range of the electronics used, resulting in a failure to capture species that vocalize infrequently (Acevedo and Villanueva-Rivera 2006, Wimmer et al. 2013, Drake et al. 2016). Only one study of which I am aware has used 
occupancy modeling together with ARUs to monitor nocturnal vocalizing marsh birds (SidieSletthedahl et al. 2015). However, that study implemeted concurrent broadcast surveying, which potentially reduces the benefits of using ARUs (Sidie-Sletthedahl et al. 2015).

The goal of this study was to evaluate the use of passive acoustic sampling with ARUs, in combination with occupancy modeling, to determine the distribution and habitat association of KingClapper Rails in intracoastal marsh complexes in eastern Virginia. Specifically, the objectives were to assess the effects of salinity and emergent vegetative community structure on rail occupancy and to quantify the detection probability of rail vocalizations using ARUs.

\subsection{METHODS}

Study Area

I conducted research in five tidal marshes along the Pamunkey River and five tidal marshes along the Mattaponi River near West Point, Virginia. These rivers are situated at the confluence of the York River and are two of the major riverways feeding into the Chesapeake Bay. The marshes where I worked occur along a salinity gradient from mesohaline (7.2 ppt) to fresh ( $0.1 \mathrm{ppt})$, although high salinity waters extend farther up the Pamunkey River than the Mattaponi River (Figure 3.1). The marshes along the Pamunkey River range in size from 287-579 ha, while the marshes along the Mattaponi River range from 125-209 ha.

The marshes themselves are regularly flooded by daily tides and, as a result, are occupied by a mosaic of emergent vegetative community types whose composition is determined by tidal flood frequency and duration (Wilson et al. 2007). Low marsh zones flooded regularly by daily tides are dominated by short smooth cordgrass (Spartina alterniflora) and black needlerush (Juncus roemerianus). High marsh areas that are flooded at average tidal height are dominated by 
saltmeadow cordgrass (S. patens), big cordgrass (S. cynosuroides), and tall smooth cordgrass. Salt marsh terrestrial border zones are infrequently flooded by spring and storm tides and can include areas of higher elevation. These areas tend to have vegetation dominated by marsh elder (Iva fructescens), groundsel tree (Baccharis halimifolia), and Olney's three-square (Scirpus americanus). Brackish terrestrial border zones have vegetation characteristics of both brackish and fresh water systems. These marshes are dominated by broad-leaved plants such as arrow arum (Peltandra virginica) and pickerelweed (Pontederia cordata), and contain dense colonies of narrow-leaved cattail (Typha angustifolia), marsh mallow (Kosteletzkya virginica), southern wild rice (Zizania aquatica), and various sedges (Carex spp.).

Marshes within these river systems have previously been surveyed for secretive marsh birds by both the Virginia Department of Game and Inland Fisheries (VDGIF) and the Center for Conservation Biology (CCB). In 2002, King Rails were detected within two marshes along the Pamunkey River (Paxton and Watts 2002). During 2006-2007, VDGIF reported the presence of King Rails within marshes of the Mattaponi River during broadcast point count surveys (J. Cooper and S. Harding, unpubl. data). However, recent trapping and lethal sampling found evidence only of Clapper Rails in both marsh systems (J. Cooper and S. Harding, unpubl. data 2014-2016).

\section{Data Collection and Acoustic Classification}

I sampled rails acoustically in 2015 in the five tidal marshes along the Pamunkey River, and, in 2016, in the five tidal marshes along the Mattaponi River. Sampling occurred during May-July in both years. I used ArcMap 10.0 (ESRI 2010) to select 75 sampling sites in the marsh complex along the Pamunkey River and 50 sampling sites in the marsh complex along the Mattaponi River. Fewer 
sites were selected within the marsh system along the Mattaponi River because the marshes were smaller in area. I constrained sample site selection so that each location was at least $400 \mathrm{~m}$ from every other survey location (Conway 2011), at least $50 \mathrm{~m}$ from marsh edge, and easily accessible by boat from the rivers.

I deployed 5 Song Meter SM3 (Wildlife Acoustics, Maynard, Massachusetts, USA) ARUs, one per marsh. The ARUs were mounted onto t-posts, which were subsequently placed into the ground such that the ARUs were approximately $1.5 \mathrm{~m}$ above the marsh substrate. I placed one ARU per marsh for a single period of two consecutive days and I then moved the ARU to a new location within that same marsh and repeated the two-day protocol. This approach allowed for concurrent sampling across the five marshes. Each sampling period started at midnight and lasted exactly 48 hrs. Digital recordings were made at $24 \mathrm{kHz}, 16$ bit and stored into hourly files. I delayed sampling for a day during rainy weather or when wind speeds exceeded $20 \mathrm{~km} / \mathrm{h}$ (Gibbs and Melvin 1993). In total, I sampled for 30 days in marshes along the Pamunkey River and for 20 days in marshes along the Mattaponi River across similar seasonal timeframes.

I conducted rapid assessment vegetative surveys within a 50-m radius circular survey plot centered at each sampling location (Figure A.3; Figure A.4). Within each survey plot I identified emergent marsh vegetative communities and open-water features. I surveyed for the following vegetative communities and open-water features: low marsh, high marsh, salt marsh terrestrial border, brackish terrestrial border, invasive, creeks, open water, and upland (Wilson et al. 2007). I estimated the percent cover for each of the vegetative community types, categorizing cover classes as: $0(0-<1 \%), 1$ (1-5\%), 2 (6-10\%), 3 (11-25\%), 4 (26-50\%), 5 (51-75\%), and 6 (76-100\%). I also measured salinity (ppt) at water's edge using a Pro30 Conductivity and Salinity Meter (YSI, Yellow Springs, Ohio, USA). 
In the laboratory, I used the interactive sound analysis software Raven Pro 1.5 (Bioacoustics Research Program 2014) to interpret the 6,000 hrs of recordings I collected. Since both species have been reported in these river systems and since they are known to hybridize here (S. S. Coster, unpubl. data), I pooled all vocalizations as King-Clapper Rails. Because I was unable to use the software to create an accurate automated detector for rail vocalizations, I manually scanned recordings aurally and visually using spectrograms. For each hourly recording file, I documented the presence or absence of rails and recorded the start, end, and duration of vocalizations.

\section{Model Development}

I estimated occupancy and detection probabilities for each river using the package “unmarked" within Program R (Fiske and Chandler 2011, R Development Core Team 2012). I considered the Pamunkey River and Mattaponi River independently in my statistical analyses due to variation in sampling year, salinity gradients, and density of rails. For my models, I created encounter histories for each sampling location by evaluating the presence or absence of rails during 6-hr intervals across the 48-hr sampling period. As a consequence, I was able to obtain and analyze 8 repeated measures at each sampling location. The models assessed whether occupancy probability $(\Psi)$ was constant or dependent on either salinity or the dominant vegetative community type. I also evaluated the influence of three potentially important covariates, day of the year, time of day, and survey number, on detection probability $(p)$. The assumptions of these occupancy models are as follows (MacKenzie et al. 2006): (a) occupancy status at each site doesn't change over the survey season; (b) $\Psi$ is constant, or differences in occupancy probability are modeled using covariates; (c) $p$ are constant across all sites and surveys or is a function of site-survey covariates; and (d) detection of species and detection histories are independent. 


\section{Model Selection}

For each river system, I estimated $\Psi$ and $p$ using likelihood-based methods (MacKenzie et. al 2002). I ran all possible combinations of covariates of $\Psi$ and $p$ ( $n=32$ models) to achieve variable balance within the model set. I assessed model fit using corrected Akaike's Information Criterion (AICc) to compare models based on log-likelihood values (Akaike 1973, Burnham and Anderson 2002). I ranked and compared models based on AICc relative differences between the top ranked model and each other model $(\triangle \mathrm{AICc})$ and $\mathrm{AICc}$ weights $\left(w_{i}\right)$ using the $\mathrm{R}$ package AICcmodavg (Burnham and Anderson 2002, Burnham et al. 2011, Mazerolle 2012). I considered models with $\triangle \mathrm{AICc}<2$ to be equally supported (Burnham and Anderson 2002). I calculated the relative importance of each variable based on the sum of $w_{i}$ of the models that included the variable (Burnham and Anderson 2002, MacKenzie et al. 2002). I applied model averaging to estimate occupancy and detection on the set of models with $\Delta \mathrm{AICc}<2$. Parameter estimates were weighted by the associated $w_{i}$ of the model and I calculated mean parameter estimates and unconditional variance estimates (Burnham and Anderson 2002). For each parameter, I report 95\% CIs based on the unconditional variance.

\subsection{RESULTS}

I detected rails at 48 of 75 survey locations (64\%) along the Pamunkey River and at 29 of 50 (58\%) locations surveyed along the Mattaponi River. I found no rails in the marshes on either river that were farthest from the confluence of the York River. Only four dominant vegetative community types were encountered at the monitoring sites and thus the dominant vegetative community type for 
each location was either low marsh, high marsh, salt marsh terrestrial border, or brackish marsh terrestrial border.

I detected differences among rivers in probability of occupancy. The best model for the Pamunkey River included salinity as an important site covariate (Table 3.1; Table C.4; Figure 3.2), such that as salinity increased within a marsh, the probability of occupancy by rails increased by a factor of 1.62 (95\% CI: 0.6, 2.65) per ppt (Figure 3.3.A). However, the top model for the Mattaponi River did not include a salinity term but did include an effect of vegetative community type on occupancy probability (Table 3.1; Table C.5). While a combined effect of vegetative community type and salinity was present in another supported model with $\triangle \mathrm{AICc}<2$, vegetative community type was the only covariate with a relative importance $>0.5$ (Figure 3.2). Finally, although the probability of occupancy of rails was higher in low marsh and salt marsh terrestrial border communities than in high marsh and brackish terrestrial borders, the model estimates for these parameters were never significantly different from zero. The overall estimated model averaged probability of rail occupancy was 0.64 (95\% CI: 0.53, 0.75) for the Pamunkey River and 0.59 (95\% CI: $0.45,0.72)$ for the Mattaponi River.

Detection probability varied between river systems and was best described by different models for each river (Table 3.1; Table C.4; Table C.5). Day of the year was the most important factor influencing probability of detecting rails along the Pamunkey River. As the sampling season progressed, the probability of detection of rails changed by a factor of -0.02 ( $95 \% \mathrm{CI}$ : $-0.03,0)$ per day (Figure 3.3.B). There were two additional models with $\triangle \mathrm{AICc}<2$; these incorporated the combined effects of date + survey and survey + time (Table 3.1). However, while survey and time were included within these additional models, neither parameter had relative importance value $>0.50$ (Figure 3.2). Along the Mattaponi River, detection probability was constant within the top model. 
There were two additional models with $\triangle \mathrm{AICc}<2$. While day of the year was included in one of the models, it had an overall relative importance value of $>0.5$ (Figure 3.2). The overall estimated probability of detecting a rail was 0.63 (95\% CI: 0.62, 0.65) for the Pamunkey River and 0.63 (95\% CI: $0.63,0.64)$ for the Mattaponi River.

\subsection{DISCUSSION}

I report the first implementation of passive autonomous acoustic surveying to determine occupancy and detection probabilities for secretive marsh birds. I observed similarities in the occupancy and distribution of rails by river, with rails occupying $64 \%$ of the sites along the Pamunkey River and 59\% of the sites along the Mattaponi River. Both marshes had similar rail detection probabilities (0.63). While estimating site occupancy can be difficult with imperfect detectability (MacKenzie et al. 2005), the models produced similar estimates to the naïve rail occupancy probabilities.

\section{Occupancy probability}

Salinity was influential in determining rail occupancy along only one of the two tributaries I studied. This may be because the Pamunkey River, where salinity was influential, has a wider salinity gradient than the Mattaponi River, where all marshes are mostly fresh water. Salinity within wetlands is defined by the local hydrology. This, in turn, determines the distribution of plant species with tolerances to salt, such that those species with the highest tolerance are situated along the shoreline (Odum 1988, Graves 2002, Wilson et al. 2007). As salinity increases within a marsh, plants sensitive to salinity become replaced by species adapted to the new salinity regimes (Chabreck 1988, Graves 2002). Similarly, this successional replacement is mimicked by wildlife within the marshes, where 
shifts in their habitat suitability of marsh vegetation and intolerance towards saltwater leads them to abandon once viable areas (Chabreck 1982, Chabreck 1988).

It appeared that due to the lack of a strong salinity gradient, vegetative community became an influential factor determining the probability of occupancy of rails in marshes along the Mattaponi River. All marshes exhibited high levels of horizontal and vertical vegetative heterogeneity. Low marsh communities are dominated by Spartina, a genus of plants that is associated with rail nesting habitat because it provides important structural diversity that rails need to avoid nest loss from tides (Oney 1954, Storey et al. 1988, Eddleman and Conway 1994; Erwin et al. 2006). Salt marsh terrestrial border zones provide rails with areas of higher elevation to escape tide waters and provide diverse vegetation for nesting materials and protection during brood-rearing (Stone 1965, Reid et al. 1994). Rising sea levels threaten emergent marsh habitat, in particular, species that are unable to acclimate to higher salinity levels to salt water inundation and increased tidal action (Zedler and Kercher 2005). Alterations in hydrological flow, inundation, and location of isohalines has the potential to alter the distribution of tidal marsh vegetative communities and alter marsh productivity (Bradley et al. 1990, Sklar and Bowder 1998, Spalding and Hester 2007).

\section{Detection probability}

Detection probability is a function of both vocalization probability and observer detection probability, or in my case ARU detection probability (Conway and Gibbs 2001, Conway and Simon 2003). Vocalization rates of rails vary due to age-, sex-, breeding status-, time of day-, and seasonally-driven variation (Tacha 1975, Johnson and Dinsmore 1986, Conway and Gibbs 2001, Conway and Gibbs 2011). To address these issues, I sampled over a relatively short period of time during the breeding season and I accounted for diel variation in the statistical models. Nevertheless, 
as has been observed in other studies, along both of the rivers, the probability of detecting rails decreased as the season progressed (Conway and Gibbs 2005, Conway and Nadeau 2010, Wiest and Shriver 2016). Likewise, I was unable to account for age-and sex-specific variation in vocalization rates.

I estimated that the probability the ARU-based system would detect a rail was $0.63(0.62$, 0.65). Previous studies using traditional survey methods found similar or lower detectability of King Rails (0.03-0.76; Budd 2007, Pierluissi and King 2008, Darrah and Krementz 2009, Rogers 2011) and Clapper Rails (0.13-0.70; Lehmicke et al. 2013, Wiest and Shriver 2016). These traditional marsh bird surveying methods use call-broadcast surveys to increase the vocalization frequency of birds (Gibbs and Melvin 1993, Conway and Gibbs 2005, Conway and Nadeau 2010). However, this surveying technique may disturb breeding birds, reduce the observer's ability to hear the birds, and prompt the bird to move towards the playback source prior to vocalizing (Tacha 1975, Kerlinger and Wiedner 1991, Legare et al. 1999, Bogner and Baldassarre 2002). Repeated surveying using playback may even habituate birds to broadcast calls (Irish 1974, Smith 1974). Thus, use of broadcast surveys can induce some bias into a study.

The use of passively recording ARUs reduces these and other types of bias (Haselmayer and Quinn 2000, Acevedo and Villanueva 2006). Furthermore, using ARUs allows simultaneous surveys at multiple locations over extended periods of time. Thus, ARUs can provide a broader spatial distribution and a greater number of survey replicates, both of which should improve occupancy estimates (MacKenzie et al. 2006). Furthermore, because data collection by ARUs does not rely upon human presence, the rails are unlikely to change their behavior in response to the observer. Finally, since ARUs provide a permanent recording of surveys, species identification can be confirmed by multiple listeners (Rempel et al. 2005). 
Our results demonstrate the suitability of ARUs to estimate the distribution and habitat associations of rails along the Pamunkey and Mattaponi Rivers in Virginia and they provide occupancy estimates that can be a baseline for future studies. The development and implementation of new tools such as ARUs provides alternative and improved methodologies for conducting longterm continuous monitoring over large spatial scales. As such, the adoption of these and other novel technologies may be an important component of understanding the effects of both short- and longterm environmental and anthropogenic threats to tidal marsh habitats.

\subsection{Literature Cited}

Akaike, H. (1973). Information theory and an extension of the maximum likelihood principle. Pages 267-281 in B. N. Petrov and F. Csaki, editors. Second international symposium on information theory. Akademiai Kiado, Budapest, Hungary.

Acevedo, M. A., and L. J. Villanueva-Rivera. (2006). Using automated digital recording systems as effective tools for the monitoring of birds and amphibians. Wildlife Society Bulletin 34: 211214.

Bioacoustics Research Program. (2014). Raven Pro: Interactive Sound Analysis Software, v. 1.5. Cornell Lab of Ornithology, Ithaca, New York.

Bledsoe, A. H. (1988). Status and hybridization of Clapper and King rails in Connecticut. The Connecticut Warbler 8: 61-65.

Bogner, H. E., and G. A. Baldassarre. (2002). The effectiveness of call-response surveys for detecting Least Bitterns. Journal of Wildlife Management 66: 976-984.

Bradley, P. M., B. Kjerfve, and J. T. Morris. (1990). Redivision salinity change in the Cooper River, South Carolina: ecological implications. Estuaries 13: 373-379. 
Budd, M. J. (2007). Status, distribution, and habitat selection of secretive marsh birds in the delta of Arkansas. Thesis, University of Arkansas, Fayetteville, AR, USA.

Burnham, K. P., and D. R. Anderson. (2002). Model selection and multimodel inference: an information-theoretic approach. $2^{\text {nd }}$ Ed. Springer-Verlag, New York, NY, USA.

Burnham, K. P., D. R. Anderson, and K. P. Huyvaert. (2011). AIC model selection and multimodel inference in behavioral ecology: some backgrounds, observations, and comparisons. Behavioral Ecology and Sociobiology 65: 23-35.

Chabreck, R. H. (1982). The effects of coastal alternation on marsh plants. Pp. 92-98 In D. F. Boesch, ed. Proc Conf. on coastal erosion and wetland modification in Louisiana: causes, consequences, and options. U.S. Fish and Wildlife Service, FWS/OBS-82/59. Washington, D.C., USA.

Chabreck, R. H. (1988). Coastal marshes: Ecology and wildlife management. University of Minnesota Press, Minneapolis, Minnesota, USA.

Conway, C. J. (2011). Standardized North American marsh bird monitoring protocol. Waterbirds 34: 319-346.

Conway, C. J., and J. P. Gibbs. (2001). Factors influencing detection probabilities and the benefits of call-broadcast surveys for monitoring marsh birds. U.S. Geological Survey, Final Report, Patuxent Wildlife Research Center, Laurel, MD, USA.

Conway, C. J., and J. P. Gibbs. (2005). Effectiveness of call-broadcast surveys for monitoring marsh birds. The Auk 122: 26-35.

Conway, C. J., and J. P. Gibbs. (2011). Summary of intrinsic and extrinsic factors affecting detection probability of marsh birds. Wetlands 31: 403-411. 
Conway, C. J., and C. P. Nadeau. (2010). The effects of conspecific and heterospecific call-broadcast on detection probability of marsh birds in North America. Wetlands 30: 358 - 368 .

Conway, C. J., and J. C. Simon. (2003). Comparison of detection probability associated with Burrowing Owl survey methods. Journal of Wildlife Management 67: 501-511.

Darrah, A. J., and D. G. Krementz. (2009). Distribution and habitat use of King Rails in Illinois and upper Mississippi river valleys. Journal of Wildlife Management 73: 1380-1386.

DeLuca, W. V., C. E. Studds, L. L. Rockwood, and P. P. Marra. (2004). Influence of land use on the integrity of marsh bird communities of Chesapeake Bay, USA. Wetlands 24: 837-847.

Digby, A., M. Towsey, B. D. Bell, and P. D. Teal. (2013). A practical comparison of manual and autonomous methods for acoustic monitoring. Methods in Ecology and Evolution 4: 675684.

Drake, K. L., M. Frey, D. Hogan, and R. Hedley. 2016. Using digital recordings and sonogram analysis to obtain counts of yellow rails. Wildlife Society Bulletin 40: 346-354.

Eddleman, W. R., and C. J. Conway. (1994). "Clapper Rail." Migratory shore and upland game bird management in North America. Tacha, T. C. and C. E. Braun, Eds. Allen Press: Lawrence, KS, USA. 167-179.

Erwin, R. M., G. M. Sanders, D. J. Prosser, and D. R. Cahoon. (2006). High tides and rising seas: Potential effects on estuarine waterbirds. Studies in Avian Biology 32: 214-228.

ESRI. (2011). ArcGIS Desktop: Release 10. Redlands, CA: Environmental Systems Research Institute.

Fiske, I. J., and R. B. Chandler. (2011). Unmarked: an R package for fitting hierarchical models of wildlife occurrence and abundance. Journal of Statistical Software 43: 1-23. 
Gibbs, J. P., and. S. M. Melvin. (1993). Call-response surveys for monitoring breeding waterbirds. Journal of Wildlife Management 57: 27-34.

Graves, C. (2002). Avian use of tidal marshes across a salinity gradient at Savannah National Wildlife Refuge, Georgia-South Carolina. Thesis, University of Tennessee, Knoxville, Tennessee, USA.

Haselmayer, J., and J. S. Quinn. (2000). A comparison of point counts and sound recording as bird survey methods in Amazonian southeast Peru. The Condor 102: 887-893.

Hobson, K. A., R. S. Rempel, H. Greenwood, B. Turnbull, and S. L. Van Wilgenburg. (2002). Acoustic surveys of birds using electronic recordings: new potential from an omnidirectional microphone system. Wilson Society Bulletin 30: 709-720.

Hutto, R. L., and R. J. Stutzman. (2009). Humans versus autonomous recording units: a comparison of point-count results. Journal of Field Ornithology 80: 387-398.

Irish, J. (1974). Post-breeding territorial behavior of Soras and Virginia Rails in several Michigan marshes. Jack-Pine Warbler 52: 115-124.

Johnson, D. H., J. P. Gibbs, M. P. Herzog, S. K. Lor, N. D. Niemuth, C. A. Ribic, M. E. Seamans, T. L. Shaffer, W. G. Shriver, S. V. Stehman, and W. L. Thompson. (2009). A sampling design framework for monitoring secretive marshbirds. Waterbirds 32: 203-215.

Johnson, R. R., and J. J. Dinsmore. (1986). The use of tape-recorded calls to count Virginia Rails and Soras. Wilson Bulletin 98: 303-306.

Kerlinger, P., and D. S. Wiedner. (1991). Vocal behavior and habitat use of Black Rails in south Jersey. Records of New Jersey Birds 16: 58-62.

Klingbeil, B. T., and M. R. Willig. (2015). Bird biodiversity assessments in temperate forests: the value of point count versus acoustic monitoring protocols. PeerJ 3: e973. 
Legare, M. L., W. R. Eddleman, P. A. Buckley, and C. Kelly. (1999). The effectiveness of tape playback in estimating Black Rail density. The Journal of Wildlife Management 63: 116125.

Lehmicke, A. J. J., J. L. Bowman, A. E. Banning, and B. L. Vasilas. (2013). Effect of tide level and time of day on detection rate and abundance of clapper rails (Rallus longirostris) in a Mid-Atlantic tidal marsh system. Wetlands 36: 364-368.

MacKenzie, D. I., J. D. Nichols, G. B. Lachman, S. Droege, J. A. Royle, and C. A. Langtimm. (2002). Estimating site occupancy rates when detection probabilities are less than one. Ecology 83: 2248-2255.

MacKenzie, D. I., J. D. Nichols, N. Sutton, K. Kawanishi, and L. L. Bailey. (2005). Improving inferences in population studies of rare species that are detected imperfectly. Ecology 86: 1101-1113.

MacKenzie, D. I., J. D. Nichols, J. A. Royle, K. H. Pollock, L. L. Bailey, and J. E. Hines. (2006). Occupancy estimation and modeling: inferring patterns and dynamics of species occurrence. Academic Press, San Diego, CA, USA.

Maley, J. M., and R. T. Brumfield. (2013). Mitochondrial and next-generation sequence data used to infer phylogenetic relationships and species limits in the Clapper/King Rail complex. Condor 115: 316-329.

Massey, B. W. and R. Zembal. (1987). Vocalizations of Light-Footed Clapper Rail. Journal of Field Ornithology 58: 32-40.

Mazerolle, M. J. (2012). Package “AICcmodavg” (v. 2.0-4.) R Foundation for Statistical Computing, Vienna. www.R-project.org. 
Meanley, B. (1985). The marsh hen: A natural history of the Clapper Rail of the Atlantic Coast salt marsh. Tidewater Publishers, Centreville, MD, USA.

Meanley, B., and D. K. Wetherbee. (1962). Ecological notes on mixed populations of King Rails and Clapper Rails in Delaware Bay marshes. The Auk 79: 453-457.

Novack, J. M., F. Gaines, J. C. Cumbee, G. Mills, A. Rodriguez-Navarro, and C. S. Romanek. (2005). The Clapper Rail as an indicator species of estuarine-marsh health. Studies in Avian Biology 32: 270-281.

Odum, W. E. (1988). Comparative ecology of tidal freshwater and salt marshes. Annual Review of Ecology and Systematics 19: 147-176.

Oney, J. (1954). Final report, Clapper Rail survey and investigations study. Georgia Game and Fish Commission, Atlanta, GA, USA.

Paxton, B. J. and B. D. Watts. 2002. Bird surveys of Lee and Hill marshes on the Pamunkey River: Possible affects of sea-level rise on marsh bird communities. Center for Conservation Biology Technical Report Series. CCBTR-03-04. College of William and Mary, Williamsburg, Virginia, USA.

Perkins, M., S. L. King, S. E. Travis, and J. Linscombe. (2009). Use of morphometric measurements to differentiate between species and sex of King and Clapper rails. Waterbirds 32: 579-584.

Pierluissi, S. and S. L. King. (2008). Relative nest density, nest success, and site occupancy of King Rails in southwestern Louisiana rice fields. Waterbirds 31: 530-540.

R Development Core Team. (2012). R: a language and environment for statistical computing v. 3.1.3. R Foundation for Statistical Computing, Vienna, Austria. http://www.R-project.org. 
Reid, F. A., B. Meanley, and L. H. Fredrickson. (1994). "King Rail.” Migratory shore and upland game bird management in North America. Tacha, T. C. and C. E. Braun, Eds. Allen Press: Lawrence, Kansas, USA. 181-191.

Rempel, R. S., K. A. Hobson, G. Holborn, S. L. van Wilgenburg, and J. Elliott. (2005). Bioacoustic monitoring of forest songbirds: interpreter variability and effect of configuration and digital processing methods in the laboratory. Journal of Field Ornithology 76: 1-11.

Rogers, S. L. (2011). King Rail (Rallus elegans) occupancy, reproductive activity, and success in fire managed coastal marshes of North Carolina and Virginia. Thesis, North Carolina State University, Raleigh, North Carolina, USA.

Sauer, J. R., J. E. Hines, J. E. Fallon, K. L. Pardieck, D. J. Ziolkowski, Jr., and W. A. Link. (2014). The North American Breeding Bird Survey, Results and Analysis 1966-2012. Version 02.19.2014 USGS Patuxent Wildlife Research Center, Laurel, MD, USA.

Sidie-Slettedahl, A. M., K. C. Jensen, R. R. Johnson, T. W. Arnold, J. E. Austin, and J. D. Stafford. (2015). Evaluation of autonomous recording units for detecting 3 species of secretive marsh birds. Wildlife Society Bulletin 39: 626-634.

Sklar, F. H. and J. A. Browder. (1998). Coastal environmental impacts brought about by alterations to freshwater flow in the Gulf of Mexico. Environmental Management 22: 547-562.

Smith, P. M. (1974). Yuma Clapper Rail study, Mohave County, Arizona, 1973. Federal Aid Wildlife Restoration Project W-54-R-6. Special Wildlife Investigations Progress Report, Job II-5.9. California Department of Fish and Game, Sacramento, CA, USA.

Spalding, E. A., and M. W. Hester. (2007). Interactive effects of hydrology and salinity on oligohaline plant species productivity: implication of relative sea-level rise. Estuaries and Coasts 30: 214-225. 
Stone, W. (1965). Bird studies at Old Cap May. Vol. 1. Dover Publication, Inc., New York, NY, USA.

Storey, A. E., W. A. Montevecchi, H. F. Andrews, and N. Sims. (1988). Constraints on nest site selection: a comparison of predator and flood avoidance in four species of marsh-nesting birds (Genera: Catotphorus, Larus, Rallus, and Sterna). Journal of Comparative Psychology 102: 14-20.

Tacha, R. W. (1975). A survey of rail populations in Kansas, with emphasis on Cheyenne Bottoms. M.S. Thesis, Fort Hays State College, Fort Hays, Kansas, USA.

Tegeler, A. K., M. L. Morrison, and J. M. Szewczak. (2012). Using extended-duration audio recordings to survey avian species. Wildlife Society Bulletin 36: 21-29.

Terres, J. K. (1991). The Audubon Society encyclopedia of North American birds. Wings Books, Avenel, New Jersey, USA.

Venier, L. A., S. B. Holmes, G. W. Holborn, K. A. McIlwrick, and G. Brown. (2012). Evaluation of an automated recording device for monitoring forest birds. Wildlife Society Bulletin 36: 3039.

Wiest, W. A., and W. G. Shriver. (2016). Survey frequency and timing affect occupancy and abundance estimates for salt marsh birds. The Journal of Wildlife Management 80: 48-56.

Wilson, M. D., B. D. Watts, and D. F. Brinker. (2007). Status review of Chesapeake Bay marsh lands and breeding marsh birds. Waterbirds 30: 122-137.

Wimmer, J., M. Towsey, P. Roe, and I. Williamson. (2013). Sampling environmental acoustic recordings to determine bird species richness. Ecological Applications 23: 1419-1428.

Zedler, J. B., and S. Kercher. (2005). Wetland resources: status, trends, ecosystem services, and restorability. Annual Reviews of Environmental Resources 30: 39-74. 
Zembal, R., B. W. Massey, and J. M. Fancher. (1989). Movements and activity patterns of the Lightfooted Clapper Rail. The Journal of Wildlife Management 53: 39-42. 
Table 3.1. Model selection results for the occupancy and detection of King-Clapper Rails in marshes in Virginia along (A) the Pamunkey River, May-July 2015; and (B) the Mattaponi River, May-July 2016. The model name shows effects on occupancy probability $(\Psi)$ and detection probability $(p)$; models are ranked based on AICc relative differences between the top ranked model and each other model ( $\triangle \mathrm{AICc})$, AICc model weights $\left(w_{i}\right)$, and number of parameters $(K)$. Parameters included salinity and dominant emergent marsh community (veg) for occupancy probability and day of the year (date), time of day (time), and survey number (survey) for detection probability. Only models with $\triangle$ AICc $<2$ are shown; each model set contained 32 models.

\begin{tabular}{|c|c|c|c|c|}
\hline River & Model & $\mathrm{K}$ & $\triangle \mathrm{AICc}^{\mathrm{a}}$ & $w_{i}$ \\
\hline \multirow[t]{3}{*}{ (A) Pamunky } & $\Psi($ salinity $), p($ date $)$ & 4 & 0 & 0.28 \\
\hline & $\Psi$ (salinity), $p$ (date + survey $)$ & 5 & 0.3 & 0.24 \\
\hline & $\Psi$ (salinity), $p($ date + time $)$ & 5 & 1.4 & 0.14 \\
\hline \multicolumn{5}{|l|}{ (B) Mattaponi } \\
\hline & $\Psi(\mathrm{veg}), p()$. & 5 & 0 & 0.22 \\
\hline & $\Psi($ veg $), p$ (date) & 6 & 1.17 & 0.12 \\
\hline & $\Psi($ salinity + veg $), p()$. & 6 & 1.38 & 0.11 \\
\hline
\end{tabular}

${ }^{\mathrm{a}}$ The $\mathrm{AIC}_{\mathrm{c}}$ value of the best model was 558.48 for model set (A) and 378.63 for (B). 


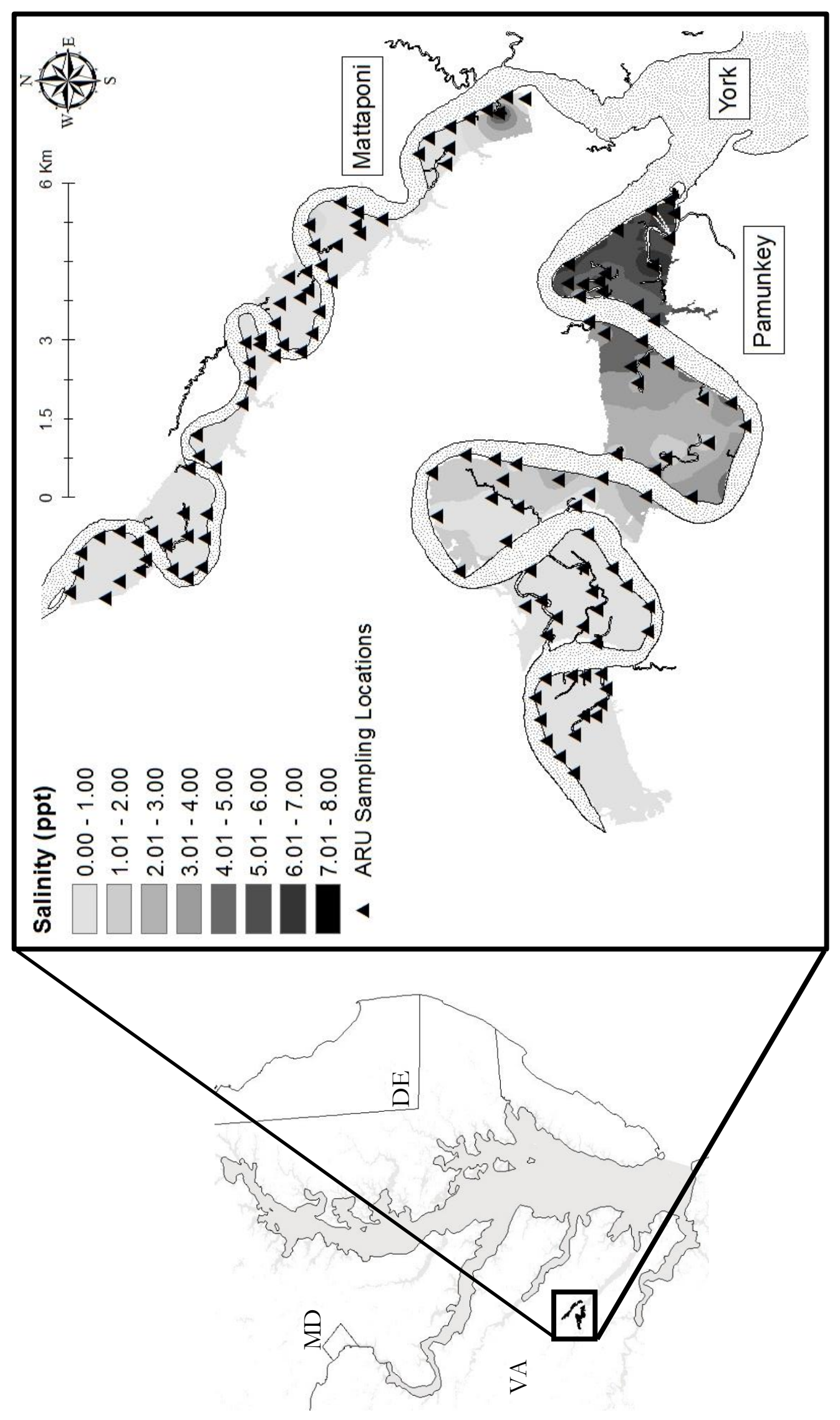

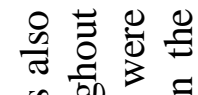

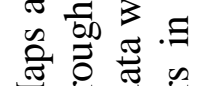

学 严

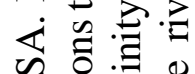

ऽ. :

.

क0

그르르을

플 छ

웅 1

实丞

$3 \longleftarrow$ on

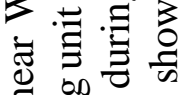

听?

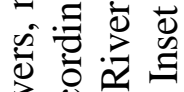

을 흘

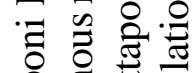

胥芯总

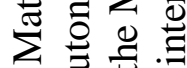

ฮ స

하류 홍

当 壱

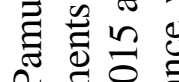

ค 유

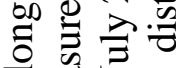

施

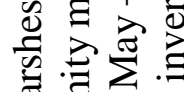

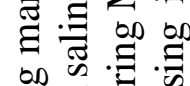

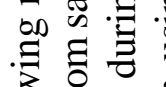

車㐫

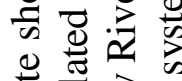

竞 $\frac{\pi}{0}$ d

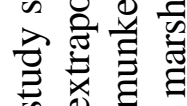

\&

D.

芯

$\sum \geqq \pi$

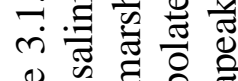

๑

总 方 


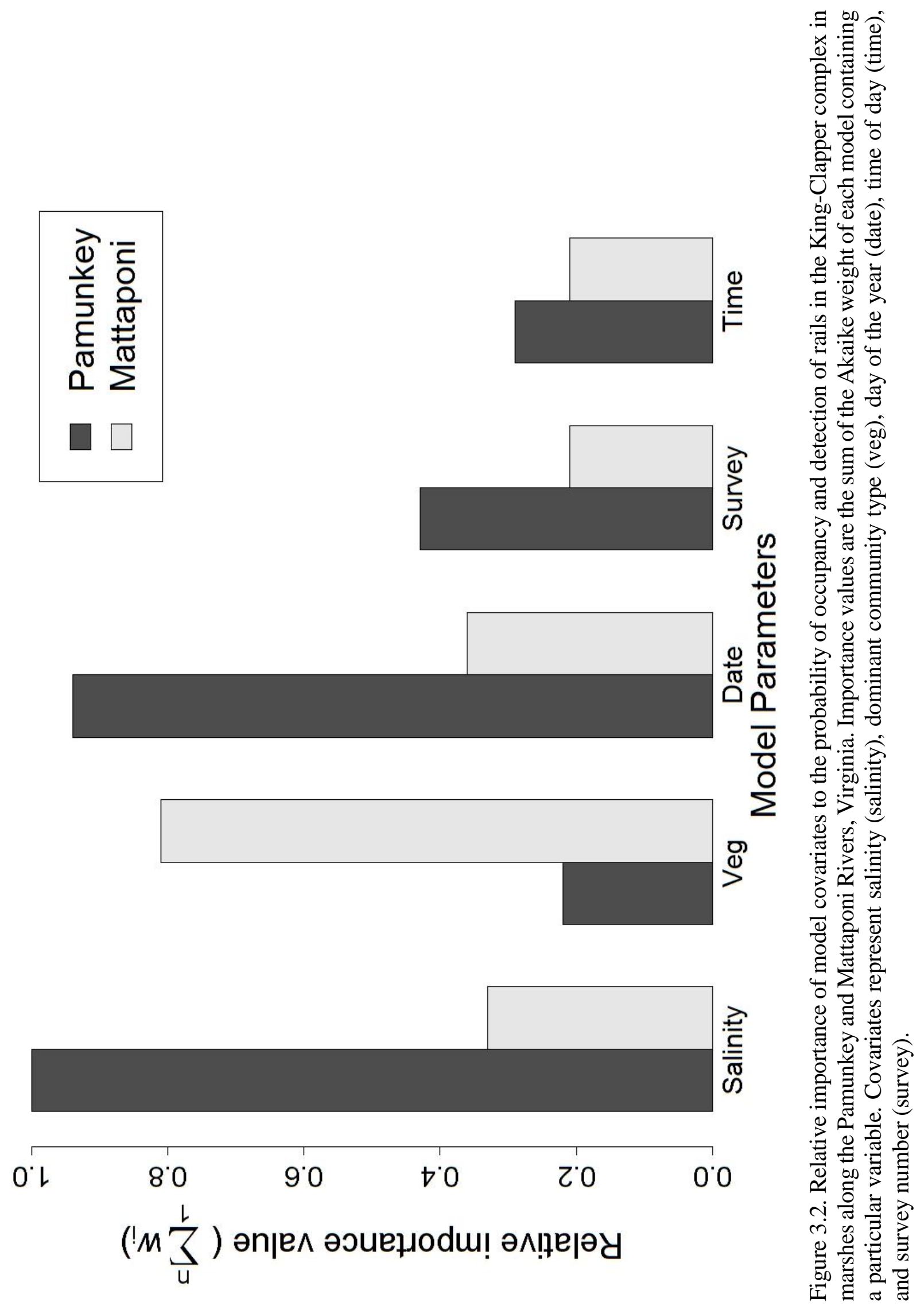




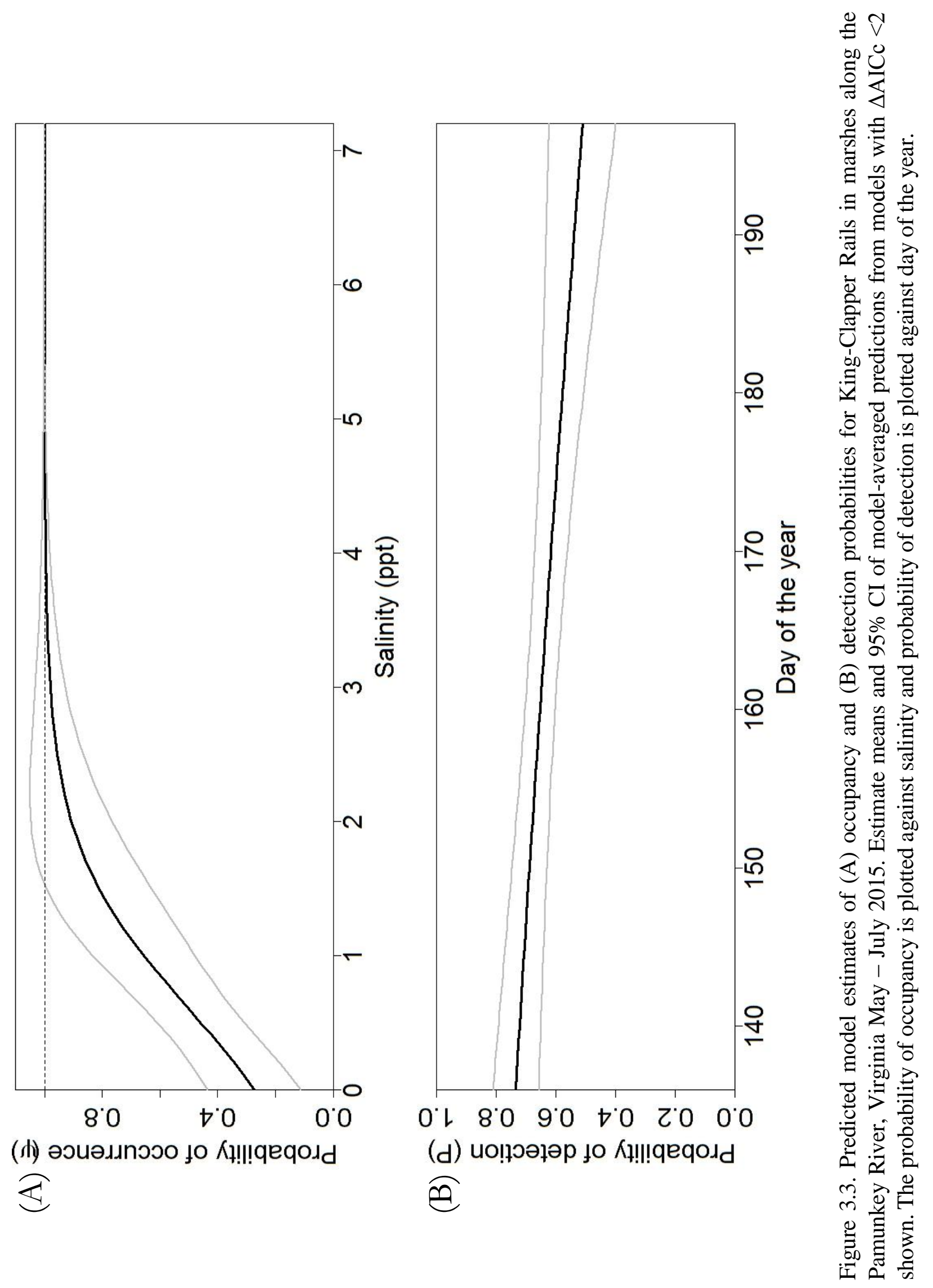




\section{APPENDICES}




\section{Appendix A}

\section{Field Data}

The following data sheets were used during the 2015-2016 field seasons to record King-Clapper

Rail detections during call-broadcast surveys and evaluate microhabitats surrounding the autonomous recording units. 


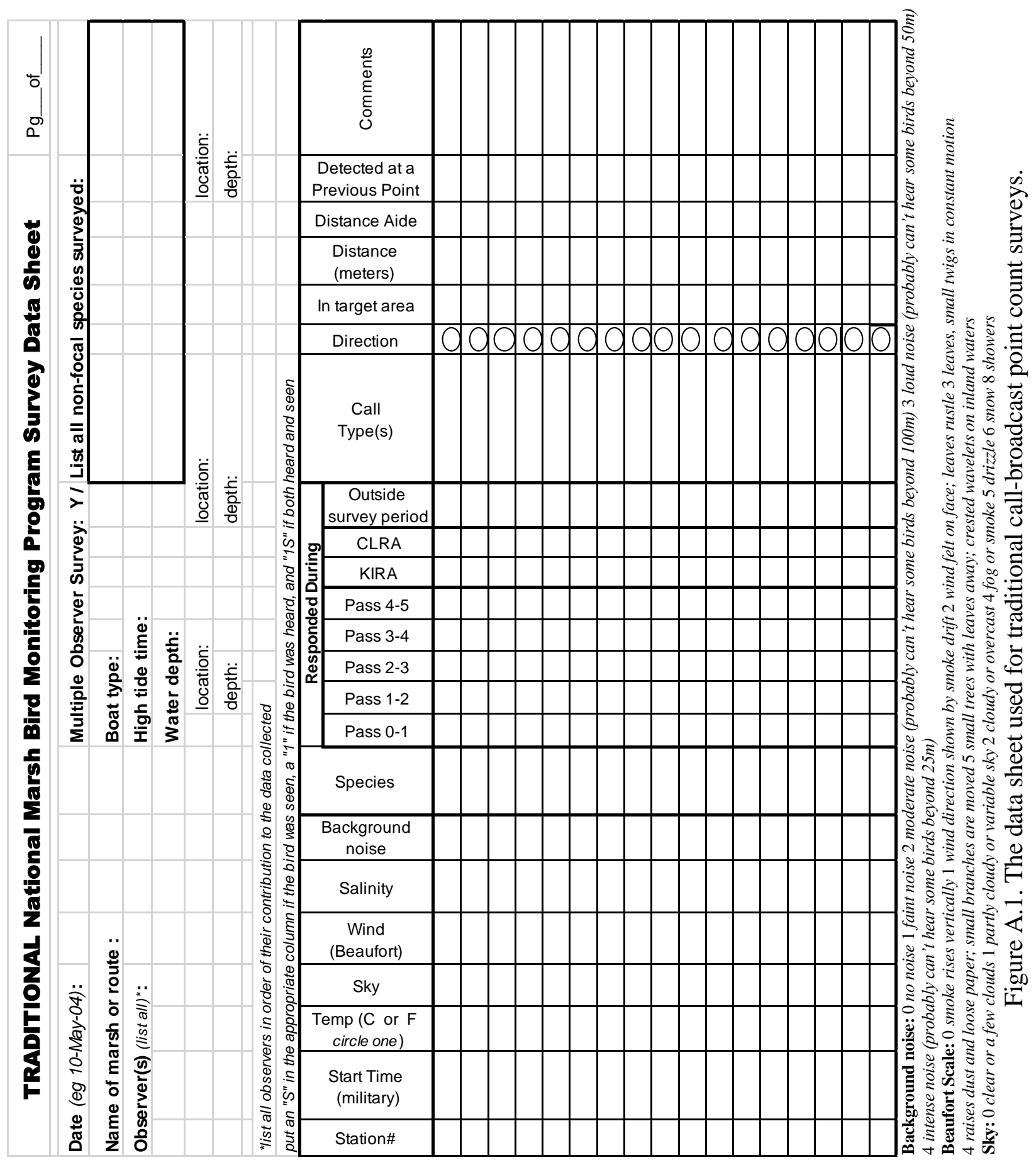




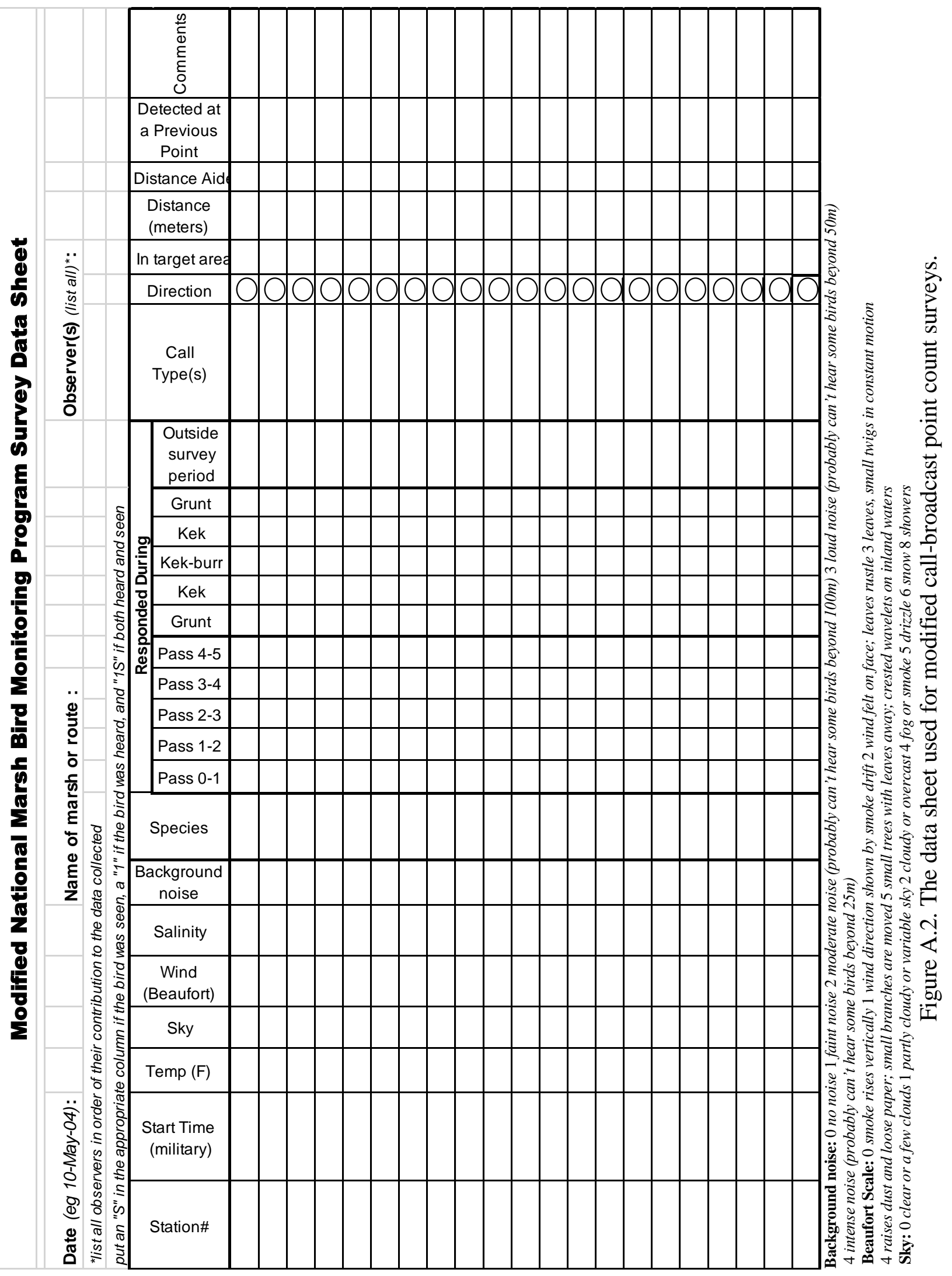




\title{
Survey Plot - Plant Communitites and Habitats
}

\author{
Marsh Name: \\ Survey Point ID: \\ Date: Time:_ Observer: \\ Tide (circle one): Low/Falling Low Low/Rising High/Rising High High/Falling \\ Tidal Amplitude:_ Density \& Height of Vegetation: \\ Cover classes: $0(0 \%) \quad \mathbf{1}(1-5 \%) \quad \mathbf{2}(6-25 \%) \quad \mathbf{3}(26-50 \%) \quad \mathbf{4}(51-75 \%) \quad \mathbf{5}(76-100 \%)$
}

\begin{tabular}{|c|c|}
\hline \multirow{2}{*}{\multicolumn{2}{|c|}{$\begin{array}{l}\text { Communities and Habitats in } \mathbf{5 0 ~} \mathbf{m} \text { Radius Survey Plot } \\
\text { Low Marsh } \\
\text { Regularly flooded by daily tides } \\
\text { Dominated by tall form Spartina alterniflora }(50+\mathrm{cm}) \\
\text { Strongly halophytic }\end{array}$}} \\
\hline & \\
\hline $\begin{array}{l}\text { High Marsh } \\
\text { Flooded by mean tide or greater } \\
\text { Often dominated by Spartina patens, Distichlis spicata, Juncus gerardii } \\
\text { Includes short form Spartina altermiflora as well as Limonium nashii, Aster } \\
\text { tenuifolius, and Triglochin maritimum } \\
\text { Strongly to moderately halophytic }\end{array}$ & \\
\hline $\begin{array}{l}\text { Salt Marsh Terrestrial Border } \\
\text { Infrequently flooded by spring and storm tides } \\
\text { Could include areas of higher elevation on marsh platform commonly islands or } \\
\text { linear patches next to excavated ditches } \\
\text { Most common: Iva frutescens, Baccharis halimifolia, Solidago sempervirens, and } \\
\text { Panicum virgatum } \\
\text { Moderately halophytic }\end{array}$ & \\
\hline $\begin{array}{l}\text { Brackish Terrestrial Border } \\
\text { Rarely flooded by tides, but often tidal influenced fresh/brackish } \\
\text { Could include fresher areas of high water table on marsh plain } \\
\text { Most common: Typha angustifolia, Scirpus robustus, Spartina pectinata } \\
\text { Could include native Phragmites australis if properly identified }\end{array}$ & \\
\hline $\begin{array}{l}\text { Invasives } \\
\text { Invasives such as Phragmites australis and Lythrum salicaria } \\
\text { Colonization and spread often result of disturbance }\end{array}$ & \\
\hline $\begin{array}{l}\text { Pannes, Pools, and Creeks } \\
\text { Channels, creeks, ditches, pannes, and pools }\end{array}$ & \\
\hline $\begin{array}{l}\text { Open Water } \\
\text { Larger areas of water: bays, rivers, ponds }\end{array}$ & \\
\hline $\begin{array}{l}\text { Wrack } \\
\text { Dead vegetation that has been cast on shore }\end{array}$ & \\
\hline $\begin{array}{l}\text { Upland } \\
\text { Non-wetland areas of upland that fall into } 50 \mathrm{~m} \text { radius circle }\end{array}$ & \\
\hline
\end{tabular}

Figure A.3. The data sheet used for vegetative community surveys. 
Date:

Survey Point ID:

Dominant Species and \% Cover in $50 \mathrm{~m}$ Radius Survey Circle(any species covering $5 \%$ or more of the circle; round to the nearest $5 \%$ )

Dominant Species 1:

Percent Cover:

Dominant Species 2:

Percent Cover:

Dominant Species 3:

Percent Cover:

Dominant Species 4:

Percent Cover:

Dominant Species 5:

Percent Cover:

Dominant Species 6:

Percent Cover:

Dominant Species 7

Percent Cover:

Dominant Species 8:

Percent Cover:

Dominant Species 9:

Percent Cover:

Dominant Species 10:

Percent Cover:

\begin{tabular}{|l|l|l|l|l|}
\hline Sample & $\begin{array}{l}\text { Conductivity } \\
(\mathbf{p S} / \mathbf{c m})\end{array}$ & $\begin{array}{l}\text { Salinity } \\
(\mathbf{p p t})\end{array}$ & $\begin{array}{l}\text { Water } \\
\text { Temp }\left({ }^{\circ} \mathrm{C}\right)\end{array}$ & $\begin{array}{l}\text { Water } \\
\text { Depth }(\mathbf{c m})\end{array}$ \\
\hline Sample 1 & & & & \\
\hline Sample 2 & & & & \\
\hline Average & & & & \\
\hline
\end{tabular}

Figure A.4. The data sheet used for dominant vegetative species surveys and water quality characteristics at marsh edge. 


\section{Appendix B}

\section{Spectrographic Analysis}

The following spectrograms display visualizations of King and Clapper rail vocalizations for 3 predominant vocalizations (kek, grunt, and kek-burr) and overlapping vocalizations by multiple rails. 


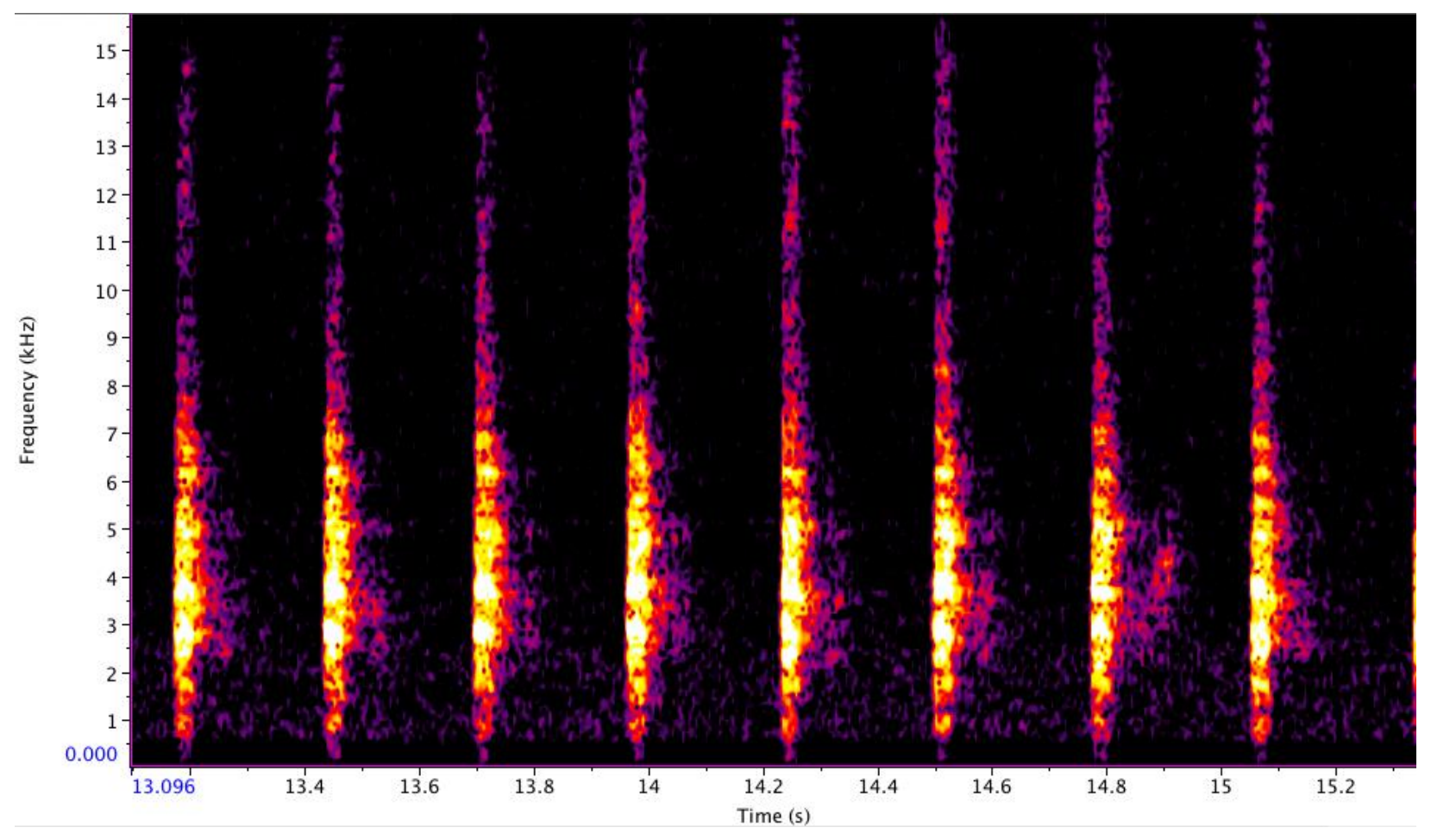

Figure B. 1. Spectrogram of a Clapper Rail "kek" call analyzed in Raven Pro 1.5. 


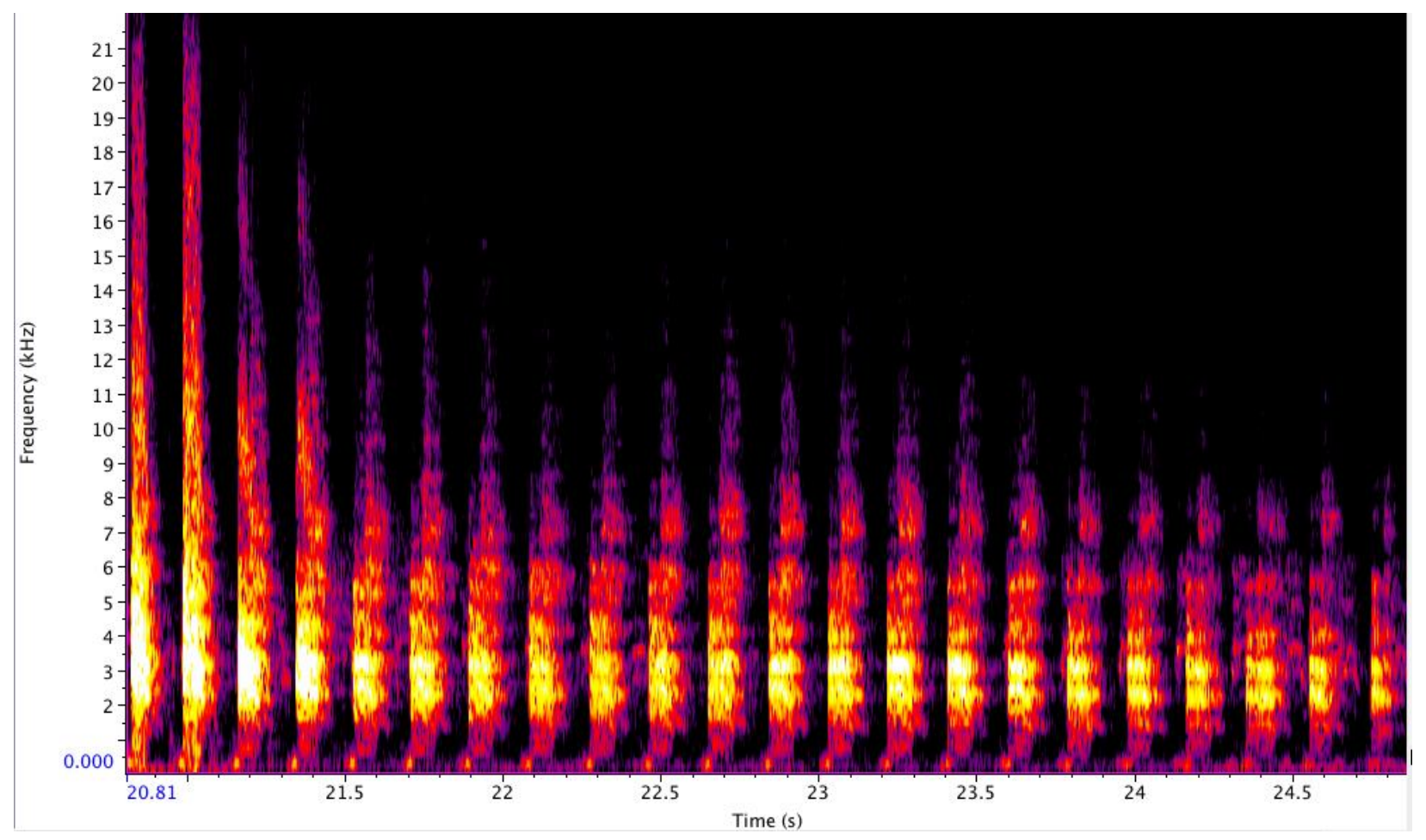

Figure B. 2. Spectrogram of a Clapper Rail "grunt" call analyzed in Raven Pro 1.5. 


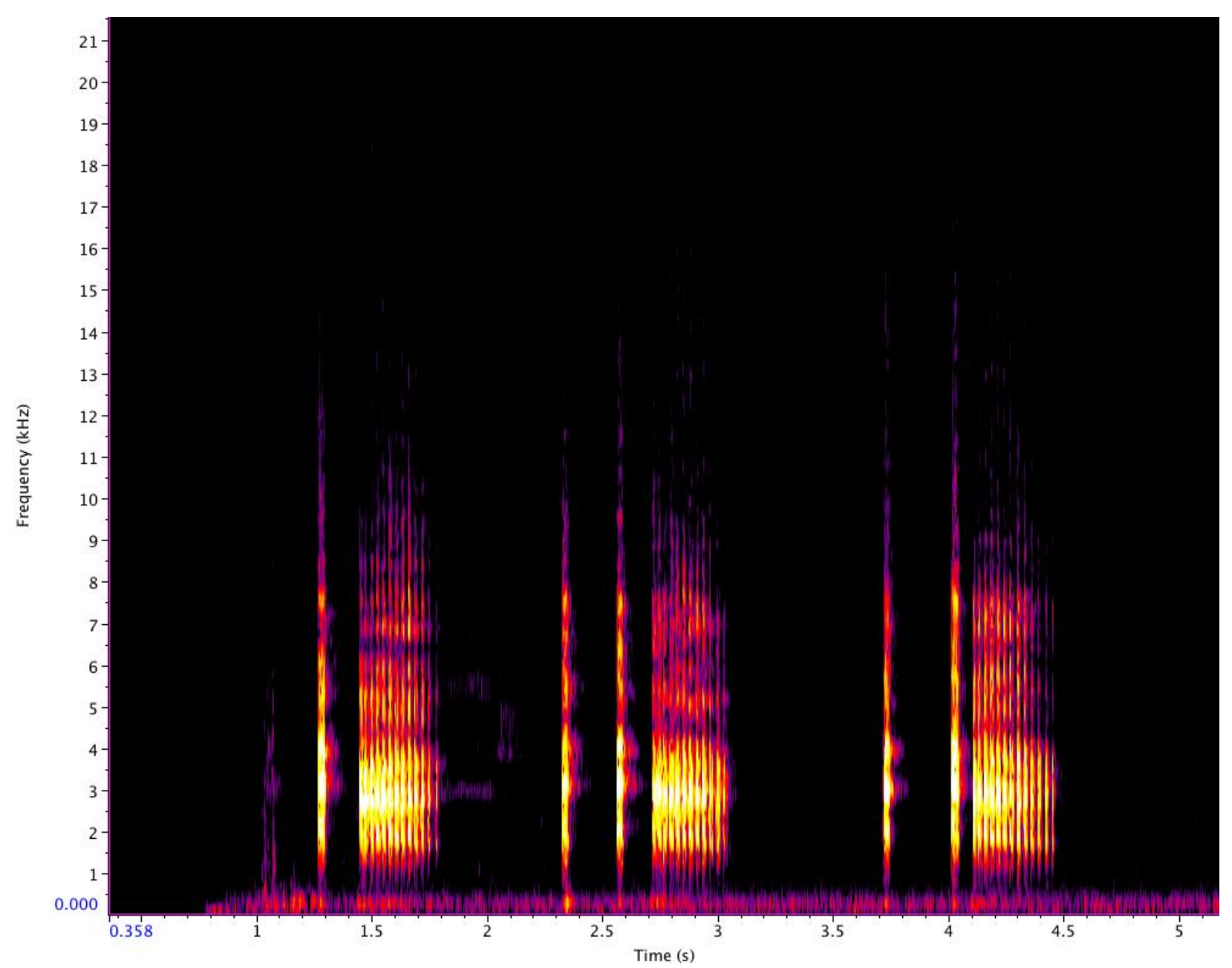

Figure B. 3. Spectrogram of a Clapper Rail "kek-burr” call analyzed in Raven Pro 1.5. 

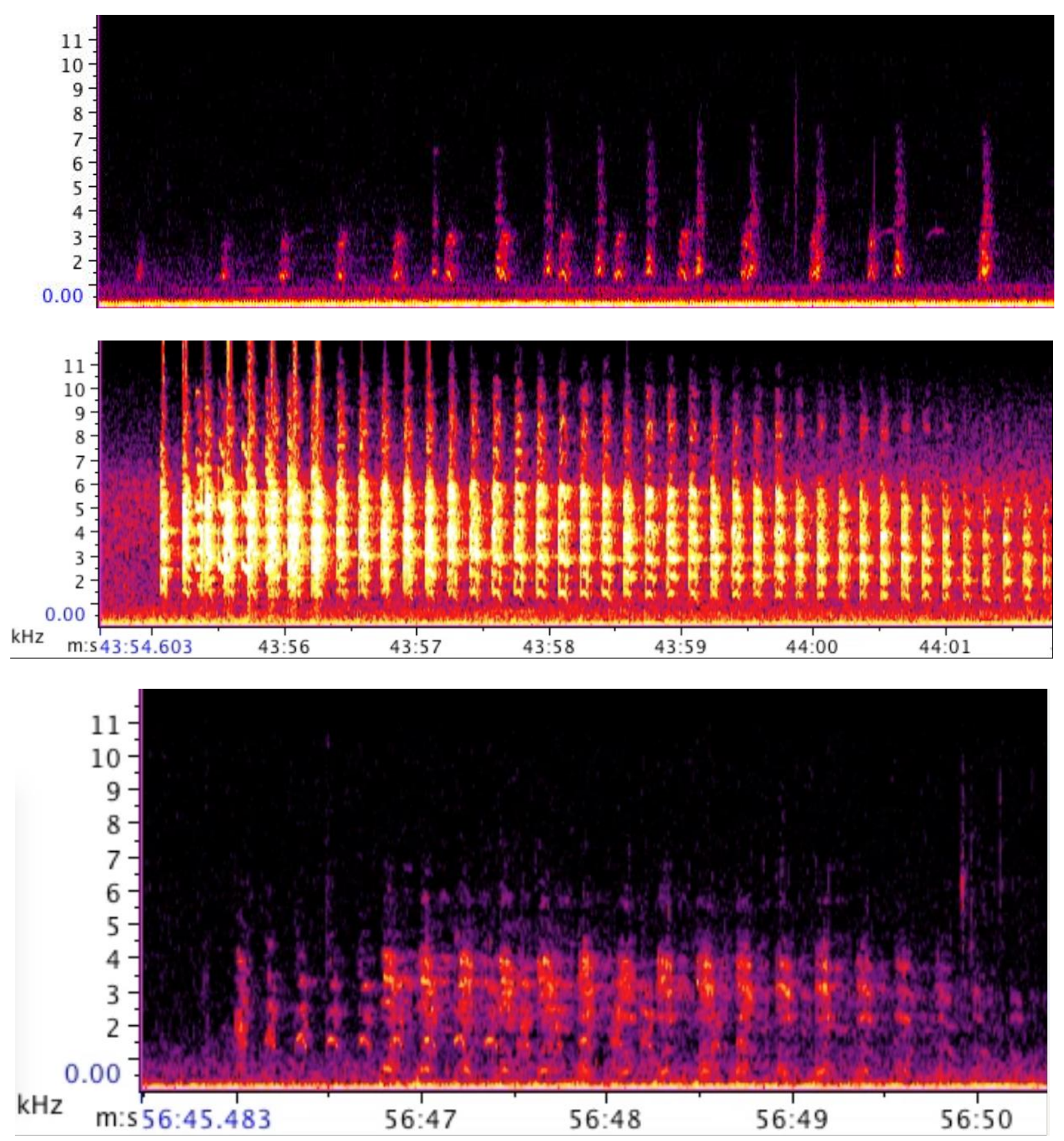

Figure B. 4. Three spectrograms of two overlapping King-Clapper rail vocalizations analyzed in Raven Pro 1.5. 


\section{Appendix C}

\section{Additional Tables and Figures}

The following tables and figures provide supplemental information to the manuscripts. 
Table C.1. The proportion of sites where at least one rail was detected for all 15 sampling locations within each marsh. The overall study area is calculated by averaging hourly proportions across all marshes. The $X^{2}$ test statistic and associated $P$ - value $(\alpha=0.05)$ assessed hourly variation in naïve occupancy for each marsh and across the study area.

\begin{tabular}{cccccc}
\hline Hour & Eltham & Lee & Hill & Sweet Hall & Study Area \\
\hline 0 & 0.800 & 0.533 & 0.400 & 0.067 & 0.450 \\
1 & 0.800 & 0.533 & 0.267 & 0.200 & 0.450 \\
2 & 0.867 & 0.533 & 0.400 & 0.133 & 0.483 \\
3 & 0.867 & 0.600 & 0.467 & 0.200 & 0.533 \\
4 & 0.800 & 0.533 & 0.267 & 0.067 & 0.500 \\
5 & 0.933 & 0.533 & 0.333 & 0.067 & 0.467 \\
6 & 0.867 & 0.600 & 0.400 & 0.200 & 0.517 \\
7 & 0.933 & 0.533 & 0.400 & 0.067 & 0.483 \\
8 & 0.933 & 0.467 & 0.400 & 0.133 & 0.483 \\
9 & 0.933 & 0.533 & 0.267 & 0.000 & 0.433 \\
10 & 0.933 & 0.400 & 0.267 & 0.133 & 0.433 \\
11 & 0.933 & 0.267 & 0.267 & 0.000 & 0.367 \\
12 & 0.933 & 0.286 & 0.200 & 0.067 & 0.373 \\
13 & 0.867 & 0.429 & 0.133 & 0.133 & 0.390 \\
14 & 0.867 & 0.357 & 0.200 & 0.267 & 0.424 \\
15 & 1.000 & 0.286 & 0.067 & 0.000 & 0.339 \\
16 & 0.867 & 0.214 & 0.000 & 0.067 & 0.288 \\
17 & 0.933 & 0.429 & 0.200 & 0.133 & 0.424 \\
18 & 0.867 & 0.500 & 0.333 & 0.067 & 0.441 \\
19 & 0.933 & 0.571 & 0.333 & 0.267 & 0.525 \\
20 & 0.933 & 0.643 & 0.267 & 0.200 & 0.508 \\
21 & 0.667 & 0.571 & 0.067 & 0.000 & 0.322 \\
22 & 0.667 & 0.429 & 0.067 & 0.067 & 0.390 \\
23 & 0.667 & 0.500 & 0.267 & 0.133 & 22.5 \\
\hline$X_{0.95,23}$ & 25.4 & 17.9 & 28.3 & 0.490 & \\
\hline & 0.331 & 0.761 & 0.206 & & 0.8 \\
\hline
\end{tabular}


Table C.2 Selection tables for models estimating detection frequencies using 48-hour autonomous acoustic recordings for King and Clapper Rails in four marshes along the Pamunkey River, near West Point, Virginia, USA, May-July 2015. Models are ranked based on AICc relative differences between the top ranked model and each other model ( $\triangle \mathrm{AICc})$, AICc model weights $\left(w_{i}\right)$, and number of parameters $(K)$. Parameters included time of day (Time), marsh location (Marsh), day of the year (Date), and tidal stage (Tide).

\begin{tabular}{lrrr}
\hline Model & $K$ & $\Delta \mathrm{AIC}_{\mathrm{c}^{\mathrm{a}}}$ & $w_{i}$ \\
\hline Count $\sim$ Time + Marsh + Date + Tide & 34 & 0 & 1 \\
Count $\sim$ Time + Marsh + Date & 29 & 20.7 & 0.00 \\
Count $\sim$ Marsh + Date + Tide & 11 & 39 & 0.00 \\
Count $\sim$ Marsh + Date & 6 & 63.6 & 0.00 \\
Count $\sim$ Time + Marsh + Tide & 33 & 210.7 & 0.00 \\
Count $\sim$ Time + Marsh & 28 & 231.1 & 0.00 \\
Count $\sim$ Marsh + Tide & 10 & 248.5 & 0.00 \\
Count $\sim$ Marsh & 5 & 271.5 & 0.00 \\
Count $\sim$ Date + Tide & 8 & 1360.7 & 0.00 \\
Count $\sim$ Time + Date + Tide & 31 & 1361.9 & 0.00 \\
Count $\sim$ Time + Date & 26 & 1367.9 & 0.00 \\
Count $\sim$ Date & 3 & 1369.3 & 0.00 \\
Count $\sim$ Tide & 7 & 1472.6 & 0.00 \\
Count $\sim$ Time + Tide & 30 & 1475.3 & 0.00 \\
Count $\sim 1$ & 2 & 1481.3 & 0.00 \\
Count $\sim$ Time & 25 & 1481.5 & 0.00 \\
\hline
\end{tabular}

${ }^{\mathrm{a}}$ The $\mathrm{AIC}_{\mathrm{c}}$ value of the best model was 4796.8 . 
Table C.3 Selection tables for models estimating vocalization frequencies using 48-hour autonomous acoustic recordings for King and Clapper Rails in two varying apparent density marshes along the Pamunkey River, near West Point, Virginia, USA, May-July 2015. Models are ranked based on AICc relative differences between the top ranked model and each other model ( $\triangle \mathrm{AICc}$ ), AICc model weights $\left(w_{i}\right)$, and number of parameters $(K)$. Parameters included time of day (Time), marsh location (Marsh), day of the year (Date), and tidal stage (Tide).

\begin{tabular}{lrrr}
\hline Model & $K$ & $\Delta \mathrm{AIC}_{\mathrm{c}}{ }^{\mathrm{a}}$ & $w_{i}$ \\
\hline Count $\sim$ Time + Marsh + Date & 27 & 0 & 0.97 \\
Count $\sim$ Time + Marsh + Date + Tide & 32 & 6.8 & 0.03 \\
Count $\sim$ Marsh + Date & 4 & 44.1 & 0.00 \\
Count $\sim$ Marsh + Date + Tide & 9 & 50.2 & 0.00 \\
Count $\sim$ Time + Marsh & 26 & 167.6 & 0.00 \\
Count $\sim$ Time + Marsh + Tide & 31 & 172.9 & 0.00 \\
Count $\sim$ Marsh & 3 & 214.4 & 0.00 \\
Count $\sim$ Marsh + Tide & 8 & 218.1 & 0.00 \\
Count $\sim$ Date & 3 & 377.2 & 0.00 \\
Count $\sim$ Date + Tide & 8 & 381.1 & 0.00 \\
Count $\sim$ Time + Date & 26 & 391.6 & 0.00 \\
Count $\sim$ Time + Date + Tide & 31 & 397.8 & 0.00 \\
Count $\sim$ 1 & 2 & 465.5 & 0.00 \\
Count $\sim$ Tide & 7 & 472.1 & 0.00 \\
Count $\sim$ Time & 25 & 477.6 & 0.00 \\
Count $\sim$ Time + Tide & 30 & 485.2 & 0.00 \\
\hline
\end{tabular}

${ }^{\mathrm{a}} \mathrm{The} \mathrm{AIC}_{\mathrm{c}}$ value of the best model was 7221.8 . 
Table C.4. Model selection results for the occupancy and detection of King-Clapper Rails in marshes in Virginia along the Pamunkey River May-July 2015. The model name shows effects on occupancy probability $(\Psi)$ and detection probability $(p)$; models are ranked based on AICc relative differences between the top ranked model and each other model ( $\triangle \mathrm{AICc})$, AICc model weights $\left(w_{i}\right)$, and number of parameters $(K)$. Parameters included salinity and dominant emergent marsh community (veg) for occupancy probability and day of the year (date), time of day (time), and survey number (survey) for detection probability.

\begin{tabular}{|c|c|c|c|}
\hline Model & $\mathrm{K}$ & $\triangle \mathrm{AICc}^{\mathrm{a}}$ & $w_{i}$ \\
\hline$\Psi$ (salinity), $p$ (date) & 4 & 0 & 0.28 \\
\hline$\Psi$ (salinity), $p$ (date + survey) & 5 & 0.3 & 0.24 \\
\hline$\Psi$ (salinity $), p($ date + time $)$ & 5 & 1.4 & 0.14 \\
\hline$\Psi($ salinity + veg $), p($ date $)$ & 7 & 2.44 & 0.08 \\
\hline$\Psi$ (salinity), $p($ date + survey + time $)$ & 6 & 2.58 & 0.08 \\
\hline$\Psi$ (salinity + veg $), p($ date + survey $)$ & 8 & 2.96 & 0.06 \\
\hline$\Psi($ salinity + veg $), p($ date + time $)$ & 8 & 4.06 & 0.04 \\
\hline$\Psi($ salinity $+\mathrm{veg}), p($ date + survey + time $)$ & 9 & 5.47 & 0.02 \\
\hline$\Psi$ (salinity), $p()$. & 3 & 5.69 & 0.02 \\
\hline$\Psi$ (salinity), $p$ (survey) & 4 & 5.81 & 0.02 \\
\hline$\Psi$ (salinity), $p$ (time) & 4 & 7.06 & 0.01 \\
\hline$\Psi($ salinity + veg $), p()$. & 6 & 7.93 & 0.01 \\
\hline$\Psi$ (salinity), $p$ (survey + time $)$ & 5 & 8.04 & 0.01 \\
\hline$\Psi$ (salinity + veg), $p$ (survey) & 7 & 8.25 & 0.00 \\
\hline$\Psi($ salinity + veg $), p$ (time $)$ & 7 & 9.50 & 0.00 \\
\hline$\Psi$ (salinity + veg $), p($ survey + time $)$ & 8 & 10.69 & 0.00 \\
\hline$\Psi(\mathrm{veg}), p($ date $)$ & 6 & 16.93 & 0.00 \\
\hline$\Psi$ (veg), $p$ (date + survey $)$ & 7 & 17.37 & 0.00 \\
\hline$\Psi(\mathrm{veg}), p($ date + time $)$ & 7 & 18.47 & 0.00 \\
\hline$\Psi(\mathrm{veg}), p($ date + survey + time $)$ & 8 & 19.79 & 0.00 \\
\hline$\Psi(\operatorname{veg}), p()$. & 5 & 22.50 & 0.00 \\
\hline$\Psi$ (veg), $p$ (survey) & 6 & 22.75 & 0.00 \\
\hline$\Psi(\mathrm{veg}), p$ (time) & 6 & 24.00 & 0.00 \\
\hline$\Psi($ veg $), p$ (survey + time $)$ & 7 & 25.12 & 0.00 \\
\hline$\Psi(),$.$p (date)$ & 3 & 31.75 & 0.00 \\
\hline$\Psi(),$.$p (date +$ survey $)$ & 4 & 31.98 & 0.00 \\
\hline$\Psi(),. p($ date + time $)$ & 4 & 33.08 & 0.00 \\
\hline$\Psi(),. p($ date + survey + time $)$ & 5 & 34.20 & 0.00 \\
\hline$\Psi(),. p()$. & 2 & 37.56 & 0.00 \\
\hline$\Psi(),$.$p (survey)$ & 3 & 37.61 & 0.00 \\
\hline$\Psi(),$.$p (time)$ & 3 & 38.86 & 0.00 \\
\hline$\Psi(),$.$p (survey +$ time $)$ & 4 & 39.79 & 0.00 \\
\hline
\end{tabular}

${ }^{a}$ The $\mathrm{AIC}_{\mathrm{c}}$ value of the best model was 558.48. 
Table C.5. Model selection results for the occupancy and detection of King-Clapper Rails in marshes in Virginia along the Mattaponi River May-July 2015. The model name shows effects on occupancy probability $(\Psi)$ and detection probability $(p)$; models are ranked based on AICc relative differences between the top ranked model and each other model ( $\triangle \mathrm{AICc})$, AICc model weights $\left(w_{i}\right)$, and number of parameters $(K)$. Parameters included salinity and dominant emergent marsh community (veg) for occupancy probability and day of the year (date), time of day (time), and survey number (survey) for detection probability.

\begin{tabular}{|c|c|c|c|}
\hline Model & $\mathrm{K}$ & $\Delta \mathrm{AICc}^{\mathrm{a}}$ & $w_{i}$ \\
\hline$\Psi(\mathrm{veg}), p()$. & 5 & 0 & 0.22 \\
\hline$\Psi(\mathrm{veg}), p($ date $)$ & 6 & 1.17 & 0.12 \\
\hline$\Psi$ (salinity + veg), $p()$. & 6 & 1.38 & 0.11 \\
\hline$\Psi($ veg $), p$ (survey) & 6 & 2.59 & 0.06 \\
\hline$\Psi(\mathrm{veg}), p$ (time) & 6 & 2.6 & 0.06 \\
\hline$\Psi$ (salinity + veg), $p$ (date) & 7 & 2.65 & 0.06 \\
\hline$\Psi(),. p()$. & 2 & 3.34 & 0.04 \\
\hline$\Psi$ (veg), $p$ (date + survey) & 7 & 3.86 & 0.03 \\
\hline$\Psi($ veg $), p($ date + time $)$ & 7 & 3.87 & 0.03 \\
\hline$\Psi(),$.$p (date)$ & 3 & 3.96 & 0.03 \\
\hline$\Psi$ (salinity + veg), $p$ (survey) & 7 & 4.09 & 0.03 \\
\hline$\Psi$ (salinity + veg), $p$ (time) & 7 & 4.1 & 0.03 \\
\hline$\Psi$ (salinity), $p()$. & 3 & 4.49 & 0.02 \\
\hline$\Psi$ (salinity), $p$ (date) & 4 & 5.16 & 0.02 \\
\hline$\Psi($ veg $), p($ survey + time $)$ & 7 & 5.29 & 0.02 \\
\hline$\Psi$ (salinity + veg $), p($ date + survey $)$ & 8 & 5.47 & 0.01 \\
\hline$\Psi($ salinity + veg $), p($ date + time $)$ & 8 & 5.49 & 0.01 \\
\hline$\Psi(),$.$p (survey)$ & 3 & 5.6 & 0.01 \\
\hline$\Psi(),$.$p (time)$ & 3 & 5.6 & 0.01 \\
\hline$\Psi(),. p($ date + survey $)$ & 4 & 6.31 & 0.01 \\
\hline$\Psi(),. p($ date + time $)$ & 4 & 6.32 & 0.01 \\
\hline$\Psi($ veg $), p($ date + survey + time $)$ & 8 & 6.68 & 0.01 \\
\hline$\Psi$ (salinity), $p$ (survey) & 4 & 6.85 & 0.01 \\
\hline$\Psi$ (salinity), $p$ (time) & 4 & 6.85 & 0.01 \\
\hline$\Psi($ salinity + veg $), p($ survey + time $)$ & 8 & 6.92 & 0.01 \\
\hline$\Psi$ (salinity), $p$ (date + survey $)$ & 5 & 7.62 & 0.00 \\
\hline$\Psi$ (salinity), $p($ date + time $)$ & 5 & 7.62 & 0.00 \\
\hline$\Psi(),. p($ survey + time $)$ & 4 & 7.95 & 0.00 \\
\hline$\Psi($ salinity + veg $), p($ date + survey + time $)$ & 9 & 8.44 & 0.00 \\
\hline$\Psi(),. p($ date + survey + time $)$ & 5 & 8.76 & 0.00 \\
\hline$\Psi$ (salinity), $p$ (survey + time $)$ & 5 & 9.31 & 0.00 \\
\hline$\Psi$ (salinity), $p$ (date + survey + time $)$ & 6 & 10.18 & 0.00 \\
\hline
\end{tabular}

${ }^{\mathrm{a}} \mathrm{The} \mathrm{AIC}_{\mathrm{c}}$ value of the best model was 378.63. 


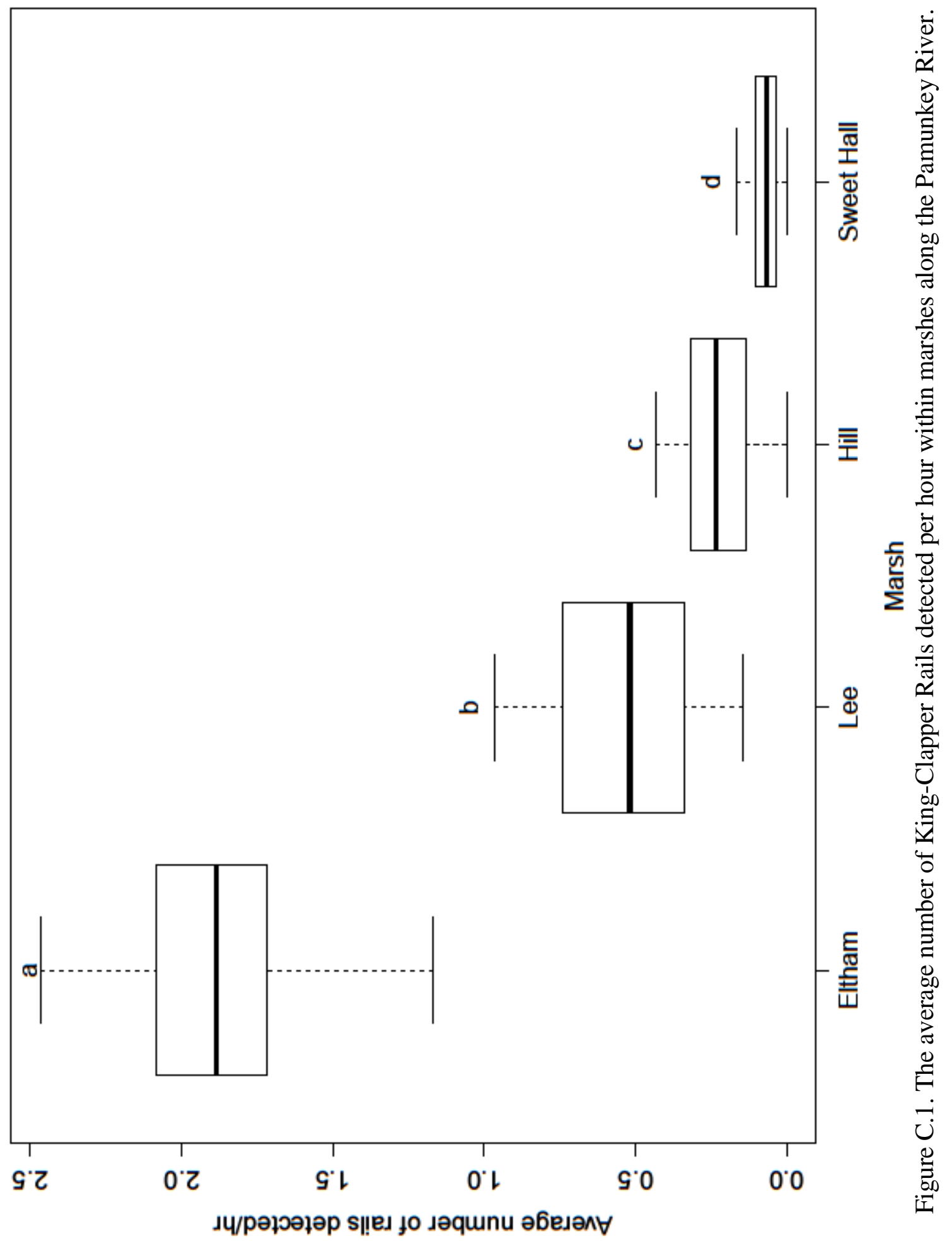




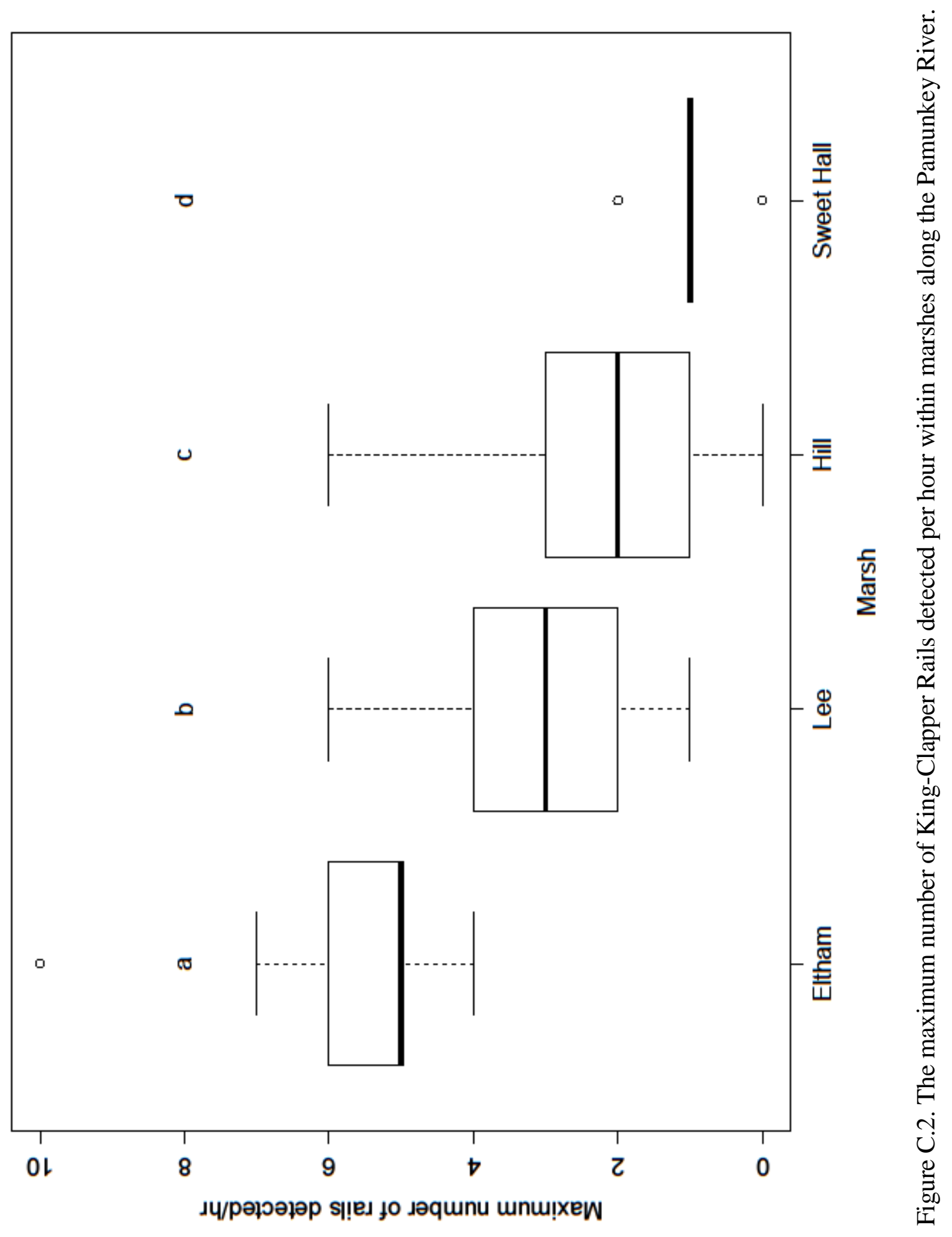

